Special issue in honor of Prof. George C. Papageorgiou

\title{
REVIEW
}

\section{Light quality, oxygenic photosynthesis and more}

\author{
D. LAZAR ${ }^{*,+,}$ (iD) , A. STIRBET ${ }^{* *,+}$, L.O. BJÖRN ${ }^{* * *}$ (iD , and G. GOVINDJEE ${ }^{\#,+}$ \\ Department of Biophysics, Centre of the Region Haná for Biotechnological and Agricultural Research, \\ Faculty of Science, Palacký University, Šlechtitelu 11, 78371 Olomouc, Czech Republic* \\ Anne Burras Lane, Newport News, 23606 Virginia, USA** \\ Department of Biology, Molecular Cell Biology, Lund University, Sölvegatan 35, SE-22462 Lund, Sweden*** \\ Department of Plant Biology, Department of Biochemistry, and Center of Biophysics \& Quantitative Biology, \\ University of Illinois at Urbana-Champaign, Urbana, IL 61801, USA
}

\begin{abstract}
Oxygenic photosynthesis takes place in thylakoid membranes (TM) of cyanobacteria, algae, and higher plants. It begins with light absorption by pigments in large (modular) assemblies of pigment-binding proteins, which then transfer excitation energy to the photosynthetic reaction centers of photosystem (PS) I and PSII. In green algae and plants, these light-harvesting protein complexes contain chlorophylls (Chls) and carotenoids (Cars). However, cyanobacteria, red algae, and glaucophytes contain, in addition, phycobiliproteins in phycobilisomes that are attached to the stromal surface of TM, and transfer excitation energy to the reaction centers via the Chl $a$ molecules in the inner antennas of PSI and PSII. The color and the intensity of the light to which these photosynthetic organisms are exposed in their environment have a great influence on the composition and the structure of the light-harvesting complexes (the antenna) as well as the rest of the photosynthetic apparatus, thus affecting the photosynthetic process and even the entire organism. We present here a perspective on 'Light Quality and Oxygenic Photosynthesis', in memory of George Christos Papageorgiou (9 May 1933-21 November 2020; see notes a and b). Our review includes (1) the influence of the solar spectrum on the antenna composition, and the special significance of $\mathrm{Chl} a$; (2) the effects of light quality on photosynthesis, measured using Chl $a$ fluorescence; and (3) the importance of light quality, intensity, and its duration for the optimal growth of photosynthetic organisms.
\end{abstract}

Keywords: Chl fluorescence induction; chromatic acclimation of cyanobacteria; photoreceptors; photosynthetic pigments; photosystems I and II; stomatal and chloroplast photoinduced movements.

\section{Highlights}

- Environmental light quality affects antenna structure and composition in phototrophs

- Results of Chl fluorescence in phototrophs depend on the excitation light quality

- The development of phototrophs is influenced by their environmental light quality
Received 31 August 2021

Accepted 15 November 2021

Published online 6 January 2022

${ }^{+}$Corresponding authors

e-mail: gov@illinois.edu dusan.lazar@upol.cz

Note a: See Allakhverdiev et al. (2016) for an article honoring the lifetime achievements of George C. Papageorgiou.

Note b: One of us (Govindjee) is very proud to remember George Papageorgiou to be his first PhD student, whose $1968 \mathrm{PhD}$ thesis in Biophysics, at the University of Illinois at Urbana-Champaign (UIUC), was extraordinarily unique, for that time; it was on 'Fluorescence induction in Chlorella pyrenoidosa and Anacystis nidulans and its relation to photophosphorylation' (available at: https://www.life. illinois.edu/govindjee/theses.html); it is equally unique that together with George, Govindjee recently paid a tribute to the father of biophysics, the prophet of photosynthesis, at UIUC, Eugene Rabinowitch, who had been on George's PhD committee (see Govindjee et al. 2019).

†Lazar and Stirbet had equal contribution.

Conflict of interest: The authors declare that they have no conflict of interest. 


\section{Introduction}

Oxygenic photosynthesis (in cyanobacteria, algae, and higher plants), during which water is oxidized to molecular oxygen and carbon dioxide $\left(\mathrm{CO}_{2}\right)$ is reduced to carbohydrates, is indispensable for the development and maintenance of life on Earth. The absorption of light is an essential step in the photosynthetic process (Blankenship 2021). In nature, the intensity and the quality (spectral composition) of sunlight plays a crucial role, in conjunction with other environmental factors, in affecting the growth of photosynthetic organisms, by operating as specific signals that regulate their acclimation, and adaptation process (see e.g., Liscum et al. 2020).

The light-harvesting apparatus of various photosynthetic organisms has evolved through different adaptation mechanisms, allowing each of them to work optimally under diverse environments by transferring excitation energy (EE) efficiently through multi-component assemblies of pigment-protein complexes (known as outer, or peripheral antenna) to the reaction centers (RCs) of PSI and PSII, and by modifying suitably their absorption cross-sections (Croce and van Amerongen 2013a,b; 2014; Ostroumov et al. 2014, Mirkovic et al. 2017, Liu and Blankenship 2019, Croce and van Amerongen 2020). In the RCs, the photoreaction is completed within 20 to $300 \mathrm{ps,} \mathrm{with}$ a maximal quantum efficiency close to 1.0 for PSI, and $\sim 0.9$ for PSII (Jennings et al. 2003, Engelmann et al. 2006, Wientjes et al. 2011, 2013a; Mamedov et al. 2015, Croce et al. 2018). Both PSI and PSII, which are very similar in the majority of these organisms, also contain inner antennas (with $\sim 100$ and $\sim 35 \mathrm{Chl} a$ in PSI and PSII, respectively) that either absorb light or receive EE from the outer antenna; the EE is directed to a small group of Chls and other cofactors in the RCs, where the primary charge separation and the initial electron transfer take place (see e.g., Zouni et al. 2001, Nelson and Junge 2015).

The organization and composition of the outer antenna in plants and green algae differ from those in cyanobacteria and red algae. The outer antenna of the photosystems in plants and green algae is modular, containing variable amounts of several types of transmembrane pigmentprotein complexes that are members of the light-harvesting complex (LHC) superfamily, containing approximately 200-400 molecules of Chls and carotenoids (Cars) per photosystem (see e.g., Croce 2020, Croce and van Amerongen 2020). The carotenoids function not only to capture light, but many of them (e.g., lutein, $\beta$-carotene, violaxanthin, fucoxanthin, and neoxanthin) also play an essential roles in photoprotection (see chapters in Demmig-Adams et al. 2014 and Xu et al. 2020a). In plants, LHCII trimers associate (via the monomeric LHCs: CP24, CP26, and CP29) with the PSII core, usually forming PSIIC $_{2} \mathrm{~S}_{2}$ and PSIIC $\mathrm{S}_{2} \mathrm{M}_{2}$ supercomplexes (see a review on PSII by Shevela et al. 2021), where S and M represent LHCII trimers that are strongly or moderately associated with the PSII core (Fig. 1A,B). PSII megacomplexes, containing additional loosely bound LHCII trimers (L) (Fig. 1C), have been found in plants such as Picea abies (L.) Karst and Pinus sylvestris (that lack Lhcb3 and CP24; Kouřil et al. 2020).

In the green alga Chlamydomonas reinhardtii (that has four types of major LHCII proteins; see e.g., Natali and Croce 2015), an adaptation mechanism to low light exists, when the M- and L-LHCII trimers interact with CP29 to form a subcomplex bound to CP47 in the PSIIC ${ }_{2} \mathrm{~S}_{2} \mathrm{M}_{2} \mathrm{~L}_{2}$ supercomplex, establishing a direct pathway for $\mathrm{EE}$ transfer from the L-LHCII to the PSII RC (Sheng et al. 2019). Further, in the PSI outer antenna of plants, four different LHCI proteins (Lhca1-4) usually bind to the PSI core (in a 1:1 stoichiometry) to form the PSI supercomplex (Fig. 1D; Ben-Shem et al. 2003, Qin et al. 2015). Additionally, PSI outer antenna contains (under several conditions), at least one LHCII trimer, forming a PSI-LHCI-LHCII complex with a 25\% larger absorption cross-section (Fig. 1E; Pan et al. 2018, Chukhutsina et al. 2020). We note that there are more than four binding sites for LHCI proteins around the PSI core, and the position of different types of LHCI are known to change in different organisms (Kubota-Kawai et al. 2019, Croce and van Amerongen 2020). On the other hand, the organization of PSI is less flexible than that of PSII under changes

Abbreviations: $\mathrm{C}_{3}$ and $\mathrm{C}_{4}$ plants - plants in which the first carbon compound produced during photosynthesis contains three, and four carbon atoms; CBCRs - cyanobacteriochromes; Chl(s) - chlorophyll(s); ChlF and ChlFI - Chl $a$ fluorescence and Chl $a$ fluorescence induction; Cphs - cyanobacterial phytochromes; CRYs - cryptochromes; Cyt - cytochrome; EE - excitation energy; FaRLiP - farred light photoacclimation of cyanobacteria; FCPs - fucoxanthin-chlorophyll a/c-binding proteins; $\mathrm{F}_{\mathrm{M}}$ - maximal Chl $a$ fluorescence; $\mathrm{F}_{\mathrm{O}}-$ minimal Chl $a$ fluorescence; $\mathrm{F}_{\mathrm{P}}-\mathrm{Chl} a$ fluorescence at its peak (P); FR(L) - far-red (light); $\mathrm{F}_{\mathrm{V}}-$ variable $(\mathrm{Chl} a)$ fluorescence; GAF - a phytochrome domain named after cGMP, adenylyl cyclase, and FhlA; $\mathrm{H}^{+}$-ATPase - adenosine triphosphatase transporting protons $\left(\mathrm{H}^{+} \mathrm{s}\right)$ across membranes (proton pump); LEDs - light-emitting diodes; LHC - light-harvesting complex; LHCSR - lightharvesting complex stress-related proteins; NPQ - nonphotochemical quenching (of Chl $a$ fluorescence); OCP - orange carotenoid protein; $\mathrm{P}_{700}$ - reaction center pigment $(\mathrm{P})$ of photosystem I, with a maximum absorbance at $700 \mathrm{~nm} ; \mathrm{PAM}$ - pulse amplitude modulation; PBS(s) - phycobilisome(s); PC - phycocyanin; PCM - photosensory core module (of phytochromes); PE - phycoerythrin; PEA plant efficiency analyzer; PEB - phycoerythrobilin; Pfr - far-red light-absorbing (active) state of phytochrome; PHOT - phototropin; Phys - common (canonical) phytochrome subfamily found in higher plants; PQ - plastoquinone; $\operatorname{Pr}$ - red-light absorbing (inactive) state of phytochrome; PUB - phycourobilin; $\mathrm{Q}_{\mathrm{A}}$ and $\mathrm{Q}_{\mathrm{B}}$ - primary and secondary plastoquinone electron acceptors of photosystem II; R - red (light); RC - reaction center; TM - thylakoid membrane; UV-A - ultraviolet radiation (wavelength range 320 to $400 \mathrm{~nm}$ ); VPD - vapor pressure deficit.

Acknowledgments: D.L. was supported by the European Regional Development Fund project 'Plants as a tool for sustainable global development' (CZ.02.1.01/0.0/0.0/16_019/0000827). Govindjee thanks Jeffrey Haas, Karl Schlipf, Thomas Uebele, and Andrew H. Debevec (Information Technology, Life Sciences, University of Illinois at Urbana-Champaign) for their valuable help during the writing of this paper. 


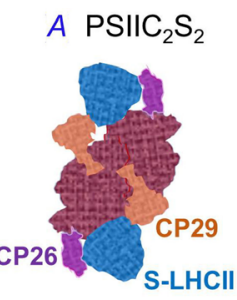

$(105 \mathrm{Ch} / \mathrm{s})$

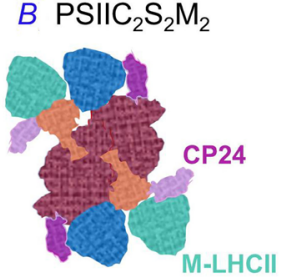

(158 Ch/s)
C PSIIC $\mathrm{S}_{2} \mathrm{M}_{2} \mathrm{~L}_{2}$

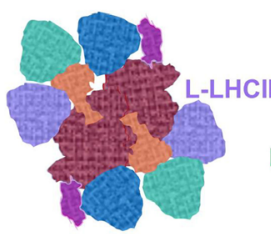

(185-189 Ch/s)
D PSI-LHCl

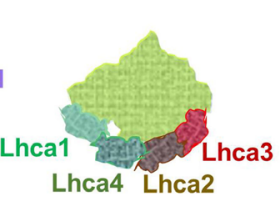

$(158 \mathrm{Ch} / \mathrm{s})$
E PSI-LHCI-LHCII

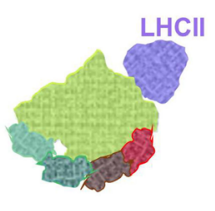

$(200 \mathrm{Ch} / \mathrm{s})$

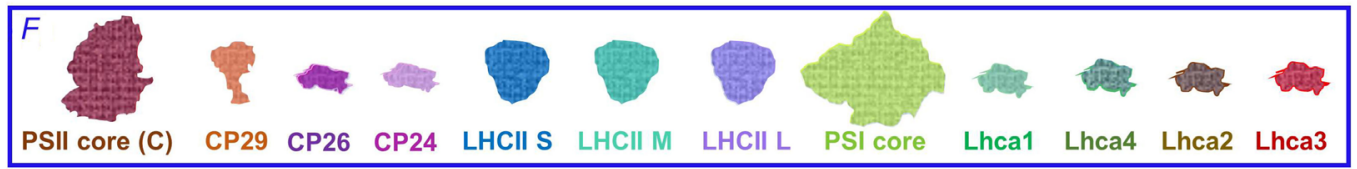

Fig. 1. The photosystems (both PSI and PSII) in plants, shown in different configurations of the light-harvesting components $(A-E)$. The PSII and PSI cores, and all the light-harvesting components, are shown in $(F)$. The S-, M-, and L-LHCII represent LHCII trimers that are strongly, moderately, or loosely associated with the PSII core, respectively. Figure modified from Croce (2020) and Croce and van Amerongen (2020).

in environmental conditions; the long-term equilibrium between these two photosystems is usually adjusted through changes in the PSII/PSI ratio (see e.g., Ballottari et al. 2007, Wientjes et al. 2017). However, Wientjes et al. (2013b) have shown that the percent of LHCII associated with PSI (in the PSI-LHCII form) changes under illumination with different light intensities; it is 65,54 , and $40 \%$ for plants grown under low, medium, and high light, respectively. Thus, although the LHCI content of PSI remains constant under different light intensities, the above observation shows that modulation of LHCII affects the total antenna size of both photosystems.

We note that PSI contains, in addition to a large fraction of Chl $a$ molecules with broad absorption peaks in the $680-685 \mathrm{~nm}$ region, about $3-10 \%$ Chl $a$ molecules that absorb above $700 \mathrm{~nm}$, the so-called red or lowenergy Chls (see e.g., Jennings et al. 2003, Croce et al. 2007, Russo et al. 2021, for land plants; Giera et al. 2018, Santabarbara et al. 2020, for algae; Gobets and van Grondelle 2001, Karapetyan et al. 2006, 2014, for cyanobacteria). The existence of 'red' Chls was first observed by Litvin and Krasnovsky (1957) and by Brody (1958) (also see Govindjee 1963). The fluorescence spectra of PSI, especially at low temperatures, are greatly influenced by the presence of 'red' Chls (Golbeck 1987, Brecht et al. 2012). The higher PSI absorption at longer wavelengths than that of PSII is responsible for Emerson's 'red drop' effect, first observed in the green alga Chlorella (Emerson and Lewis 1943; cf. Emerson and Rabinowitch 1960), which is an abrupt decrease in the yield of oxygen evolution per absorbed quanta, beyond $685 \mathrm{~nm}$ (see also Emerson et al. 1957). This red drop is due to an imbalance in PSI and PSII excitation, with relatively low absorption in the far-red light by PSII; thus, the number of electrons available to PSI (provided by PSII) is limited in light beyond $685 \mathrm{~nm}$, which leads to a decrease of the photosynthetic yield in the FR region. 'Red' Chl $a$ molecules have intermolecular interactions between them forming strongly excitonically coupled dimers or trimers, and even larger aggregates. The presence of 'red' Chls in PSI increases the absorption cross-section of the system; further, it plays a critical role in the regulation of energy transfer from the bulk Chls to $\mathrm{P}_{700}$, as well as in the dissipation of excess excitation energy as heat (Karapetyan et al. 2014). Also, it has been shown, in plants, that the EE transfer from the 'red' Lhcas (i.e., Lhca3 and Lhca4) to the PSI core is slower than from the 'blue' ones (i.e., Lhca1 and Lhca2) (Engelmann et al. 2006, Wientjes et al. 2011), but the photon utilization efficiency by PSI-LHCI remains close to unity. The physiological role of 'red' Chls is important under 'canopy-(like) shading' conditions when the photon fluxes are low and the photosynthetic process is limited by light absorption (Rivadossi et al. 1999); however, here excitation energy transfer from the 'red' Chls to PSI reaction center takes place through thermal activation (i.e., uphill energy transfer; Jennings et al. 2003), a process that increases the photoprotective efficiency of PSI-LHCI (Matsubara et al. 2007). Therefore, when it comes to light harvesting, the presence of a significant amount of 'red' Chls in PSI is one of the main differences between PSI and PSII supercomplexes. On the other hand, while the lowestenergy Chls in PSII are those responsible for the $\mathrm{F}_{695}$ fluorescence band of PSII core complexes at $77 \mathrm{~K}$ (see e.g., Shibata et al. 2013, Hall et al. 2016), various studies show that oxygen evolution is possible under illumination with wavelengths above $700 \mathrm{~nm}$ in many phototrophs, including the green alga Chlorella vulgaris, and higher plants, such as sunflower, bean, and spinach (Myers and Graham 1963, Greenbaum and Mauzerall 1991, Pettai et al. 2005a,b; Thapper et al.2009); the above must be due to the presence of additional red-shifted PSII Chls in PSII. Indeed, lowenergy PSII Chls with maximum absorption above $700 \mathrm{~nm}$ are present in various species (see Santabarbara et al. 2020), such as the diatoms Phaeodactylum tricornutum, Nitzschia closterium, Chromera velia, and Phaeodactylum tricornutum acclimated to low red light (having Chl a 
with an emission band at $710 \mathrm{~nm}$ at room temperature, $\mathrm{F}_{710}$; Fujita and Ohki 2004, Bína et al. 2014, Kotabová et al. 2014, Herbstová et al. 2017), the moss Physcomitrella patens (Alboresi et al. 2011), and the aerial green alga Prasiola crispa from Antarctica (it has $\mathrm{F}_{713}$ at room temperature, and $\mathrm{F}_{735}$ at $77 \mathrm{~K}$; Kosugi et al. 2020). However, the low-energy PSII Chls are present in a smaller number than in PSI and have lower maximum emission wavelengths.

On the other hand, in cyanobacteria and red algae, there are large water-soluble protein assemblies, the phycobilisomes (PBSs), absorbing green light, functioning as an outer antenna for both the photosystems (but especially for PSII), allowing these organisms to live at greater depths than those that primarily use Chl $a$ and Chl b (e.g., Harris et al. 2018); as mentioned earlier, the PBSs cover the stromal surface of the thylakoid membrane (TM) and transfer EE efficiently to both the PSI and the PSII cores (Acuña et al. 2018a,b). The hemidiscoidal PBS is the most common type in cyanobacteria; it has two main domains, several peripheral rods, and a 'core'; the latter connects all the rods and transfers the excitation energy to both PSI and PSII [see Fig. 6 (shown later), under 'Acclimation of cyanobacteria to changes in environmental light quality'].

The PBSs contain a large number of covalently bound linear tetrapyrrole phycobilin chromophores, which strongly absorb light in the 500-640-nm range, depending on the type of phycobilin, protein surrounding, and the presence of various linkers (colorless polypeptides known to be involved in the assembly of phycobiliproteins in PBS; Nobel 2009, Harris et al. 2018). The most common phycobiliproteins are phycocyanin (PC, orangered absorbing), allophycocyanin (red absorbing), and phycoerythrin (green absorbing), although other spectral variants also exist. Note that, in general, the presence of various accessory pigments, which absorb light at higher energies than the antenna $\mathrm{Chl} a$ (e.g., Chl $b$, phycobilins, carotenoids), leads to directed downhill energy transfer at a very fast rate before it is trapped; further, the trapping time depends on the number of Chl $a$ molecules in the antenna (see van Amerongen et al. 2000). Although the crystal structure of the PSI core complex of cyanobacteria (Jordan et al. 2001) is quite similar to that of the plants (Ben-Shem et al. 2003), there are some differences. These differences are responsible for, e.g., the trimeric PSI form (found in the most characterized cyanobacteria; see e.g., Jordan et al. 2001), and the tetrameric PSI form (common in the heterocyst-forming cyanobacteria and their close relatives; see e.g., Semchonok et al. 2016), as compared to the monomeric PSI form, present in plants and in algae. Furthermore, the PSI/PSII ratio in cyanobacteria, instead of being close to 1 , as is in plants and green algae, is much higher ( 2 to 10 times) under different environmental conditions (Sonoike et al. 2001). Therefore, due to this high stoichiometric ratio of PSI to PSII, 80-95\% of Chl $a$ and $73-93 \%$ of Cars are located in PSI in cyanobacteria. Further, the number of 'red' Chls depends on the state of PSI aggregation: fewer 'red' Chls are present in PSI monomers than in PSI trimers (Gobets and van Grondelle
2001).

Studies using electron microscopy and other methods have clearly shown differences in size, composition, and organization of the outer antenna of the photosystems between different species, reflecting adaptation to the spectral composition of environmental light, and acclimation to changes in both the quality and the quantity of light (Croce and van Amerongen 2014, 2020; Natali and Croce 2015, Mirkovic et al. 2017, Pi et al. 2019, Sheng et al. 2019, Suga et al. 2019, Chukhutsina et al. 2020, Kouřil et al. 2020, Pan et al. 2020). For example, plants grown under low light have an increased number of LHCIIs to maximize light absorption, but this number decreases under high light, minimizing photodamage (Anderson and Andersson 1988). Here we note that, by selectively reducing peripheral LHC complex subunits under high light, important improvement of the photosynthetic efficiency in crops has been predicted (e.g., Ort et al. 2015, Slattery and Ort 2021), and promising results have already been obtained with the green alga Chlamydomonas (see e.g., Negi et al. 2020; cf. Bielczynski et al. 2020).

In addition to 'light capture', plants use pigments as photoreceptors to sense light changes that trigger chloroplast movement in the cells, which increase or decrease the total leaf transmittance, and regulate the stomatal opening, and thus the $\mathrm{CO}_{2}$ influx and water evaporation. Since the spectral distribution of ambient light can vary tremendously under aquatic environment, changes in PBS composition take place in many cyanobacteria, through chromatic acclimation (CA; see a review by Sanfilippo et al. 2019, and the subsection 'Acclimation of cyanobacteria to changes in environmental light quality', see below). During the CA, cyanobacterial cells use a complex network of photoreceptors to sense the color of the ambient light and use this information to optimize the photosynthetic light harvesting (Grossman 2003, Kehoe and Gutu 2006, Montgomery 2016, Hirose et al. 2019, Wiltbank and Kehoe 2019). Some terrestrial cyanobacteria synthesize $\mathrm{Chl} d$ and $\mathrm{Chl} f$ during chromatic acclimation to far-red (FR) light $(\lambda=700-800 \mathrm{~nm}$; see Fig. 2 for the absorption spectra of different types of Chls); this is known as far-red light photoacclimation (FaRLiP) (Sanfilippo et al. 2019). These far-red acclimated cyanobacteria are known to significantly remodel their core PSI and PSII, and the PBS to facilitate the absorption of FR light for their growth (Chen et al. 2010, Chen and Blankenship 2011, Gan et al. 2014, Ho et al. 2020, Kato et al. 2020, Mascoli et al. 2020). For example, some of these cyanobacteria can synthesize and incorporate $\sim 8 \% \mathrm{Chl} f$ into their PSI (see the cryo-electron microscopy data on Fischerella thermalis PCC 7521 by Gisriel et al. 2020a), which extend their light utilization to $\sim 800 \mathrm{~nm}$ (see also Tros et al. 2021). Some of the new Chls, mentioned above (Chl $d$, Chl f), participate not only in light harvesting, but also in photochemical reactions of both PSI and PSII (Miyashita et al. 1996, Boichenko et al. 2000, Larkum and Kühl 2005, Nürnberg et al. 2018). In the model of Nürnberg et al. (2018) for Chroococcidiopsis thermalis, a widely spread extremophile cyanobacterium that 


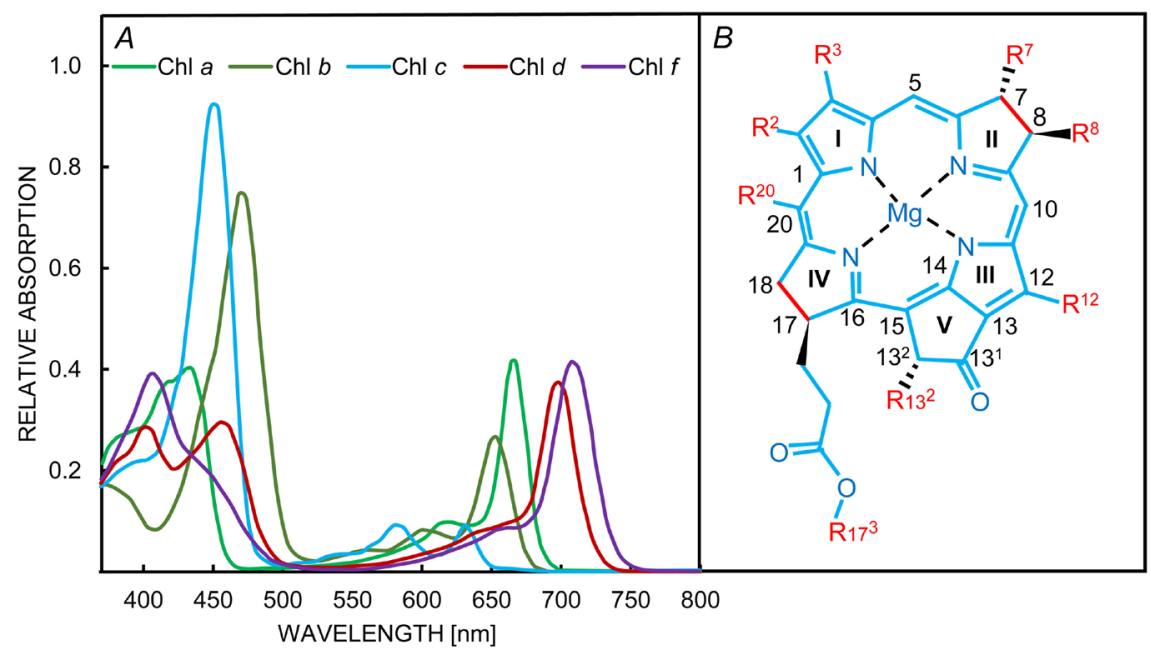

Fig. 2. Different types of chlorophylls (Chls) are used by oxygenic photosynthetic organisms. (A) The absorption spectra of Chl $a$, Chl $b$, $\mathrm{Chl} c, \mathrm{Chl} d$, and $\mathrm{Chl} f$ in solution. (B) Tetrapyrrole structure of the Chls; for information on the substitutions (red-colored), see a table in Croce and van Amerongen (2014). Figure modified from Croce and van Amerongen (2014, 2020).

contains $\sim 90 \%$ of Chl $a, \sim 10 \%$ of $\mathrm{Chl} f$, and $<1 \%$ of Chl $d$ when grown under 750-nm illumination, the Chl $f$ at $745 \mathrm{~nm}$ and $\mathrm{Chl} f$ (or $d$ ) at $727 \mathrm{~nm}$ were assumed to participate in charge separation in PSI and PSII, respectively. Zamzam et al. (2020) found experimental evidence for the PSII model of Nürnberg et al. (2018), in which the primary PSII electron donor is a 'far-red' Chl $\left(\mathrm{P}_{720}\right.$ in the $\mathrm{Chl}_{\mathrm{D} 1}$ position), and the secondary donor is the Chl $a\left(\mathrm{P}_{\mathrm{D} 1}\right)$ of the central $\mathrm{Chl}$ pair. This shows that by shifting, even partially, the antenna of PSII towards lower energy, the system might require also a reconfiguration of the RC, which would otherwise be excessively depopulated in the excited state. However, analysis of structural data in several recent studies (Gisriel et al. 2020a,b; Kato et al. 2020) excludes the involvement of Chl $f$ in the photochemistry of PSI. On the other hand, Chl $d$, a pigment that has the long-wavelength absorption maximum in organic solvents shifted by $\sim 30 \mathrm{~nm}$ toward longer wavelengths than $\mathrm{Chl} a$ (Fig. 2), is the predominant photosynthetic pigment in Acaryochloris marina (which contains only traces of Chl $a$; Larkum and Kühl 2005). Chl $d$ functions not only as a light-harvesting pigment in the antenna but also as a redox-active cofactor in both PSII and PSI reaction centers. The structure of the PSI supercomplex of this cyanobacterium has been recently obtained using cryo-electron microscopy (Hamaguchi et al. 2021). It clearly shows a distinctly different arrangement of electron carriers and light-harvesting complexes than those in other types of reaction centers I: the special pair of Chls in the RC is a dimer of Chl $d$ and its epimer Chl $d^{\prime}$ $\left(\mathrm{P}_{740}\right.$; see Hu et al. 1998); the two accessory Chls ( $\mathrm{A}_{\mathrm{A}}$ and $\left.\mathrm{A}_{\mathrm{B}}\right)$ are also $\mathrm{Chl} d$, while the primary electron acceptors $\left(\mathrm{A}_{0 \mathrm{~A}}\right.$ and $\left.\mathrm{A}_{0 \mathrm{~B}}\right)$ are two Pheo $a$ molecules (instead of two Chl $a$; see Kumazaki et al. 2002). Besides the presence of $\mathrm{Chl} d$ in the reaction center, the replacement of Chl $a$ with Pheo $a$ is also a very distinctive property of this PSI.

Furthermore, a few other oxygenic organisms, besides cyanobacteria, have other differences in their Chl composition. For example, diatoms and brown algae do not have Chl $b$, but they contain Chl $c$ (see Fig. 2 for Chl $c$ absorption spectrum), as an adaptation for harvesting the blue-green light available under water (see e.g., Alami et al. 2012, Mirkovic et al. 2017, Levitan et al. 2019). The diatoms contain special protein complexes from the LHC superfamily, called fucoxanthin-chlorophyll a/c-binding proteins (FCPs; Wang et al. 2019, Büchel 2020). The PSI-FCPI in the diatoms binds 16 FCPI subunits, which has the largest number of auxiliary antennas associated with PSI reported thus far (Xu et al. 2020b). Further, a special light acclimation was observed in the pennate diatom Phaeodactylum tricornutum (Oka et al. 2020), which synthesizes a red-shifted type of FCP under weak or red light, extending its light-absorption capacity to longer wavelengths. In this perspective, we review several implications of the diversity in composition and organization of the antenna used by photosystems in different organisms, and the strong correlation of this phenomenon with the light quality in their environment (e.g., Björn 1976, Kiang et al. 2007a,b; Björn et al. 2009), which is especially evident between terrestrial and aquatic plants, since the solar spectra at diverse water depths differ considerably from the spectra incident on Earth (e.g., Stomp et al. 2007a,b). We also discuss below how differences in pigment composition of the antenna between different photosynthetic organisms influence their response to the wavelengths of the excitation light used in Chl fluorescence measurements, which is a popular method in the study of several important aspects of photosynthesis (see e.g., chapters in Papageorgiou and Govindjee 2004).

In the last section of this paper, we will discuss what is known about the influence of the quality (i.e., the wavelength) of the actinic light on the growth and photosynthetic activity of oxygenic organisms, including 
those grown indoors (see e.g., Hogewoning et al. 2010, Dueck et al. 2016, Ptushenko et al. 2020, Paradiso and Proietti 2021).

\section{Spectral signatures of photosynthesis: Why chlorophyll $a$ ?}

A characteristic of oxygenic organisms is the dual function of Chl $a$ : light harvesting and photochemistry (see 'Introduction'). Important initial studies on spectral properties of Chl $a$ and its biosynthesis have been carried out by Felix Litvin and his coworkers (see e.g., Belyaeva 2003), by C. Stacy French in the USA (see e.g., French 1971), and by others (see Govindjee and Braun 1974). Reasons for the omnipresence of $\mathrm{Chl} a$ in oxygenic photosynthesizers have been discussed by many (see e.g., French et al. 1972, Katz and Norris 1973, Mauzerall 1973, 1976; Björn 1976, Kiang et al. 2007a, Björn et al. 2009, Marosvölgyi and van Gorkom 2010, Björn and Ghiradella 2015, Arp et al. 2020). Katz and Norris (1973), after examining all available data on Chl absorption and fluorescence spectroscopy in the visible spectrum, both in vitro and in vivo, have pointed out that the main in vivo long-wavelength absorption band, at the red end, is due to Chl $a$ in almost all oxygenic photosynthetic organisms. This explains the main role of Chl $a$ in photochemistry, as its lowest energy, compared to the other pigments, allows the excitation energy transfer, via resonance, to it. Further, Mauzerall $(1973,1976)$ has rationalized the structurefunction relation of $\mathrm{Chl}$ in physicochemical terms, but in addition, he also emphasized the evolutionary viewpoint of photosynthesis and of Chls (for further information, see Xiong et al. 2000, Dismukes et al. 2001, Olson and Blankenship 2004, Larkum 2006, Xiong 2006, Björn and Govindjee 2009, Hohmann-Marriott and Blankenship 2011). In David Mauzerall's view, the uniqueness of Chl $a$ on the global scale of photosynthesis (which appears to be irreplaceable, on Earth) seems to be due to its special physicochemical properties.

On the other hand, Björn (1976) studied specifically the maximal efficiency of the conversion of solar radiation into chemical energy in the photosynthetic systems, considering it as a function of both the solar spectrum and the absorption spectrum of the light-harvesting pigments. To find the optimum absorption characteristics for a photosynthetic pigment, he used the theoretical approach of Ross and Calvin (1967) (cf. Knox 1969); these results showed that, in full sunlight, the optimum absorption maximum for a narrow-banded photosynthetic pigment is at $\sim 707 \mathrm{~nm}$, which works fine for the in vivo forms of Chl, as they all have half-band width of about $10-20 \mathrm{~nm}$. Further, it was shown by Björn (1976) that, when the radiant flux density is decreased by $10 \%$, the optimum wavelength of the absorption peak is at shorter wavelengths, by $\sim 12 \mathrm{~nm}$; therefore, for one-tenth of the maximal irradiance, the new predicted optimum absorption maximum would be at $694 \mathrm{~nm}$, and for one hundredth, $682 \mathrm{~nm}$. Therefore, since the absorption maximum at $682 \mathrm{~nm}$ is closer to that of PSII in oxygenic organisms, this specific band seems to be tuned to the maximal utilization of light when the radiant energy is severely limiting (i.e., at low light), but not under high light. Further, Björn (1976) studied theoretically a photosynthetic system with two absorption bands to see the effect of an accessory pigment on the maximal efficiency of light utilization. By calculating the maximal increment in the chemical potential caused by the presence of a second band, besides the one at $682 \mathrm{~nm}$, an optimized accessory absorption band at $642 \mathrm{~nm}$ was predicted (Fig. 3 in Björn 1976); this band was assigned to $\mathrm{Chl} b$ in higher plants and green algae, and to allophycocyanin (APC) in cyanobacteria (for APC see e.g., Mimuro 2004). However, we note that the effect of this second absorption band on the chemical potential was small. Further, Björn (1976) also studied the effect of the Soret bands of Chls on the photochemical redox potential and found that its effect was negligible, even though this additional band leads to an increase in the rate of the excitation of the system.

Furthermore, Kiang et al. (2007a,b) have discussed responses to several intriguing questions, such as 'Why do plants have a 'red edge' in the red', or 'should extrasolar photosynthesis be the same (as that of normal photosynthesis)?' (cf. Ritchie et al. 2018). Kiang et al. (2007a) discussed the absorbance characteristics of pigments, present in different photosynthesizers, and showed that these are strongly correlated with those of atmospheric spectral transmittance. Based on these data, they speculated that the near-infrared (NIR) end of the absorption spectra of the pigments must have evolved in response to the major absorbance bands of the air or water environment of the organisms, being due to both solar spectrum and the presence of oxygen. Kiang et al. (2007a) proposed several rules regarding where the photosynthetic pigments would peak in absorbance, and assumed that, most probably, these would account for the so-called 'green bump' (also known as 'green trough') in land plants, which is due to their relatively lower absorptance for the green light. While specific absorption wavelengths of the RCs were not predicted from the available data, Kiang et al. (2007a) explained the excitation energy transfer kinetics from the LHCs to the RCs, by pointing out that even if the resonance excitation energy transfer (the Förster mechanism) toward the red is the dominant mechanism of light harvesting and energy trapping, the light energy absorbed at wavelengths longer than of the RCs (i.e., by the so-called 'red' Chls, or Chls $d$ and $f$ ) can still be transferred uphill to the RCs (Jennings et al. 2003, Giera et al. 2018, Kosugi et al. 2020, Tros et al. 2021).

In the perspective on 'Why Chlorophyll $a$ ?', Björn et al. (2009), where George C. Papageorgiou was one of the authors, examined the near ubiquity of Chl $a$ function, not only in light harvesting but in the primary photochemistry of PSII and PSI. Further, this paper provides not only historical (i.e., how evolution turned out to use Chl $a$, and photosynthesis in general), but spectral, and chemical points of view. First, Björn et al. (2009) emphasized the omnipresence of Chl $a$, pointing out that Chl $b$ not only appeared later but has an absorption spectrum that is not so suitable when it is not associated with that of Chl $a$; on the other hand, while $\mathrm{Chl} c$ may have preceded $\mathrm{Chl} a$, it has a weak absorption in the red region (Fig. 2; for the evolution 
of Chls, see Larkum 2006). Second, these authors point out that the six Chl $a$ molecules of the PSI RC and the six Chls $a$ of the PSII RC have never been completely replaced by any other Chl (see, however, the earlier discussion in the 'Introduction' on the presence of Chl $d$ and Pheo $a$ molecules in the PSI RC of Acaryochloris marina). And third, Björn et al. (2009) pointed out that excited Chl $a$ molecules become redox active only when they are located in an appropriate protein environment, where compatible redox-active cofactors exist at an appropriate distance, which is true for both PSI RC and PSII RC, but not for the core and peripheral LHCs. As far as the question 'Why the plants are green?', Björn et al. (2009) emphasized that the low absorption of $\mathrm{Chl}$ in the green region of the spectrum does not prevent plants from utilizing green light, as many layers of TMs containing Chl $a$ and Chl $b$ lead to up to $95 \%$ light absorption, which means that a shade plant can effectively intercept nearly all the visible light, even in the green region (for a further discussion on the green light used for photosynthesis, see: Nishio 2000, Raven 2009, Terashima et al. 2009). The detour effect (see the next section 'Light quality effects on photosynthesis, inferred from Chl fluorescence induction') might lead to the absorption of green light.

On the other hand, Marosvölgyi and van Gorkom (2010) have stated that, to their knowledge, except for Björn (1976) 'no one has challenged the assumption that black, or gray, would be better' for photosynthesis. In Hans van Gorkom's opinion, this is an irrelevant question, since the optimization analysis used by Lars Olof Björn predicts a strong influence of Fraunhofer lines in the solar irradiance on the spectral shape of the optimized absorption band, and does not predict absorption at other wavelengths. The Fraunhofer lines in the solar spectrum are caused by absorption by chemical elements in the solar atmosphere. However, some of the lines originate from molecules in the Earth's atmosphere (telluric lines), between which, those produced from water vapor absorption (the strongest in the visible spectrum) and oxygen are the most important; however, we note that the oxygen was not present when chlorophyll was selected by Nature. In their paper 'Cost and color of photosynthesis', Marosvölgyi and van Gorkom (2010) have extended the analysis presented by Björn (1976) to optically thick systems, taking the energy cost into account. We also remark that the optimization method for maximal energy production, used by Marosvölgyi and van Gorkom (2010), has been recently applied by Lehmer et al. (2021) to calculate the region of photon absorption by (eventual) photosynthetic organisms on an Earth-like planet around F through late $\mathrm{M}$ type stars that have different temperatures (thus color, i.e., emission spectrum). This knowledge is of importance when we search for life on other planets based on their reflectance spectra. Accepting these ideas, Lehmer et al. (2021) found that for planets near stars of yellow-white color (e.g., Polaris), the absorption peak of the possible photosynthetic pigments is expected to be situated in the blue region of the spectrum, whereas, for planets near the stars of yellow (Sun), orange (e.g., Arcturus), or red-orange (e.g., Proxima Centauri) color, the peak absorption of photosynthetic pigments tends to be in the red, the far-red or the near infra-red, respectively. These peaks are dependent not only on the stellar type, being examined, and planetary atmospheric composition, but also on the atmospheric water vapor concentration (see above), which alters the availability of surface photons, and therefore the predicted pigment absorption. However, Arp et al. (2020) have proposed a different type of optimization for the above question, and that too, to determine the expected spectral absorption bands of two main pigments of a photosynthetic organism living in an environment characterized by a specific solar spectrum. Arp et al. (2016) have also discussed a theoretical analysis of the conditions for minimal energy fluctuations and optimized power conversion efficiency of a nanoscale quantum heat engine photocell with two monochromatic photon-absorbing channels (2QHC). Here, these authors had found that, for two specific wavelengths from the solar spectrum, the fluctuations of the incident solar power can be naturally suppressed in the output, without any active feedback or adaptive control mechanisms. Thus, Arp et al. (2020) used a version of the optimization model, used earlier for the 2QHC photocell model, and theoretically derived the optimized absorption characteristics of two pigments for solar power conversion of several photosynthetic organisms living in niches with different solar spectrum characteristics. Under the full solar spectrum incident on Earth, the wavelength bands predicted for the two pigments were attributed to the LHCII complex, which contains mainly $\mathrm{Chl} a$ and $\mathrm{Chl} b$. However, we note that these bands were shifted toward the orange region of the spectrum, compared to those measured in vivo (Fig. $3 A, D$ in Arp et al. 2020), or to those predicted by Björn (1976) using a different optimization criterion (i.e., 707 and $682 \mathrm{~nm}$ under maximal irradiance, or 682 and $642 \mathrm{~nm}$ under $1 / 100$ of the maximal irradiance; see earlier discussion). If we accept the idea that minimizing the excitation energy fluctuations is also a valid criterion for the optimization of light-harvesting systems, then $\mathrm{Chl} b$ together with Chl $a$ must play a regulatory role in the photosynthesis of terrestrial plants. Further, Arp et al. (2020) presented examples of purple bacteria, and green sulfur bacteria; we, however, note that in the case of green sulfur bacteria, there are serious errors, in this paper, related to the information used about the photopigments involved. We suggest that the hypothesis presented by Arp et al. (2020) must be re-examined by applying similar optimization methods for various photosynthetic aquatic organisms, known to possess different accessory pigments, depending on the light conditions in their respective niches. Indeed, Stomp et al. (2007a,b) had already found that differences in light spectrum offer opportunities for niche differentiation for phytoplanktons, which allow coexistence of aquatic species with photopigments absorbing different wavelengths of light (see Stomp et al. 2004, 2008). In these studies, it was shown that the shoulders in the absorption spectrum of (pure) water create gaps in the underwater light spectrum (Fig. $3 A$ ), due to the exponential nature of light attenuation, and that the wavebands between these gaps define several distinct niches in the underwater light 

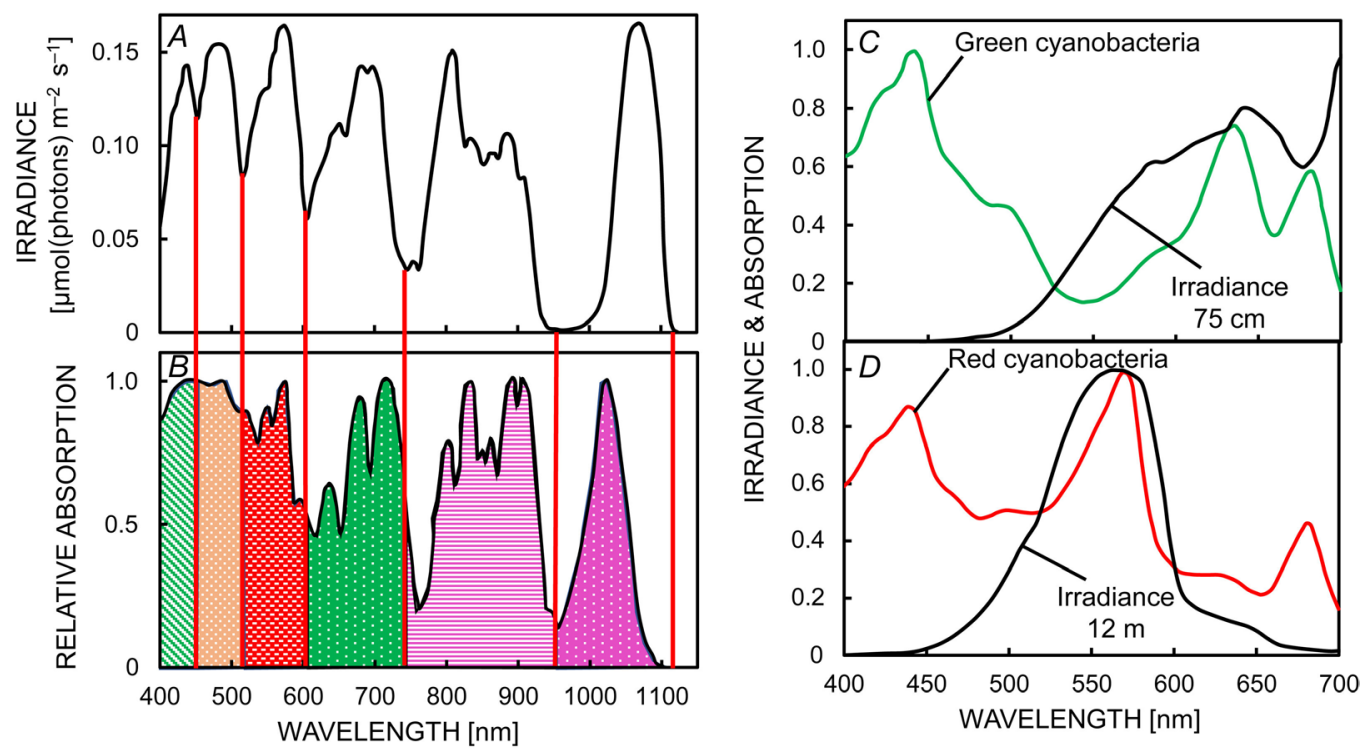

Fig. 3. Underwater differentiation of niches for photosynthetic aquatic microorganisms. Stomp et al. (2007a) have suggested that the light absorption by water determines 'dips' (marked by red lines) in the underwater light spectra, which create a series of distinct niches for phototrophic microorganisms. $(A)$ The overlay of 100 underwater light spectra was calculated at the euphotic depth. $(B)$ The overlay of light absorption spectra of 20 phototrophic species (i.e., oxygenic photosynthetic microorganisms, and photosynthetic bacteria). Two examples of absorption spectra used in the panel $(B)$ are shown in: $(C)$ for green-colored cyanobacteria, mostly using red light absorbed by phycocyanin (peak at $630 \mathrm{~nm}$ ) and Chl $a$ (peak at $680 \mathrm{~nm}$ ); and $(D)$ for red-colored cyanobacteria (Synechococcus strains) mostly using green light absorbed by phycoerythrin (peak at $560 \mathrm{~nm}$ ). The absorption spectra shown in black correspond to the underwater 'light spectra' of these two species. Figure modified from Stomp et al. (2007a).

spectrum (Fig. 3B). The relative similarity between the dips in the curves presented in Fig. $3 A, B$ seems to confirm the hypothesis of Stomp et al. (2007a). Further research is needed to fully understand the origin and evolution of the spectral signatures of oxygenic photosynthesis, not only for Chl $a$, but all other photosynthetic pigments.

\section{Light quality effects on photosynthesis, inferred from Chl fluorescence induction}

\section{Use of Chl $a$ fluorescence induction in the study of photosynthesis: Basics}

One of the most often used methods in the study of photosynthesis is Chl $a$ fluorescence (ChlF; reviewed by, e.g., Kalaji et al. 2014, 2017; Bąba et al. 2019, Hu et al. 2020 ); it is only $3-8 \%$ of the total absorbed light (Duysens 1979, Trissl et al. 1993). The emission spectrum of in vivo $\mathrm{ChlF}$ at room temperature has a major maximum at about $685 \mathrm{~nm}$, and another smaller and broader shoulder at about $740 \mathrm{~nm}$; both these bands have been ascribed mainly to PSII with a minor PSI contribution that increases at wavelengths beyond $685 \mathrm{~nm}$ (Dau 1994, Govindjee 1995, 2004).

Chl $a$ fluorescence induction (ChlFI) shows the dependence of ChlF emission on the time of illumination of a sample that had been previously adapted to darkness. During ChlFI, electron transport in both PSI and PSII occur, followed by the induction of the Calvin-Benson cycle (see Krause and Weis 1991, Baker 2008; and chapters in Papageorgiou and Govindjee 2004, and in DemmigAdams et al. 2014). Measurement of the ChlFI is very popular in photosynthesis research since it provides much information on various aspects of photosynthesis (e.g., Schreiber et al. 1986, Strasser and Strasser 1995). For reviews and some original papers on ChlFI, coauthored by George Papageorgiou, see Govindjee and Papageorgiou (1971), Papageorgiou (1975, 1996), Papageorgiou et al. (2007), Tsimilli-Michael et al. (2009), Kan̆a et al. (2009, 2012), Papageorgiou and Govindjee (2011), Stamatakis et al. (2007, 2016), and Stirbet et al. (2019). Also, see other reviews, e.g., that by Lazár (1999, 2006, 2015), Schreiber (2004), Strasser et al. (2004), Stirbet and Govindjee (2011, 2012), Stirbet et al. (2018, 2020), and Tsimilli-Michael (2020).

The ChlFI begins with a fast $(\sim 0.3 \mathrm{~s})$ fluorescence rise followed by a slow $(\sim 300 \mathrm{~s})$ decrease. Such kinetics was first observed by Kautsky and Hirsch (1931), who had used their eyes to detect these changes! George Papageorgiou, while working for $\mathrm{PhD}$ in Govindjee's Lab, contributed much in the early stage of ChlFI research (e.g., Papageorgiou and Govindjee 1967, 1968a,b). It is generally accepted that the variable ChlF is mostly from Chl $a$ in PSII, whereas the contribution from Chls of PSI is rather negligible (e.g., only $\sim 4 \%$ increase of $\mathrm{ChlF}$ of isolated PSI upon closing its RC; see Wientjes and Croce 2012). A somewhat higher (8-17\%) PSI contribution to the variable fluorescence has been predicted by Lazár (2013) using theoretical mathematical simulations; this was confirmed by Schreiber and Klughammer (2021), 
who measured the ChlF rise in vivo both at emission wavelengths lower than $710 \mathrm{~nm}$ (mostly PSII ChlF) as well as longer than $700 \mathrm{~nm}$ (enriched in PSI ChlF). The curves, reflecting variable PSI ChlF, resembled those theoretically simulated by Lazár (2013). Both in the simulations and experiments, the variable PSI ChlF was lower when the PSI acceptor side was oxidized (i.e., when the system was in a 'light-adapted' state). This observation is consistent with the low contribution of variable PSI ChlF, observed using the same experimental protocol (Pfündel 2021).

ChlF rise from the initial fluorescence $\left(\mathrm{F}_{\mathrm{O}}\right.$; the ' $\mathrm{O}$ ' level) to the peak $\left(\mathrm{F}_{\mathrm{P}}\right.$, or $\mathrm{F}_{\mathrm{M}}$, which is the ' $\mathrm{P}$ ' level in saturating light) is fast $(\sim 300 \mathrm{~ms})$, reflecting mostly the reduction of the first plastoquinone electron acceptor of PSII, Q (Duysens and Sweers 1963). However, for a discussion of other possibilities, see Lazár (2006), and Stirbet and Govindjee $(2011,2012)$.

The variable $\left(\mathrm{F}_{\mathrm{V}}\right)$ to maximal $\left(\mathrm{F}_{\mathrm{M}}\right) \mathrm{ChlF}$, i.e., $\left(\mathrm{F}_{\mathrm{M}}-\mathrm{F}_{\mathrm{O}}\right) /$ $F_{M}$, is widely used as a proxy for the maximal quantum yield of PSII photochemistry for the dark-adapted state (Kitajima and Butler 1975, Genty et al. 1989). For healthy leaves, it is 0.83 (Björkman and Demmig 1987, Lazár and Nauš 1998), which matches the value obtained independently from time-resolved ChlF measurements (see e.g., Wientjes et al. 2013a), supporting the use of $F_{V} / F_{M}$ ratio as a proxy for the quantum yield of PSII photochemistry.

Here we mention that the $F_{M}$ level is often reached using multiple turnover saturating light pulse. If a single turnover saturating flash is used in the presence of DCMU [3-(3,4-dichlorophenyl)-1,1-dimethylurea], which inhibits the electron transport from $\mathrm{Q}_{\mathrm{A}}$ to $\mathrm{Q}_{\mathrm{B}}$, the maximal ChlF measured, denoted as $F_{1}$, has values significantly lower than $\mathrm{F}_{\mathrm{M}}$, leading to $\mathrm{F}_{\mathrm{V}} / \mathrm{F}_{1}$ ratios between $\sim 0.6$ and $\sim 0.4$ (see e.g., Joliot and Joliot 1979, Magyar et al. 2018). Since $Q_{A}$ is reduced at both $F_{1}$ and $F_{M}$ levels, the increase of $F_{M}$ over $F_{1}$ was attributed to conformational changes of PSII (Schansker et al. 2011, Prášil et al. 2018, Laisk and Oja 2020, and Sipka et al. 2019, 2021). Thus, conforming to these views, the $F_{M}$ reflects not only the reduction of $Q_{A}$, but also the conformational changes of PSII. However, we will further refer in this review to the $F_{V} / F_{M}$ ratio obtained using multiple turnover saturating light pulse as a proxy for the quantum yield of PSII photochemistry, as used in standard ChlFI measurements, and since the reported light-induced conformational changes seem to be a natural phenomenon.

The decrease of ChlF emission during the ChlFI (from the ' $\mathrm{P}$ ' to the ' $\mathrm{S}$ ', or the ' $\mathrm{T}$ ' level) is due to both photochemical and nonphotochemical quenching (NPQ) of ChlF. The ferredoxin-NADP ${ }^{+}$-reductase and several enzymes of the Calvin-Benson cycle are inactive in darkness, and they are activated (with a delay) upon illumination, and carbon assimilation becomes the major sink for electrons (available in NADPH) and energy (ATP). Under these conditions, the electrons can flow to $\mathrm{NADP}^{+}$, and thus, the electron transport chain in the TM becomes less reduced, leading to a decrease in ChlF, known as photochemical quenching. All other effects causing a decrease in ChlF, except for the photochemical one, are grouped into the NPQ of ChlF. Since the movement (or turning away from light) of the chloroplasts in the leaf under high light conditions (the so-called avoidance movement; e.g., Haupt and Scheuerlein 1990, Baránková et al. 2016), and the state 1 (high ChlF) to state 2 (low ChlF) transition (Papageorgiou and Govindjee 2011) decrease the measured ChlF, both are considered to be NPQ processes (Stirbet et al. 2020). However, according to Papageorgiou and Govindjee (2014), it is preferable to consider as NPQ only those processes in which the excess energy in Chls is dissipated as heat. In this sense, the photoinhibition initiated by the photodamage of PSII (e.g., Kale et al. 2017) might be also considered an NPQ process, since the photoinhibited PSIIs dissipate heat (Anderson and Aro 1994, Chow 1994, Vavilin et al. 1998). But the typical NPQ process is the quickly reversible 'high-energy' NPQ $\left(\mathrm{q}_{\mathrm{E}}\right)$, which develops in a few seconds and relaxes within 1-2 min in darkness (reviewed in Demmig-Adams et al. 2014). In plants, the $\mathrm{q}_{\mathrm{E}}$ is related to the formation of trans-thylakoid $\Delta \mathrm{pH}$ in light (Wraight and Crofts 1970, Briantais et al. 1979), formation of zeaxanthin and antheraxanthin from violaxanthin (Yamamoto et al. 1962, Yamamoto and Higashi 1978), and to the presence of PSII protein subunit S (PsbS) (Li et al. 2000). In algae, the $\mathrm{q}_{\mathrm{E}}$ is much more species-dependent than that in plants. In unicellular green algae, or other algal groups (e.g., diatoms), the extent of $\mathrm{q}_{\mathrm{E}}$ depends on the light-harvesting complex stress-related (LHCSR) proteins (Peers et al. 2009). In most organisms, the LHCSR level is strongly light-dependent, and in some species, such as the green alga Chlamydomonas reinhardtii, acclimation to low light leads to very low NPQ levels (Peers et al. 2009). In cyanobacteria, the $\mathrm{q}_{\mathrm{E}}$ is affected by the presence of an orange carotenoid protein (OCP), a soluble protein binding a ketocarotenoid (Wilson et al. 2006). After being activated by high intensity of white or blue light, the OCP acts both as a light sensor and a quencher of excitation energy at the level of PBS (Harris et al. 2016, Kirilovsky and Kerfeld 2016, Magdaong and Blankenship 2018).

Many parameters reflecting the function of the photosynthetic electron transport chain in the TM have been successfully evaluated from the fast ChlF rise measured under illumination by high light $[\sim 3,000$ $\mu \mathrm{mol}$ (photons) $\mathrm{m}^{-2} \mathrm{~s}^{-1}$ or more], the so-called O-J-I-P transient (reviewed, e.g., by Strasser et al. 2004 and Stirbet and Govindjee 2011). By application of pulses of saturating light during the slow ChlFI decrease, many other parameters, reflecting both the photochemical and nonphotochemical quenching, can be calculated as well (reviewed, e.g., by Lazár 2015). However, the most used parameter determined from the fast ChlF measurement is $\mathrm{F}_{\mathrm{V}} / \mathrm{F}_{\mathrm{M}}$, which is used as a measure of the maximal quantum yield of PSII photochemistry (see above).

\section{Importance of the quality of excitation and actinic light in Chl fluorescence study of photosynthetic organisms}

We provide below a brief account of the available instruments for measuring ChlF. Two approaches have been developed for the measurements of the ChlFI. In 
the first, continuous excitation light is used to drive photosynthesis and ChlF; the intensity of ChlF signal reflects not only the quantum yield of ChlF, but also the intensity of excitation light. A commercially available fluorometer using this type of measurement is the Plant Efficiency Analyser (PEA, Hansatech, Norfolk, UK), a shutterless and LED-based instrument. In the second, continuous actinic light is used to drive photosynthesis, and microsecond flashes of high frequency modulated light are used for the excitation of ChlF (measuring flashes). With this method, called the pulse amplitude modulation (PAM) technique, the magnitude of the ChlF signal reflects the quantum yield of ChlF. Also, with this type of fluorometer, it is possible, in principle, to measure the ChlF using light of one color for the measuring flashes, and another beam of different colors for the actinic light. In addition to the above-mentioned instruments for the measurement of the ChlFI under continuous light, techniques based on the application of light flashes/pulses of different intensity and duration have also been developed. These include (1) the pump-and-probe technique (PAP: e.g., Mauzerall 1972), also called single flash induced transient fluorescence yield technique (SFITFY: e.g., Belyaeva et al. 2014); (2) the fast repetition rate technique (FRR: e.g., Kolber et al. 1998), also called light-induced fluorescence transient (LIFT: e.g., Osmond et al. 2017); and (3) the flash fluorescence induction (FFI: e.g., Nedbal et al. 1999) method. For details, see the papers cited above.

The first commercially available fluorometer based on the PAM technique was Walz 101 (Walz, Effeltrich, Germany), which with the use of a so-called 'saturation pulse method' has been used to separate the photochemical and nonphotochemical quenching of the excited state of Chl $a$ (Schreiber 2004). This version of the fluorometer uses white light for both the measuring flashes and the actinic light. One of the recent Walz PAM-fluorometers, PAM-2500, uses orange $(630 \mathrm{~nm})$ light, for measuring flashes and blue or red beam for actinic light. Another current fluorometer is Dual-PAM-100 (also from Walz); it uses blue $(460 \mathrm{~nm})$ excitation flashes, and this instrument can be equipped with an optional measuring head, which provides orange $(620 \mathrm{~nm})$ measuring flashes for measurements on cyanobacteria (see below). Further, this Dual-PAM-100 measures ChlF simultaneously with absorption changes in $\mathrm{P}_{700}$ (Chl $a$ pair in the RC of PSI) by $820 \mathrm{~nm}$ transmittance changes. Further, it can also measure transmission changes at $515 \mathrm{~nm}\left(\mathrm{P}_{515}\right.$ signal), which reflects voltage across the TM.

Going back to the first PEA fluorometer, we note that it used $650 \mathrm{~nm}$ actinic light; although the current Handy PEA also uses $650 \mathrm{~nm}$ excitation, the new Pocket PEA uses $627 \mathrm{~nm}$ excitation. Still another instrument, from the same company, is $M-P E A$ (Multi-Function Plant Efficiency Analyser); it is quite versatile since it measures not only ChlF and $\mathrm{P}_{700}{ }^{+}$kinetics, but also delayed (Chl $a$ ) fluorescence (DF). Among other manufacturers, we mention Photon Systems Instruments (PSI, Czech Republic); this company was one of the early manufacturers. The original fluorometer from PSI is FL-100 with which ChlF is measured both by PAM and continuous excitation techniques. A current fluorometer from PSI is a hand-held unit, the FluorPen, which uses $470 \mathrm{~nm}$ excitation light, but their FL-6000 has the possibility of using both 460 and $623 \mathrm{~nm}$ for excitation. For a comparison of the $\mathrm{O}-\mathrm{J}-\mathrm{I}-\mathrm{P}$ ChlF transients measured by Handy PEA with that by FluorPen, see Padhi et al. (2021); the observed differences between the O-J-I-P transients from Arabidopsis thaliana leaves were due mainly to the use of different colors of excitation light (the topic of our current review): blue (in FluorPen) and red (in HandyPEA).

To measure the effects of different colors of light via ChlF, a MULTI-COLOR-PAM fluorometer has been developed by Walz (Schreiber et al. 2011, 2012). This fluorometer provides six different wavelengths for the measuring light $(400,440,480,540,590$, and $625 \mathrm{~nm})$, as well as six different wavelengths of continuous actinic light and saturating pulse: blue to red (440, 480, 540, 590 , and $625 \mathrm{~nm}$ ), and 'white' light (obtained using light in the 420-640 $\mathrm{nm}$ range). The use of light of different wavelengths is particularly important when working with organisms that have different antenna pigment composition, or for the study of wavelength-dependent processes, as, e.g., reversible state transitions, and the OCP quenching, as well as for the studies on the wavelength dependence of the rates of electron transport, and changes in absorption cross-sections, particularly of PSII.

To compare measurements made using different colors (wavelengths) of light, many measurements must be made to obtain statistically meaningful data. For this, Hogewoning et al. (2012) used a laboratory-built fluorometer with red and green light measuring flashes, modulated at different frequencies, and applied simultaneously to the samples. ChlF emission induced by these flashes was detected selectively and simultaneously, using two laboratory-built demodulators (lock-in amplifiers), one for each of the two excitation wavelengths; this is a complicated system and requires precise adjustment of two photodiodes and demodulators. Further, if the experiment would require a parallel use of three or more measuring light beams, the difficulties would be even greater! The simultaneous measurement of $\mathrm{ChlF}$ emission, under excitation by two (or potentially more) colors of measuring flashes, was, however, improved by Lysenko et al. (2018); these authors developed bicolor (potentially multicolor) fast-Fourier PAM Chl fluorometry where the sample was simultaneously excited by red $(660 \mathrm{~nm})$ and blue $(470 \mathrm{~nm})$ measuring flashes (duration of $\sim 1.4 \mathrm{~ms}$ ) at a frequency of $360 \mathrm{~Hz}$ and $370 \mathrm{~Hz}$, respectively. Data of ChlF emission (at $740 \mathrm{~nm}$ ) were processed by real-time fast-Fourier transform to obtain the amplitudes of ChlF excited by the light flashes, mentioned above. In this system, the bicolor ChlF excitation was combined with actinic light and saturating pulses of blue or red color. Lysenko et al. (2018) used this measuring technique on the leaves of Ficus benjamina, and then discussed the implications of calculated quantum yields of PSII photochemistry.

Most of the above-mentioned measuring methods have been used in experiments on many plant leaves, where the light-harvesting pigments are Chls, and thus, many fluorometers use blue and/or red excitation light, mostly 
absorbed by Chls. However, the situation is different with cyanobacteria, which differ from plants and green algae in several aspects, as reviewed by Campbell et al. (1998) and Stirbet et al. (2019). In cyanobacteria: (1) light is mainly absorbed by phycobiliproteins (see also the 'Introduction') in the external light-harvesting antenna of both PSI and PSII, the PBSs; (2) the TM contains both the photosynthetic and respiratory electron transport components; (3) the PSI/PSII ratio is higher ( 2 to 10 , depending on the environmental conditions) compared to about 1 in leaves and green algae; (4) state transitions involve the movement of PBSs from PSII to PSI and vice versa (see also Papageorgiou and Govindjee 2011, 2014); further, this phenomenon is more important here than in higher plants and green algae (but in some algae, e.g., in Chlamydomonas, the state transition also plays a significant role; see Kodru et al. 2015); and lastly (5) the NPQ is OCP-driven (see above). Based on these facts, different methods have been used to obtain the correct ChlFI in cyanobacteria, as compared to those earlier developed for leaves and green algae. An example of a change concerning the quality of light to be used for ChlF measurements in cyanobacteria is because, unlike plants, they are not in state 1 after dark-adaptation, but in the state 2 (i.e., PBSs are attached to PSIs); this is because their plastoquinone pool is reduced, due to other metabolic reasons (see e.g., Stirbet et al. 2019). In state 2, lower values of $F_{O}$ and $F_{M}$ are observed when compared to state 1 (where PBSs are attached to PSIIs); this is a consequence of several processes, leading to an incorrect low $\mathrm{F}_{\mathrm{V}} / \mathrm{F}_{\mathrm{M}}$ ratio, of about 0.3-0.4 (see e.g., Ogawa et al. 2017, Stirbet et al. 2019). Thus, it is important to have cyanobacteria in state 1 before the measurement of $\mathrm{F}_{\mathrm{V}} / \mathrm{F}_{\mathrm{M}}$. This is obtained by exciting them with far-red light (which, as in plants and green algae, is mostly absorbed by Chls of PSI), or by a weak blue light, when PSI drains electrons from the electron transport chain, because of their high PSI/PSII ratio, which, thus, keeps the PQ pool oxidized, and the cells go into the state 1 . We emphasize that the blue light must be really weak $\left[\sim 30 \mu \mathrm{mol}\right.$ (photons) $\left.\mathrm{m}^{-2} \mathrm{~s}^{-1}\right]$ since otherwise, it would induce the OCP-driven NPQ. Even when cyanobacteria are in state 1 before the measurement, the PBSs can move to PSI during the saturation pulse used to measure $F_{M}$, thus affecting this ChlF level. Therefore, $F_{M}$ in cyanobacteria is best measured by using DCMU; under this condition, the PQ pool remains oxidized. However, as mentioned earlier, the contribution of the constant ChlF of PSI to $F_{O}$ and $F_{M}$ levels is high in cyanobacteria, due to high PSI/PSII ratio, and this must be subtracted from both the ChlF levels (at $F_{O}$ and $F_{M}$ ) to obtain the correct $\mathrm{F}_{\mathrm{V}} / \mathrm{F}_{\mathrm{M}}$, which is about 0.82 (see Stirbet et al. 2019 and references therein).

We also note that if a leaf is excited, at room temperature, by UV-A radiation, centered at $355 \mathrm{~nm}$, the fluorescence emission spectrum shows, in addition to ChlF peaks at $\sim 690 \mathrm{~nm}$ (red) and $740 \mathrm{~nm}$ (far-red), also blue $(440 \mathrm{~nm})$ and green $(520 \mathrm{~nm})$ fluorescence. This bluegreen fluorescence comes mainly from the cell walls of the epidermis, the vascular bundles as well as the trichomes. The fluorophore responsible for this fluorescence is mainly ferulic acid, but also several other compounds (e.g., secondary phenolic products: chlorogenic acid, caffeic acid, and sinapic acid; and flavonoids, e.g., quercetin, in the vacuole of epidermal cells). To simultaneously measure all the above fluorescence signals, two different laboratory-made multicolor fluorescence imaging systems have been developed by Hartmut Lichtenthaler and his coworkers (see Lichtenthaler 2021). These two systems differ in the source used for measuring flashes of UV-A radiation: either a laser (Lichtenthaler et al. 1996) or a flash lamp (Lichtenthaler and Babani 2000). Continuous white light is used in both systems to drive photosynthesis. By evaluating the ratios of the red-to-the far-red, and the blue-to-the red, or the blue-to-the far-red fluorescence emission, we can obtain important information about the sample used. For example, the red-to-the far-red ratio has been shown to decrease with increasing Chl concentration in the leaf (Hák et al. 1990); further, the ratios of the blue-to-the red and the blue-to-the far-red have been shown to decrease with the increasing concentration of nitrogen in the leaves (Langsdorf et al. 2000). At present, a multicolor fluorescence imaging system, similar to the systems mentioned above, has been produced by Photon Systems Instruments (PSI, Czech Republic), which has been used, e.g., for early detection of pathogen infection (Pérez-Bueno et al. 2015), and for the early detection of stress, by toxic compounds, using photoautotrophic cell suspension cultures, as sensitive biomarkers (Segečová et al. 2019).

Furthermore, upon UV-A excitation, low levels of blue-green fluorescence have been observed not only from isolated chloroplasts (Latouche et al. 2000) but from cyanobacteria (Mi et al. 2000) as well as from algal cells (White et al. 2014). This fluorescence is from NADPH. We note that the well-known DUAL-PAM-100 fluorometer (Walz, Effeltich, Germany) has also been equipped with optional measuring heads for NADPH fluorescence (Schreiber and Klughammer 2009).

\section{Interaction of blue, green, and red light with plant leaves, and its influence on the interpretation of $\mathrm{Chl}$ fluorescence}

Although only one color of light, usually either red or blue, is used in fluorometers based on continuous light excitation, two different wavelengths of light are simultaneously used in PAM measurements with newer fluorometers: red actinic light to drive photosynthesis, and blue measuring light flashes to excite ChlF. Since the light of different wavelengths penetrates differently in the samples, the methods used to measure ChlFI affect the results and their interpretation (see below).

In a dilute solution of $\mathrm{Chl}$ with homogeneous spatial distribution, the prevailing optical effect causing attenuation of excitation light intensity is the absorption of light, based on the Beer-Lambert law. However, plant leaves and algal/cyanobacterial suspensions are optically dense (i.e., have a high concentration of Chls); in addition, they are heterogeneous concerning the distribution of Chls. Thus, excitation light has a complex gradient inside 
the leaf, as well as in algal/cyanobacterial suspensions; it deviates from the Beer-Lambert law, and the gradient depends on the quality (wavelength) of the excitation light. Since different microstructures inside the leaf or cell suspension receive different light intensities, their ChlF emission is also different.

We emphasize that different optical phenomena contribute to a complex light gradient inside leaves, as well as in algal/cyanobacterial suspensions. Since Chl molecules are packed in chloroplasts and TMs inside chloroplasts, Chls that receive the light first, shield the others below them. This effect is known as the 'sieve effect' or 'flattening of absorption spectrum' since it leads to a decrease and broadening of absorption peaks of the pigments (Duysens 1956, Das et al. 1967, Jávorfi et al. 2006, Merzlyak et al. 2009, Baránková et al. 2016, Nauš et al. 2018). On the other hand, there is 'scattering' of light (all optical effects causing changes in the direction of light propagation), which increases the path length of the excitation light beam in the sample, and thus, the probability of light absorption. This effect is known as the detour effect (Kok 1948, Terashima and Saeki 1983, Merzlyak et al. 2009, Baránková et al. 2016, Nauš et al. 2018). Hence, an increased concentration of the pigments causes a decrease of absorption due to the sieve effect, but also an increase of absorption due to the detour effect, and as a result, light absorbance is a nonlinear function (Baránková et al. 2016, Nauš et al. 2018). Both the sieve and detour effects lead to similar relative changes in the absorption spectra of the photosynthetic sample: an increase in the green region, and a decrease in both the red and the blue region (Terashima et al. 2009, Nauš et al. 2018).

Optical phenomena and resulting light gradients are related to the leaf structure in higher plants. In the upper (adaxial) part of bifacial leaves (e.g., tobacco, pea), the first layer is a cuticle layer (which also contains trichomes), which is formed by waxes. A layer of epidermis cells is under this layer, followed by a layer of cylindrical palisade mesophyll cells. Under these layers, there are sphere-like spongy mesophyll cells, separated by air cavities, followed again by the epidermis and the cuticle in the lower (abaxial) leaf side, which also contains stomata. Since both the palisade and spongy mesophyll cells contain Chls, this is where most of the light absorption takes place in the leaf. Air cavities, in the spongy mesophyll cells, are responsible for most of the light 'scattering' by light refraction and reflection, which is due to the difference in refractive indexes of air/cell interfaces. In unifacial leaves (e.g., maize, barley), mesophyll is not differentiated into palisade and spongy cells but is composed of compactly arranged isodiametric cells. Thus, the overall optics is different.

The light gradients within leaf tissues were first estimated from measurements with a fiber optic probe (Vogelmann and Björn 1984, Vogelmann et al. 1989, Cui et al. 1991) or from scattered light (Takahashi et al. 1994, Koizumi et al. 1998), measured from the leaf crosssection, upon illumination of the leaf surface, assuming that the intensity of the scattered light inside the leaf is proportional to the internal light fluence rate. Based on qualitative agreement among the light gradients estimated by the above methods and the profiles of carbon fixation as well as ChlF of leaf cross-sections, upon illumination of the leaf surface, Vogelmann and Han (2000) suggested that the ChlF profiles within the leaf cross-sections may be used to estimate the light gradients within a leaf. This was confirmed by Vogelmann and Evans (2002), who combined measurements of ChlF of leaf cross-sections upon illumination of leaf surface as well as upon epiillumination (perpendicular to leaf cross-section surface). Thus, ChlF profiles within the leaf cross-section upon illumination of leaf surface seem to provide a valid measure of light absorption through a leaf, and, thus, such ChlF profiles were used for that purpose in several subsequent studies (see below).

Since the structure of leaves is not the same when going from the adaxial or the abaxial leaf side, different light gradients are expected when a leaf is illuminated from one or the other side. Steeper light gradients (utilizing ChlF) have been reported when the abaxial leaf side was illuminated (Vogelmann and Evans 2002, Evans and Vogelmann 2003, Brodersen and Vogelmann 2010, see Fig. $4 A, B$ ). In addition to the detour effect (see above), due to light refraction on air/spongy cell interfaces, the steeper light gradient is probably also caused by light scattering from grana, since a higher number of grana and more appressed grana stacks are present in spongy chloroplasts (Terashima and Inoue 1985a). Moreover, these gradients also differ if the incident light is collimated and perpendicular to the leaf surface or diffuse, the diffuse light being absorbed more within the leaf (Brodersen and Vogelmann 2010). Further, light gradients also exist inside macroalgae (Lichtenberg and Kühl 2015, Lichtenberg et al. 2017) as well as in algal/cyanobacterial suspensions, grown in photobioreactors (see e.g., Li et al. 2016, Fuente et al. 2017).

It is well known that Chls have a higher absorption coefficient in the blue region than in the red and a very small one in green light. Moreover, carotenoids also absorb blue light. Consequently, about $90 \%$ of blue and red light is attenuated in the upper $20 \%$ of the leaf's depth, while a high fraction of green light penetrates deeper into the leaf (Cui et al. 1991). Indeed, measurements of ChlF profiles and gradients across the mesophyll of absorbed monochromatic light in spinach leaves have shown that the blue light is fully absorbed in the first $\sim 150 \mu \mathrm{m}$ beneath the leaf surface, followed by the red light $(\sim 200 \mu \mathrm{m})$, and then the green light $(\sim 300 \mu \mathrm{m})$ (see e.g., Vogelmann and Evans 2002, Johnson et al. 2005, Brodersen and Vogelmann 2010, Slattery et al. 2016). As a result of the above, most of the ChlF measured under illumination with red or blue light is from the upper layers of the leaves.

Because of differences in light absorption profile of light, there are also gradients in the content of Chl and ribulose-1,5-bisphosphate carboxylase/oxygenase (Rubisco) inside the leaves (Terashima and Inoue 1985b, Nishio et al. 1993, Sun et al. 1998, Evans 1999, Evans and Vogelmann 2003). In bifacial leaves, these gradients are less steep than the gradients of blue and red light, but they 


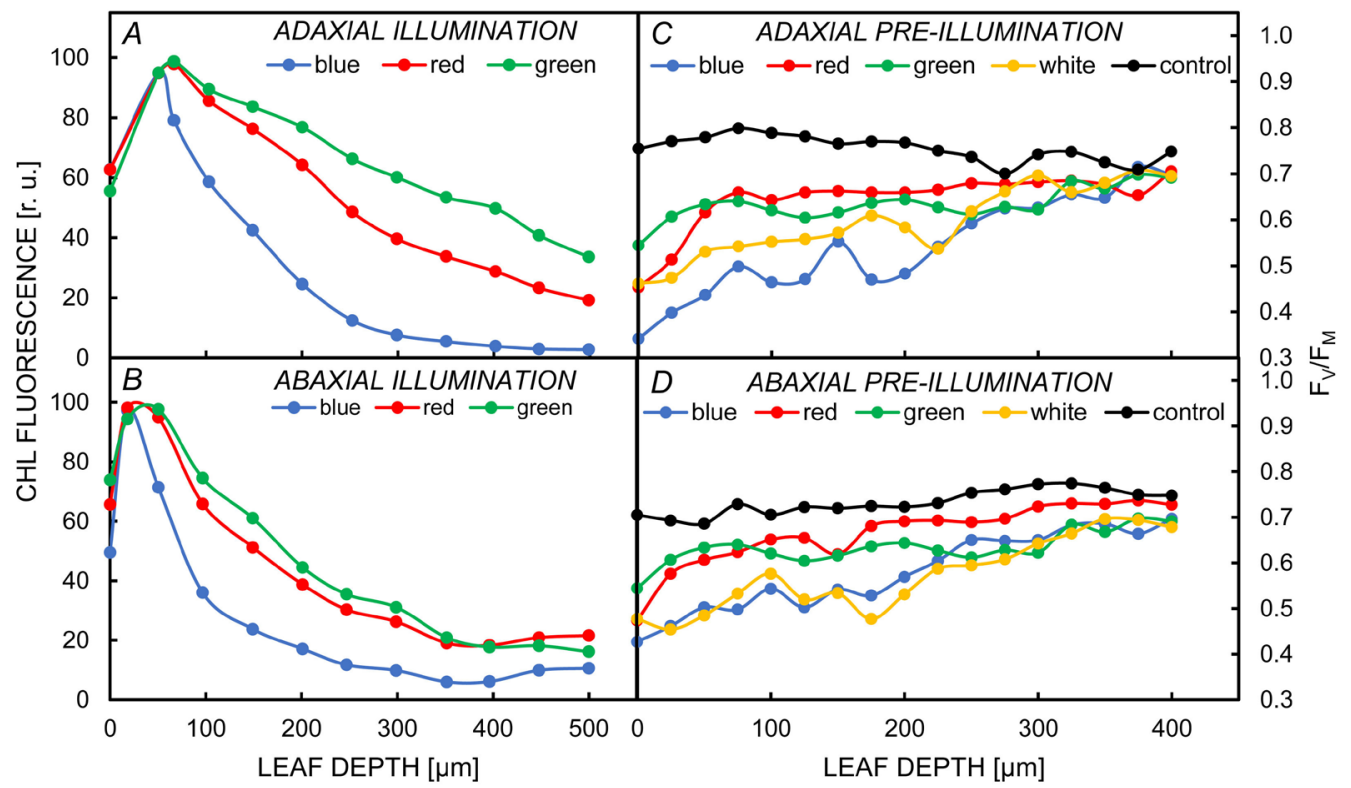

Fig. 4. Gradients of chlorophyll (Chl) fluorescence and $\mathrm{F}_{\mathrm{V}} / \mathrm{F}_{\mathrm{M}}$ ratio upon illumination $(A, B)$, or preillumination $(C, D)$, of spinach leaves (from the adaxial or abaxial side), by using different colors of light: blue, red, and green, but also white, for $(C, D)$. $(A, B)$ Chl fluorescence was measured from different parts (cross-sections) of leaves, using an imaging fluorometer, and the fluorescence gradients were used as proxies for gradients of light inside the leaf (see the text). $(C, D)$ Here, the leaves were treated with $1 \mathrm{mM}$ lincomycin (an inhibitor of prokaryote-type protein synthesis), and preilluminated for $1 \mathrm{~h}$; then, Chl fluorescence was measured with a fiber optic microprobe fluorometer. The gradients of $\mathrm{F}_{\mathrm{V}} / \mathrm{F}_{\mathrm{M}}$ in control leaves (without lincomycin and light treatment) are also shown (see the black curves in $C, D$ ). The gradients of $\mathrm{F}_{\mathrm{V}} / \mathrm{F}_{\mathrm{M}}$ were used to evaluate the photoinhibition effect of different colors of light (see the text). Figure modified from Vogelmann and Evans (2002) and Oguchi et al. (2011).

match that of the green light.

The above-mentioned light gradients affect the photosynthetic activity inside the leaves, which is reflected in the measured ChlF signals. Using the PAM technique (see above) and a fiber-optic microprobe, Schreiber et al. (1996) measured the $F_{V} / F_{M}$ ratio at different depths of Syringa vulgaris leaves under red light illumination and obtained almost constant values of $0.77-0.80$ (Fig. $4 C, D$, black symbols and lines). However, the $\mathrm{F}_{\mathrm{V}} / \mathrm{F}_{\mathrm{M}}$ dropped to $\sim 0.5$ after 5 min of preillumination with strong white light [5,000 $\mu \mathrm{mol}$ (photons) $\left.\mathrm{m}^{-2} \mathrm{~s}^{-1}\right]$, when measured just under the leaf surface (i.e., at $20-\mu \mathrm{m}$ depth), but it remained approximately at the control level when measured at $180 \mu \mathrm{m}$. Thus, photoinactivation of PSII does not occur homogeneously at different depths in the leaf. In a similar type of experiment, leaves of Capsicum annuum were preilluminated, for $60 \mathrm{~min}$, with strong light $[2,000$ umol(photons) $\mathrm{m}^{-2} \mathrm{~s}^{-1}$ ] of different colors, and the $\mathrm{F}_{\mathrm{V}} / \mathrm{F}_{\mathrm{M}}$ ratio, measured just under the illuminated leaf surface, dropped to $\sim 0.45$ after preillumination with white, green, and red light, while the drop of $\mathrm{F}_{\mathrm{V}} / \mathrm{F}_{\mathrm{M}}$ was higher (i.e., to $\sim 0.2$ ) after preillumination with blue light (Terashima et al. 2009). Further, there was a less steep change in $\mathrm{F}_{\mathrm{V}} / \mathrm{F}_{\mathrm{M}}$, measured within the leaf depth, when the preillumination was with green light. All the observed effects have been explained, in addition to the existence of different light gradients for different light colors (see above), by the fact that the Mn-cluster of the oxygenevolving complex (OEC) absorbs UV light, and thus the highest inactivation of the Mn-cluster (reflected in the $\mathrm{F}_{\mathrm{V}} / \mathrm{F}_{\mathrm{M}}$ decrease) is by blue (which has some UV in the beam used), then by green, and then by red light (Terashima et al. 2009). Different effects of preillumination by the white, blue, green, and red light of low, medium, and high intensities on the $F_{V} / F_{M}$ ratio measured from the leaf surface (Oguchi et al. 2009), and at particular depths of the leaves (Evans 2009, Oguchi et al. 2011, Evans et al. 2017; Fig. $4 C, D$ ) have led to the conclusion that there are two mechanisms involved in PSII photoinactivation: (1) when the excess energy, not used in photosynthesis or dissipated as heat, causes PSII photoinactivation; and (2) when the excitation of $\mathrm{Mn}$, in the Mn cluster of OEC, causes the release of $\mathrm{Mn}$ from the cluster, leading to PSII damage.

The effect of light gradients on the shape of the O-J-I-P ChlF transient and selected ChlF levels, evaluated from the data, measured on TM suspensions, with different concentrations of $\mathrm{Chl}$, under red light illumination, was explored by Sušila et al. (2004). Further, data obtained by using different thicknesses of the sample, and different intensities of excitation light, were explained by using a model for the $\mathrm{O}-\mathrm{J}-\mathrm{I}-\mathrm{P}$ transient, which also considers light gradient inside the sample. In this model, particular layers of the sample had different excitation light intensity, 
due to the light gradient, and the simulated ChlF transient was a sum of individual ChlF transients of particular sample layers. Results of the simulations qualitatively agreed with the experimental data (for details, see Sušila et al. 2004).

The above study was followed by that of Pfündel (2009), who used excitation flashes of light of different wavelengths (430 to $680 \mathrm{~nm}$ ), given at 10 -nm intervals, to measure both the $F_{O}$ and $F_{M}$ levels; Pfündel (2009) also used a pulse of saturating white light on leaves of barley and maize (from the adaxial side of the leaf). The emission spectra of $F_{O}$ and $F_{M}$ were quite similar for barley $\left(\mathrm{C}_{3}\right.$ plant $)$ and maize $\left(\mathrm{C}_{4}\right.$ plant $)$ leaves; they both showed excitation peaks at 440, 480, 610, and $660 \mathrm{~nm}$. However, the spectra of $\mathrm{F}_{\mathrm{O}}$ and $\mathrm{F}_{\mathrm{M}}$ of $\mathrm{Chl} b$-less barley mutant showed peaks at 440, 500, and $670 \mathrm{~nm}$. For barley, the calculated $\mathrm{F}_{\mathrm{V}} / \mathrm{F}_{\mathrm{M}}$ ratio was $0.74-0.78$, when excited by $470 \mathrm{~nm}$ and $490 \mathrm{~nm}$ light. For maize, $\mathrm{F}_{\mathrm{V}} / \mathrm{F}_{\mathrm{M}}$ had a minimum value of 0.72 (excitation $520 \mathrm{~nm}$ ) and a maximum of 0.79 (excitation $430 \mathrm{~nm}$ ). The Chl $b$-less mutant showed a different spectrum for $\mathrm{F}_{\mathrm{V}} / \mathrm{F}_{\mathrm{M}}$, with the lowest value of 0.69 (excitation $470 \mathrm{~nm}$ ), indicating the lack of Chl $b$. Although the $\mathrm{F}_{\mathrm{O}}, \mathrm{F}_{\mathrm{M}}$, and $\mathrm{F}_{\mathrm{V}} / \mathrm{F}_{\mathrm{M}}$ values, mentioned above, showed minima and maxima at particular wavelengths, all values had high data variance. The wavelength dependence, observed in the excitation spectrum of $F_{V} / F_{M}$ in the samples of barley and maize, is due to the different absorption spectra of PSII and PSI in the plants used by Pfündel (2009).

Evans et al. (2017), using Setaria viridis (a $\mathrm{C}_{4}$ plant) and Spinacea oleracea (a $\mathrm{C}_{3}$ plant), compared photosynthetic electron transport rates (ETR) measured via ChlF from the leaf surface and gas exchange (gross $\mathrm{CO}_{2}$ assimilation rate, i.e., the sum of $\mathrm{CO}_{2}$ assimilation rate and mitochondrial respiration) using different fractions of blue and red actinic light illumination. For leaves of both species, mentioned above, and by using an increasing fraction of blue actinic light, the ETR was higher than the rate of photosynthesis, measured by gas exchange. These observations agreed with theoretical simulations based on a multilayer photosynthesis model of Evans (2009), and after considering reported gradients of blue and red actinic light, the concentration of $\mathrm{Chl}$, and Rubisco content inside the leaves (see above).

Going back to the data on ChlF, the measured signal is known to be affected by reabsorption of fluorescence (Agati et al. 1993, Nauš et al. 1994, Gitelson et al. 1998, Romero et al. 2018). This is because the major (685 nm) part of the ChlF emission spectrum overlaps with the major Chl absorption band (at $680 \mathrm{~nm}$ ). Thus, a large part of ChlF ( $\sim 680 \mathrm{~nm})$ is reabsorbed and re-emitted as ChlF. However, since ChlFI is usually measured at wavelengths longer than $700 \mathrm{~nm}$, the reabsorption alone does not significantly affect the detected ChlF signal.

The existence of ChlF reabsorption was considered in experiments by Rappaport et al. (2007) who recommended the use of green light for excitation of the sample. When green light of moderate intensity was used, the time course of ChlF rise was similar at $680 \mathrm{~nm}$ (i.e., at a wavelength of high ChlF reabsorption, and thus the detected ChlF was mostly from the leaf layers close to the detector), or $>750 \mathrm{~nm}$ (i.e., for wavelengths when $\mathrm{ChlF}$ reabsorption is minimal and thus, all leaf layers contribute about equally to the detected ChlF signal), indicating that green light penetrates deeper leaf layers, and is homogeneous throughout the leaf.

The above examples refer to measurements with leaves. Remelli and Santabarbara (2018) measured emission spectra (from 600 to $800 \mathrm{~nm}$ ) of $F_{O}$ and $F_{M}$ upon excitation of the cyanobacterium Synechocystis sp. PCC 6803 with different wavelengths (from 420 to $680 \mathrm{~nm}$ ) of light. The $F_{V} / F_{M}$ ratios, calculated from these spectra, showed pronounced variation, reaching a maximal value at wavelengths close to the $684 \mathrm{~nm}$ emission, upon excitation at $435 \mathrm{~nm}$. This variability was due to the contribution of PSI ChlF in the red tail of the emission spectrum, and to an uncoupled/weakly coupled fraction of PBS, in the short wavelength emission wing. The same results as above were obtained also for the cyanobacterium Synechococcus PCC 7402 (Santabarbara et al. 2019). On the other hand, the emission spectra of the $\mathrm{F}_{\mathrm{V}} / \mathrm{F}_{\mathrm{M}}$ ratio of green algae Chlamydomonas reinhardtii and Chlorella sorokiniana showed only minor variations, irrespective of the excitation wavelength (Santabarbara et al. 2019).

\section{Acclimation of oxygenic photosynthetic organisms to different colors of light}

\section{The importance of photoreceptors}

As photoautotrophs, photosynthetic organisms are sensitive to their light environment. They possess various photoreceptors that sense key environmental cues, such as the intensity, quality (wavelength), and directionality of light. They have a complicated network of signal transduction that enables a variety of physiological adjustments in response to changes in the light environment (Kami et al. 2010, Briggs 2014, Dueck et al. 2016, Rockwell and Lagarias 2017, Ptushenko et al. 2020). The use of light-emitting diodes (LEDs) has helped us gain new knowledge about these processes (see e.g., Darko et al. 2014 for details).

There are many types of photoreceptors in different photosynthetic organisms (for cyanobacteria, see Bhaya 2016, Wiltbank and Kehoe 2016, 2019, Villafani et al. 2020; for plants, see Möglich et al. 2010, Kong and Okajima 2016, Paik and Huq 2019; and for algae, see Rockwell et al. 2014, Rockwell and Lagarias 2017). Some of these photoreceptors are directly involved even in the perception of non-light stimuli, such as temperature (thermosensing; see Paik and Huq 2019). Below, we discuss the involvement of several of these photoreceptors in the acclimation of the light-harvesting apparatus in cyanobacteria to environmental light changes, and on the regulation of photosynthesis through stomatal opening/ closing and chloroplast photorelocation movements in plants. Lastly, we will present examples of the effects of light quality on the growth of different species of plants, 
and the advantages of using high-intensity LEDs for the optimization of light in systems, such as greenhouses, soilless systems, and vertical gardening.

\section{Acclimation of cyanobacteria to changes in environmental light quality}

As mentioned earlier, cyanobacteria can sense changes in the color of the ambient light, which trigger reversible acclimation processes, including the remodeling of their PBS antenna complex, which increase the efficiency of light harvesting for photosynthesis (Kehoe and Gutu 2006, Hirose et al. 2013, Sanfilippo et al. 2019). Initially, such a change was known as 'complementary chromatic adaptation' (CCA; see e.g., Gaidukov 1903), since changes in the pigmentation of cyanobacterial cells were modulated in a complementary way with the color of the light in the environment. However, since many noncomplementary types of these processes were later discovered (Villafani et al. 2020), and because they involve changes in gene expression, rather than changes in genetic composition (necessary for an adaptation process), all these phenomena are now called 'chromatic acclimation' (CA).

The phytochromes are important photoreceptors that are found in all oxygenic photosynthetic organisms; they contain a linear tetrapyrrole (bilin) chromophore covalently attached to a GAF domain (named after the three proteins that contain this domain: N-terminal cGMP phosphodiesterase; adenylyl cyclase; and FhlA) for light perception via 15,16-photoisomerization. The GAF domain is usually part of a larger photosensory core module (PCM) of phytochromes (Fig. 5). In common (canonical) phytochromes found in plants (Phy) and in cyanobacteria (e.g., Cph1; Yeh et al. 1997, Rockwell and Lagarias 2017), the PCM has three domains (PAS-GAF-PHY; see also Rockwell and Lagarias 2010, Wiltbank and Kehoe 2019); it is connected with a carboxy-terminal output domain via a flexible hinge region (see also Hoang et al. 2019). On the other hand, the PCM in Cph2 has only two domains (GAF-PHY; Wallner et al. 2020), while the cyanobacteriochromes (CBCRs), which are small photoreceptors usually found as modular components in multidomain cyanobacterial signaling proteins, have GAF-only photosensory modules (Rockwell

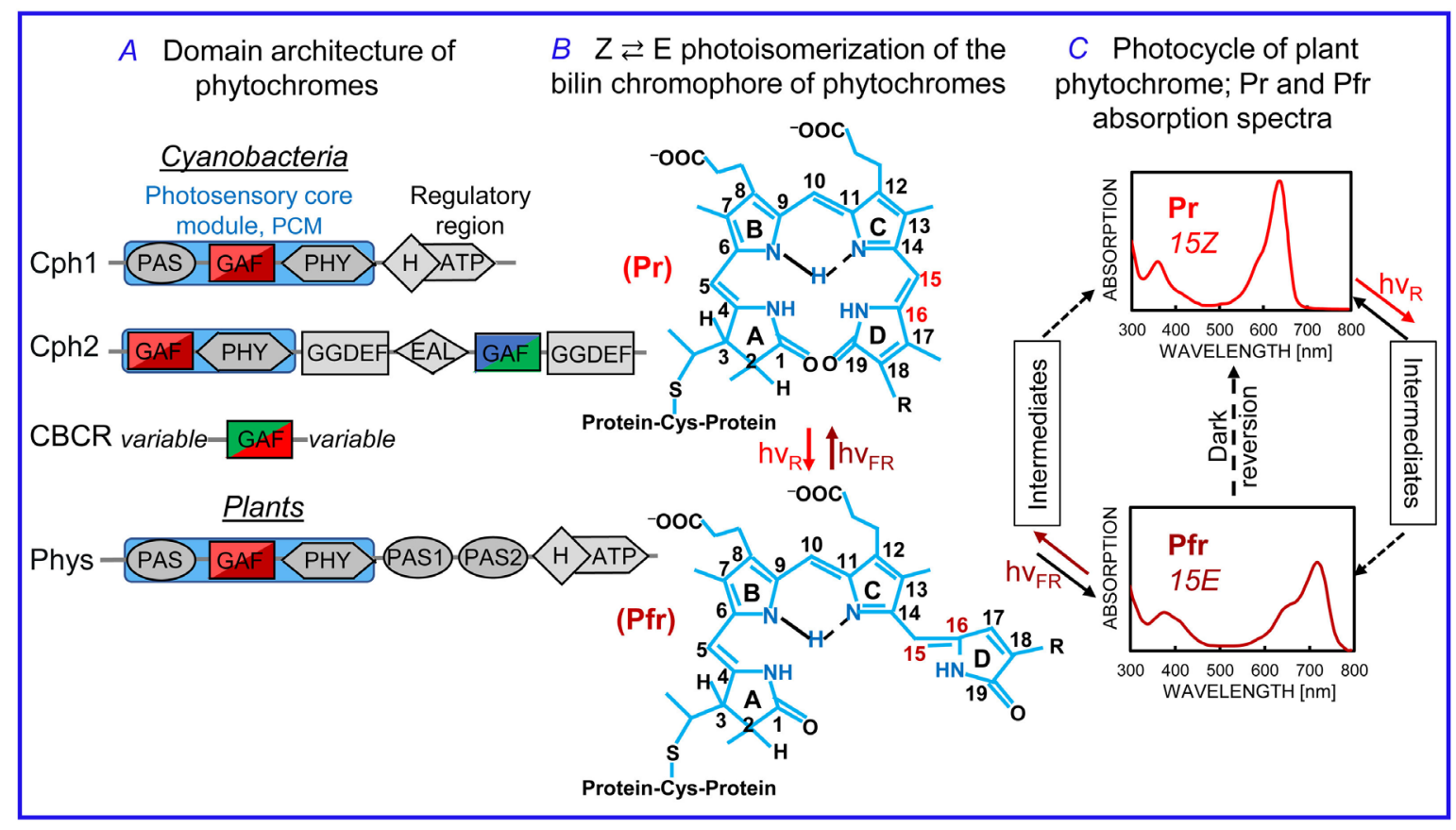

Fig. 5. Domain structure of phytochrome subfamilies in cyanobacteria and plants $(A)$, and phytochrome photoconversion $(B$ and $C)$. (A) Phytochromes have a modular domain architecture, usually consisting of a globular N-terminal photosensory core module (PCM), with the most complex PCMs containing three protein domains (PAS-GAF-PHY, with GAF binding the bilin chromophore), and a C-terminal regulatory region, which contains histidine kinase (-related) regulatory domains. The PAS domain of PCM is missing in $\mathrm{Cph} 2$, while the molecules of Phys have two additional PAS domains in the regulatory region, important for nuclear localization (Rockwell et al. 2006). There are also small CBCR photoreceptors that contain only a GAF domain, functioning as modular components in multidomain cyanobacterial signaling proteins, which are important in cyanobacterial chromatic acclimations. $(B)$ The primary photochemical step of the $\mathrm{Pr} \rightleftarrows$ Pfr conversion: $\mathrm{Z} \rightleftarrows$ E photoisomerization of the phytochrome bilin chromophore. Cph1 and Cph2 bind phycocyanobilin, Phys bind phytochromobilin, and CBCR can bind various bilin pigments as chromophores. $(C)$ Plant phytochrome photocycle and dark reversion, with Pr and Pfr absorption spectra. See the text for details. CBRC - cyanobacteriochromes; Cph1 and Cph2 - phytochrome subfamilies, named after cyanobacterial phytochromes 1 and 2 from Synechocystis sp. PCC 6803; Cys - cysteine; Phys - phytochrome subfamily found in plants; plant Pr and Pfr - red-light absorbing and far-red light absorbing states of phytochrome. Figure modified from Li et al. (2011), Rockwell and Lagarias (2017), and Wiltbank and Kehoe (2019). 
and Lagarias 2017, Fushimi et al. 2020, Moreno et al. 2020) (Fig. 5A). In all these subfamilies of phytochromes, light absorption by the bilin chromophore induces the photoisomerization of the $\mathrm{C} 15-\mathrm{C} 16$ bilin double bond, which triggers reversible photoconversion between the $15 \mathrm{Z}$ dark state and the $15 \mathrm{E}$ photoproduct state, with the two chromophore configurations having different spectral properties (Fig. 5B,C; Yeh et al. 1997, Rockwell and Lagarias 2017). Then the Pfr migrates to the nucleus where the PCM domain can interact with regulatory transcription factors (Rockwell et al. 2006, Oh and Montgomery 2017). CBCRs are essential in many chromatic acclimation types (Wiltbank and Kehoe 2019), and in contrast to the canonical phytochromes that are red/far-red receptors, they perform a variety of photocycles at different wavelengths (colors) of light: UV-A, visible, and far-red (Ikeuchi and Ishizuka 2008, Hirose et al. 2013, Blain-Hartung et al. 2018). We also note that the photoreceptors responsible for chromatic acclimation also induce changes in cell morphology and physiology of cyanobacteria, besides those in the PBS structure (Sanfilippo et al. 2019).

The phenomenon of chromatic acclimation was first observed in cyanobacteria which contain phycocyanin $\left(\mathrm{PC} ; \lambda_{\max }=620 \mathrm{~nm}\right)$ and phycoerythrin $\left(\mathrm{PE} ; \lambda_{\max }=540 \mathrm{~nm}\right)$, out of which $\sim 70 \%$ showed differences in their response to green and red light. These cyanobacteria have been classified into three groups (Fig. 6A; Tandeau de Marsac 1977): Type I - no change in PC or PE content under both green and red light (i.e., no chromatic change); Type II - PE accumulation under green light, but not under red light, but PC is constitutively produced; and Type III - PE accumulation under green light, but not under red light, and PC accumulation under red light, but not under green light. Here we note that the Type III group is also responsible for similar responses to teal (blue-green) and yellow light (Wiltbank and Kehoe 2016). Moreover, a $4^{\text {th }}$ group, Type IV, has been found in the unicellular marine cyanobacterium Synechococcus, considered to be the second-most abundant phototroph on our Earth. This CA takes place in one subgroup of Synechococcus, called blue-green generalists, and it involves the replacement of three molecules of green absorbing phycoerythrobilin (PEB; $\lambda_{\max }=550 \mathrm{~nm}$ ) with an equivalent number of blue absorbing phycourobilin (PUB; $\lambda_{\max }=495 \mathrm{~nm}$ ) when the ambient light changes from green to blue, and the reverse occurs when the ambient light changes from blue to green, while the $\mathrm{PC}$ and $\mathrm{PE}$ content does not change (Fig. 6B; Palenik 2001, Everroad et al. 2006, Sanfilippo et al. 2019). However, in the other two subgroups of Synechococcus, known as the blue-light specialists (having a high PUB:PEB ratio, and absorbing efficiently blue light), and the green-light specialists (having a low PUB:PEB ratio, and absorbing efficiently green light), the PUB:PEB ratios are not influenced by changes in the ambient light color (i.e., there is no CA).

The $2^{\text {nd }}$ and the $3^{\text {rd }}$ group, described above, are now known as CA2, and CA3 types (Fig. 6A), and are initiated by the CBCR photoreceptors CcaS and RcaE, respectively (Kehoe and Gutu 2006, Hirose et al. 2013, Sanfilippo et al. 2019). The exact process by which the relative amounts of blue and green light are being sensed in the $4^{\text {th }}$ group of cyanobacteria (now the CA4 type; Fig. $6 B$ ) is still unknown. It appears that CBCRs are not involved here, since genes encoding such proteins have not been found in the genome of Synechococcus cells. However, it was found that the light signal is mediated via the chromophore lyases MpeZ and MpeW, and the transcriptional regulators FciA and FciB (Shukla et al. 2012, Sanfilippo

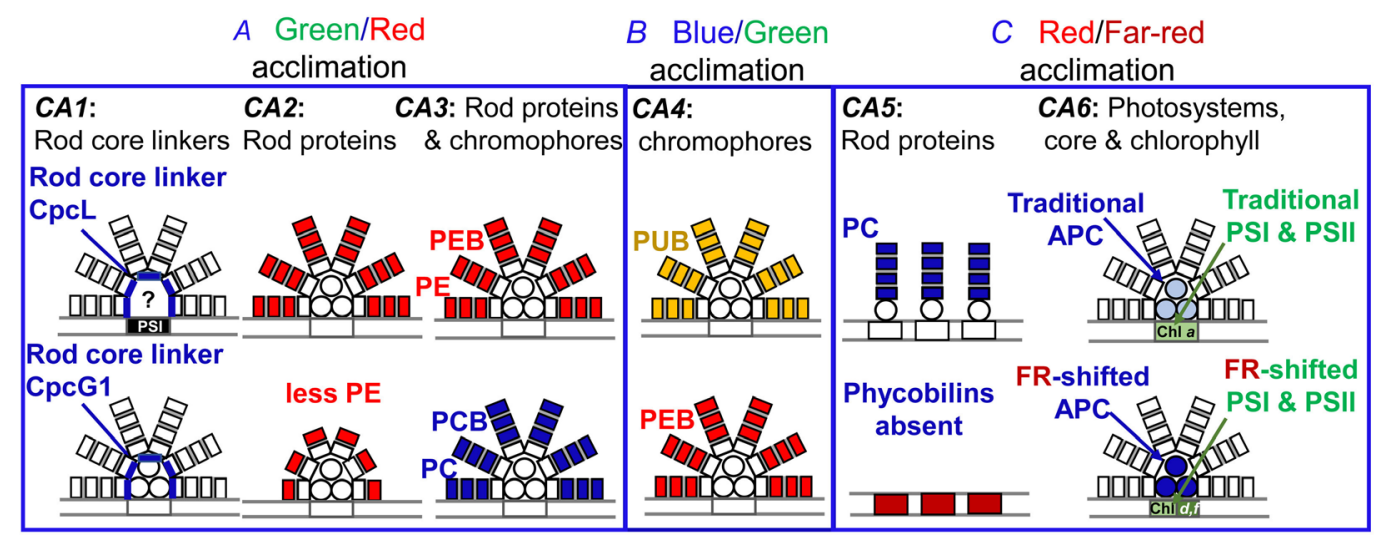

Fig. 6. A diagram of different types of chromatic acclimation (CA) in cyanobacteria; here, the nature of changes in light-harvesting structures are specified for each type of CA; the phycobilisomes (PBS) are shown attached to the thylakoid membrane, in which the photosystems are demarked by two vertical lines. For simplicity, the positions of the PBS are illustrated in the same manner in almost all cases, and the CA changes are shown in color. The three major types of CA are: $(A)$ green/red acclimation, including the CA1, CA2, or the CA3 type; $(B)$ blue/green acclimation CA4; and $(C)$ red/far-red acclimation, including CA5 or CA6 type (also called FaRLiP). In the first row are shown CA changes in the PBS induced under green light (for $A$ ), blue light (for $B$ ), and red light (for $C$ ), while in the second row are shown changes under red light (for $A$ ), green light (for $B$ ), and far-red light (for $C$ ). APC - allophycocyanin; PC - phycocyanin; PCB - phycocyanobilin; PE - phycoerythrin; PEB - phycoerythrobilin; PUB - phycourobilin. See the text for further details. Modified from Sanfilippo et al. (2019). 
et al. 2016).

Two other types of CA, labeled CA5 and CA6 (Fig. 6C), are present in cyanobacteria shaded from the red light, but functioning in far-red $(\lambda>700 \mathrm{~nm})$ light; these contain far-red absorbing Chl $d$ and Chl $f$ (see 'Introduction', and Sanfilippo et al. 2019, Hirose et al. 2019). The CA5 was discovered in Acaryochloris marina MBIC11017, which, in addition to possessing far-redabsorbing $\mathrm{Chl} d$, can increase dramatically the PC content of its rod-shaped PBS, when placed under orange-red (625 nm) light (Duxbury et al. 2009). On the other hand, the presence of CA6/FaRLiP is responsible for a physiological response, by the organism, involving an extensive remodeling of the photosynthetic apparatus, which, in turn, allows growth under far-red light, since it contains the far-red-absorbing PBS and photosystems containing Chl $f$ and Chl $d$ (Chen et al. 2009, 2010, 2011; Gan et al. 2014; Ohkubo and Miyashita 2017). FaRLiP occurs especially in cyanobacteria inhabiting a microbial mat in the terrestrial environment, and the knotless phytochrome RfpA, which is part of a large cluster of FaRLiP genes and is essential for this chromatic acclimation (Zhao et al. 2015, Ho et al. 2016).

\section{Photomorphogenesis and regulation of photosynthesis in plants through stomatal and chloroplast movement}

Photomorphogenesis refers to the development of form and structure in plants, as affected by light, a phenomenon quite different from photosynthesis. It deals with the regulation of plant growth under a broad range of light intensities and wavelengths and allows plants to optimize their use of light and space. For this, plants have acquired several major photoreceptor molecules, including phytochromes (PHY; Franklin and Quail 2010), and two types of blue-light photoreceptors, cryptochromes (CRY; Yu et al. 2010, Chaves et al. 2011), and phototropins (PHOT; Christie and Briggs 2001, Lin 2002, Christie 2007, Goh 2009). These plant photoreceptors are implicated in direct perception, and/or modulation of responses, of a wide range of environmental cues, or to plant development stages and responses to dynamic environmental stimuli (D'Amico-Damião and Carvalho 2018, Paik and Huq 2019). In contrast to spectrally diverse cyanobacterial and algal phytochromes (Rockwell et al. 2014, Rockwell and Lagarias 2017, Fushimi and Narikawa 2019, 2021; Villafani et al. 2020), plants possess only red/far-red receptors (i.e., canonical phytochromes; Castillon et al. 2007, Bae and Choi 2008, Li et al. 2011), which direct diverse responses through photoconversion between a red $(660 \mathrm{~nm})$ light-absorbing ground state Pr and a farred $(730 \mathrm{~nm})$ light-absorbing photoactivated state Pfr (Fig. 5). These phytochromes 'measure', so to say, the ratio of the red light to far-red light, allowing the plant to sense the quantity of available useful light, and to trigger shade avoidance responses (Ruberti et al. 2012). On the other hand, the phototropins (PHOT) and cryptochromes (CRY), which bind flavin mononucleotide (FMN) as chromophore, are important for plant responses to UV-A/blue light (see below, and a review by Christie et al. 2015).

Arabidopsis contains several blue-light photoreceptors, including two types of PHOT (PHOT1 and PHOT2; Lin 2002, Harper et al. 2003, Christie 2007, Goh 2009) and three types of CRY (CRY1, CRY2, and CRY3, also called CRY-DASH; Wang and Lin 2020). The receptors PHOT1 and PHOT2 mediate phototropism (i.e., turgordriven movement of a plant organ away or toward from a light source; see e.g., Liscum et al. 2020), as well as stomatal and chloroplast movement (Briggs and Christie 2002, Christie et al. 2015), which play an important role in the optimization of photosynthesis. On the other hand, CRY1, CRY2, and CRY-DASH are involved in a variety of growth and developmental processes. Further, CRY1 and CRY2, together with PHOT1 and PHOT2, serve to entrain the plant circadian clock to the phase of daily light-dark cycles (Somers et al. 1998). We note that PHOT1 and PHOT2 are bound on plasma membranes, while the other photoreceptors are localized in the nucleus or the cytoplasm (Ronald and Davis 2019, Hayes 2020, Ishishita et al. 2020). This difference probably makes the phototropins particularly useful in deciphering directional light cues.

Below, we discuss mainly the involvement of plant photoreceptors in the closing and the opening of stomata, and the accumulation/avoidance movements of chloroplasts; further, we mention how the above affect ChlF measurements.

\section{Stomatal movement}

The surface of most leaves is impermeable to gases and water, and the regulation of $\mathrm{CO}_{2}$ uptake and water loss by transpiration takes place through stomatal pores located in the epidermis of leaves, each surrounded by a pair of guard cells (Fig. 7A). There are large differences in how the stomata of different plant species develop and are patterned (Rudall et al. 2013, Bertolino et al. 2019). Together with the stomatal size and density, the number and placement of stomatal pores on leaf surfaces determine the capacity of stomata to allow $\mathrm{CO}_{2}$ to enter the leaf, i.e., stomatal conductance $\left(g_{\mathrm{s}}\right)$, which was correlated with the rate of photosynthesis, when other factors are not limiting (Wong et al. 1979, Xiong and Flexas 2020).

The number, size, and distribution of stomata vary widely in vascular plants (see e.g., Xiong and Flexas 2020). Moreover, the stomatal development may also be adjusted over long periods, with stomatal size and density being adapted to suit environmental conditions. For example, atmospheric $\mathrm{CO}_{2}$ availability strongly influences the dorsoventral organization of leaf structure, and studies from periods when $\mathrm{CO}_{2}$ concentrations were low have shown an increased stomatal size and a reduced stomatal density (Bertolino et al. 2019). Between various vascular plants, leaves with stomata on both upper (adaxial) and lower (abaxial) sides, i.e., 'amphistomatous', allow higher photosynthetic productivity compared to leaves with stomata only on the abaxial surface, known as 'hypostomatous' (Drake et al. 2019). However, most plants have stomata only on the abaxial side of the leaves (Kollist et al. 


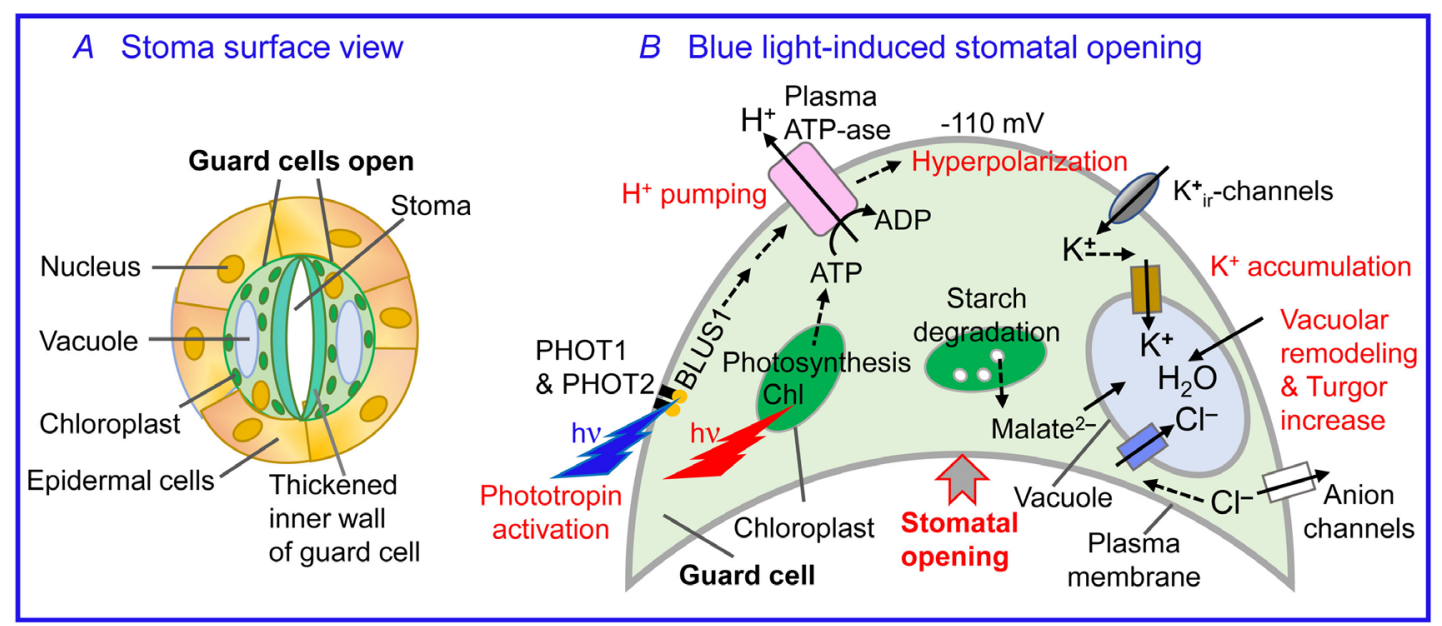

Fig. 7. Mechanism of the blue light-induced stomatal opening. $(A)$ Schematic illustration of a stoma surface view. $(B)$ Diagram showing the sequential steps of blue light-induced stomatal opening mechanism in a guard cell: $(1)$ the blue light activates the phototropins PHOT1 and PHOT2 (bound on plasma membrane), which transmit the incoming signal to the cytosolic protein kinase Blue Light Signaling1 (BLUS1), which indirectly (2) induces the activation of plasma $\mathrm{H}^{+}$-ATPase, leading to efflux of $\mathrm{H}^{+} \mathrm{s}$; this step leads to (3) hyperpolarization of the plasma membrane, which induces (4) an influx of $\mathrm{K}^{+}$ions in the cell through $\mathrm{K}^{+}{ }_{\mathrm{ir}}$-channels, which accumulate rapidly in the vacuole, together with $\mathrm{Cl}^{-}$, malate ${ }^{2-}$ (produced during starch degradation), and water, thus increasing the turgor pressure of the guard cell, which is then followed by (5) vacuolar remodeling, leading to stomatal opening. Modified from Inoue and Kinoshita (2017).

2014, Muir 2015, Chater et al. 2017), as this prevents the entry of foliar pathogens on the adaxial leaf side (McKown et al. 2014). The plant species with amphistomatous leaves are mostly from the dicots; further, in the amphistomatous leaves, the stomatal density is generally higher on the abaxial side, and the abaxial guard cells are usually more sensitive to environmental and internal signals (Wang et al. 1998). On the other hand, most floating aquatic plants (e.g., lotus, water lily) have stomata only on the adaxial side of the aerial leaves, which are generally permanently open (see e.g., Shtein et al. 2017).

For stomatal movement, both red and blue light triggers the activation of signal transduction cascades, which interact with or are activated by phytohormones. Changes in stomatal aperture are achieved through changes in the volume and the turgor pressure of the guard cells, which involve the activity of electrogenic proton pumps in the plasma membrane and/or metabolic activity that lead to the accumulation of $\mathrm{K}^{+}$salts and sugars in these cells (Assmann et al. 1985, Roelfsema and Hedrich 2005, Shimazaki et al. 2007, Daszkowska-Golec and Szarejko 2013, Inoue and Kinoshita 2017, Matthews et al. 2020, Wang et al. 2020). Each of the two guard cells contains all the necessary components for stomatal opening, e.g., from the perception of the blue light to the increase in the cell volume. Adjustment of stomatal opening is triggered by environmental factors, e.g., changes in light intensity and quality, temperature, concentrations of $\mathrm{CO}_{2}$, and vapor pressure deficit (VPD), as well as internal signaling cues, which vary between and within species (see Khanna et al. 2014, Lawson and Blatt 2014, Aasamaa and Aphalo 2016, Lawson and Vialet-Chabrand 2019, Driesen et al. 2020, Matthews et al. 2020, Xu et al. 2021).
For example, there is an important difference between the plants with crassulacean acid metabolism (CAM), which open their stomata at night to obtain $\mathrm{CO}_{2}$ from the atmosphere (Lüttge 2002), and most $\mathrm{C}_{3}$ and $\mathrm{C}_{4}$ plants that open their stomata when light falls on them in the morning and close them in darkness (Kollist et al. 2014). However, generally, an increase in light intensity or temperature (up to an optimum), as well as low $\mathrm{CO}_{2}$ concentration and VPD, trigger stomatal opening, while the closure is induced by the reverse process, as well as by the presence of abscisic acid, which is a phytohormone (e.g., Bernacchi et al. 2007, Kollist et al. 2014, Matthews and Lawson 2019). Also, since stomata and photosynthesis do not respond with the same rapidity to changes in light intensity and spectral quality (Shimazaki et al. 2007), temporal and spatial disconnections between these two processes take place when there are short-term light fluctuations (see e.g., Vialet-Chabrand et al. 2017, Lawson et al. 2018, Matthews et al. 2018, 2020).

Stomata are open when photosynthesis takes place in the mesophyll and guard cell chloroplasts (Suetsugu et al. 2014), but they close when electron transport is inhibited (Matthews et al. 2020). Under red light, when photosynthesis takes place, $\mathrm{CO}_{2}$ concentration decreases in the leaf leading to an inhibition of the anion channels in the guard cells (Lee et al. 2007). This leads to $\mathrm{K}^{+}$uptake, which, together with water (transported via aquaporins), generates the turgor necessary to open the stomata. However, the anion channels are activated if the $\mathrm{CO}_{2}$ increase is high, inducing stomatal closure. On the other hand, PHOT1 and PHOT2 phototropins, present in the guard cells, act as major blue-light receptors, which is especially important for early morning stomatal opening 
(Kinoshita and Shimazaki 2002). This process is activated through autophosphorylation of two serine residues in the kinase activation loop, which then initiates the signaling for stomatal opening (Fig. 7B). The activated phototropins phosphorylate a cytosolic protein kinase, the Blue Light Signaling1 (BLUS1; Takemiya et al. 2013), which transmits the signal, and induces the activation of plasma $\mathrm{H}^{+}$-ATPases (Yamauchi et al. 2016). Then, the ATPase functions to drive $\mathrm{H}^{+}$transport, hyperpolarizing the plasma membrane $(-110 \mathrm{mV})$, which activates the inwardrectifying $\mathrm{K}^{+}$channels $\left(\mathrm{K}^{+}{ }_{\text {ir }}\right.$-channels), producing an influx of $\mathrm{K}^{+}$ions in the guard cells that are rapidly transported into the vacuole, together with $\mathrm{Cl}^{-}$, malate ${ }^{2-}$, and $\mathrm{NO}_{3}{ }^{-}$. The result is a dynamic change in the vacuolar structure and an increased turgor pressure (Fig. 7B), leading to stomatal opening (Andrés et al. 2014).

Iino et al. (1985) have shown that even a short (30-60 s) blue-light pulse induces stomatal opening, which is sustained for more than $10 \mathrm{~min}$ after the pulse. During the stomatal closure, inhibition of $\mathrm{H}^{+}$-ATPase, together with the activation of anion channels, leads to depolarization of the plasma membrane $(-50 \mathrm{mV})$, which then induces an ion efflux, and shrinking of the guard cells.

While the absorption of blue light by PHOT1 and PHOT2 receptors triggers the signaling cascade for stomatal opening, the CRY1 and CRY2 blue receptors have been shown to function, together with PHOT, in mediating this process (see e.g., Mao et al. 2005, Liu et al. 2011). Although the PHOTs have relatively greater importance at the start of illumination, both PHOT and CRY receptors are necessary for stomatal opening throughout the photoperiod (Wang et al. 2020). In addition, photosynthesis indirectly influences the stomatal opening under blue light, as both the sensitivity and the magnitude of stomatal response to blue light depends on the intensity of the background red light (Karlsson 1986). Furthermore, illumination of intact (attached) leaves with green light, together with blue light (or immediately preceding the blue light pulse), was shown to reverse the blue lightspecific opening in a dose-dependent fashion, while green light alone did not induce stomatal closing (Frechilla et al. 2000, Talbott et al. 2002, 2006). We note that the above-described phenomenon is fully reversible and takes place only in the morning phase of the stomatal movement, which is potassium-dependent. Thus, the stomatal opening is an intricate process, and, much more research is needed to understand it all.

The role of blue light in the stomatal opening was explored through measurements of ChlF, first with guard cells (Zeiger et al. 1980, Ogawa et al. 1982, Mawson et al. 1984). Then, Srivastava and Zeiger (1992) measured ChlF induction with chloroplasts isolated from Vicia faba guard cells, and found, using red light illumination, a slow (within $10 \mathrm{~s}$ ) monophasic decrease of ChlF signal after a peak; this was followed by experiments with blue-light illumination, when a biphasic decrease with fast (within a half-second) and some slow steps were observed, the faster decrease indicating a specific response of the guard cell chloroplasts to blue light. In experiments on leaves of grapevines and vines, Flexas et al. (2002) found that decreasing stomatal conductance (i.e., stomatal closure) is accompanied by a decrease of steady-state ChlF; further, the relationship between the two variables was not linear. In field experiments with Quercus sp. and tulip poplar, Marrs et al. (2020) found that stomatal closure led to decreases in both stomatal conductance and the rate of $\mathrm{CO}_{2}$ assimilation. All of this was accompanied by significant decreases in the effective and maximal quantum yields of PSII photochemistry; however, the decrease in stomatal conductance was accompanied by only a slight decrease in the steady-state ChlF. A detailed modeling study is needed to fully understand the nuances of the above interesting observations.

\section{Chloroplast movement: Photorelocation}

In response to changes in environmental light conditions, chloroplasts adjust their location in the cell by 'accumulating' at places, to better absorb the incident light, or by moving away ('avoidance'), to 'avoid' absorbing the incident light. This phenomenon is dubbed 'photorelocation' movement since it is initiated by light. These movements optimize the use of light in photosynthesis and minimize the damage due to exposure to excess light (see e.g., Suetsugu and Wada 2007, 2009). Both the accumulation and the avoidance movement of chloroplasts (referred to as positive and negative blue/UV-A light-dependent chloroplast phototaxis) depend on the functioning of actin filaments (Kadota et al. 2009, Suetsugu et al. 2010); they are mediated in most plants by PHOT1 and PHOT2 receptors, located on the outer membrane of the chloroplasts (see above, and a review by Kong and Wada 2014). One of the methods to detect chloroplast movement involves measuring changes in red light transmittance (T) through the leaf blade during changes in light conditions (Fig. 8A). In weak or intermediate light, chloroplasts slowly $(\sim 1-2 \mathrm{~h})$ accumulate along the periclinal walls (i.e., perpendicular to the direction of incident light), and this response fine-tunes the photosynthesis through a decrease in total leaf transmittance. Under strong blue light, chloroplasts relocate in minutes $(\sim 30 \mathrm{~min})$ to the edges of anticlinal cell walls (i.e., parallel to the direction of incident light), and this response provides them protection against photodamage (Fig. $8 B$ ). Both PHOT1 and PHOT2 are essential in the accumulation response, while PHOT2 alone induces the avoidance response (Jarillo et al. 2001). Indeed, PHOT2 mutant plants are defective in the avoidance movement, while other phototropin-mediated responses display a constitutive accumulation response, irrespective of light intensity, leading to enhanced leaf photosynthesis, and increased biomass production (Gotoh et al. 2018a).

Studies by Suetsugu and Wada (2009) on the photorelocation movement of chloroplasts have shown that: (1) signals for the avoidance response function only in the irradiated areas, while those for the accumulation response are also transferred towards chloroplasts located farther down; (2) signals for the avoidance response disappear 


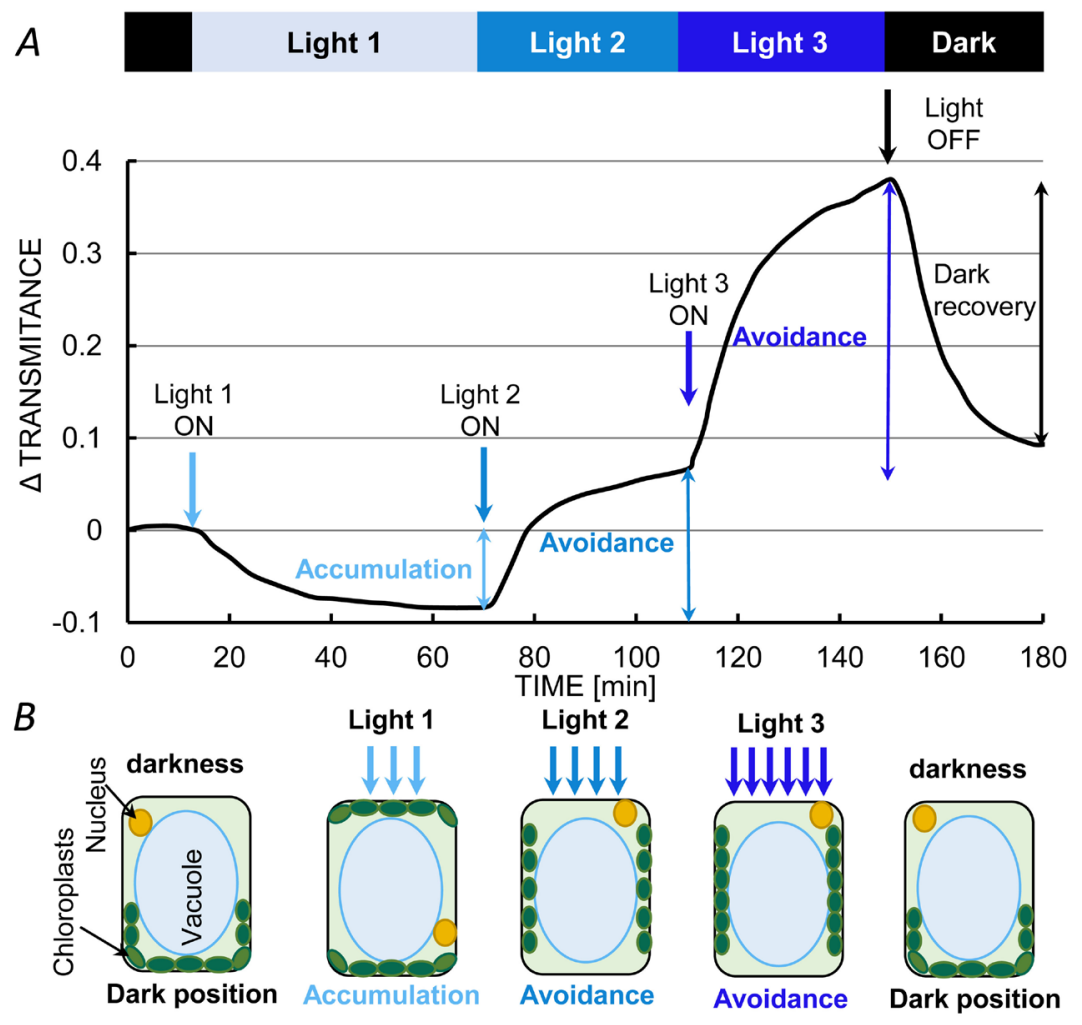

Fig. 8. Chloroplast photorelocation movements. (A) Measurement of light-induced changes as red light transmittance $(\Delta \mathrm{T}=$ $\mathrm{T}_{\mathrm{t}}-\mathrm{T}_{0}$ ) in Arabidopsis thaliana leaf under illumination with the blue light of 3,20 , and $50 \mu \mathrm{mol}$ (photons) $\mathrm{m}^{-2} \mathrm{~s}^{-1}$ (labeled as Light 1,2 , and 3 ), given for 60,40 , and $40 \mathrm{~min}$. (B) Schematic drawing of chloroplast positions under different illumination conditions: in darkness (at the bottom of the cells), during the accumulation response under low light (below the cell surface, i.e., periclinal wall, and at the bottom of the cells), and avoidance response under medium and high light (on the sidewall, i.e., anticlinal wall). Modified from Suetsugu et al. (2016) and Wada (2016). rapidly after the light is turned off, whereas those for the accumulation response are long-lived; (3) the avoidance response in the surface mesophyll layer facilitates diffusion of $\mathrm{CO}_{2}$ from the air spaces into the mesophyll chloroplasts, as well as light absorption in the deeper cell layers, both of which favor increase in net photosynthesis.

The influence of the photorelocation movement of chloroplasts on the absorptance/transmittance of photosynthetically active radiation (PAR) depends on leaf anatomy, being e.g., more pronounced in leaves with a single layer of chloroplast-containing cells than in those with well-developed palisade parenchyma and multiple cell layers (Brugnoli and Björkman 1992). Also, the narrower, more columnar, cells, found in sun leaves, restrict the ability of chloroplasts to move, while the broader, more spherical cells of shade leaves facilitate chloroplast rearrangement, allowing efficient light capture under low-light conditions (Gotoh et al. 2018b). Indeed, it has been shown that chloroplast movement-dependent changes in leaf absorptance are greatest in shade plant species, where absorptance changes of $>10 \%$ were observed between high- and low-light treatments (Davis et al. 2011). The number and morphological heterogeneity of chloroplasts also influence the effects of accumulation/ avoidance movements: large chloroplast phenotypes usually exhibit greater PSII photodamage than those with intermediate phenotypes, while plants with small chloroplast phenotypes show no abnormalities in their photorelocation efficiency and photosynthetic capacity (Dutta et al. 2017).

Plants have evolved different strategies to optimize the amount of light used for photosynthesis as well as to reduce the risk of damage when exposed to excess light; for this, the chloroplast photorelocation movement, discussed above, plays a specific role. For example, Howard et al. (2019) have shown the relative importance of chloroplast movement, NPQ, as well as ETR concerning the shortterm stress tolerance of Arabidopsis thaliana grown under different light conditions; Howard and coworkers showed that $\mathrm{ETR}_{\max }$ and $\mathrm{NPQ}_{\max }$ play important roles in avoiding damage to plants grown under intermediate light intensities, while the chloroplast avoidance response is beneficial for plants grown under low light.

Prolonged illumination of leaves with strong blue light causes chloroplast avoidance movement, and a decrease of the absorption cross-section of chloroplasts (see e.g., Nauš et al. 2010, Baránková et al. 2016). Thus, if ChlF induction is measured under blue-light illumination, there is a different absorption cross-section of the sample at the beginning (i.e., in the dark-adapted state) than at the end of the measurement (i.e., blue-light adapted state). Therefore, the basic ChlF levels $\left(F_{O}\right.$ and $\left.F_{M}\right)$ for the dark-adapted state, and the ChlF levels in the blue-light adapted state $\left(F_{O^{\prime}}, F_{(t)}\right.$, and $\left.F_{M}{ }^{\prime}\right)$, are characterized by different absorption cross-sections of the sample, which affect the values of parameters evaluated using basic ChlF levels. Pfündel et al. (2018) explored the effect of blue-light illumination on the ChlF levels using leaves of Arabidopsis thaliana adapted to low and high light [100 and $250 \mu \mathrm{mol}$ (photons) $\left.\mathrm{m}^{-2} \mathrm{~s}^{-1}\right]$ : only the low-light-adapted leaves showed the blue-light effect, with a decrease in the blue-lightadapted ChlF levels by $\sim 30 \%$. Based on several different 
approaches, but all leading to the same formula, a correction factor by which the blue-light-adapted ChlF levels must be divided to obtain the ChlF levels corrected for the chloroplast movement, has been derived by Kasajima et al. (2015), as well as by Pfündel et al. (2018), and Semer et al. (2019); for details, see the cited papers.

\section{Light quality effects on growth of different plant species used in horticulture}

The manufacture of high-intensity light-emitting diodes (LEDs) of different colors (including white light) has opened new possibilities to develop multi-color driving algorithms to control plant photosynthesis, growth, and photomorphogenesis for plants grown in greenhouses for horticulture, as well as in soilless systems, and in vertical gardening (Hogewoning et al. 2007, 2012; Wu et al. 2018, Paradiso and Proietti 2021). These LEDs offer a great advantage, for their use, over the earlier light sources (e.g., incandescent, fluorescent, and high-intensity discharge lamps), since they have specific wavelengths, smaller size, better durability, longer lifetime, cool-emitting surfaces, and lower power consumption (Pattison et al. 2018, He et al. 2019). However, to select appropriate LEDs, detailed knowledge is needed on morphological and physiological responses of different plant species to the quality of light and their triggering signaling. Many studies are now available on the growth and functioning of a large number of plants under specific and different wavelength ranges of light (see e.g., reviews by Hogewoning et al. 2010, Ouzounis et al. 2015, Dueck et al. 2016, Ptushenko et al. 2020, Palmitessa et al. 2021).

Further, data are now available on the growth of many plants grown under blue or red light or their combination, sometimes with white light. For example, Wang et al. (2016) used lettuce plants grown for $30 \mathrm{~d}$ under $200 \mu \mathrm{mol}$ (photons) $\mathrm{m}^{-2} \mathrm{~s}^{-1}$ of red or blue, or a mixture of red and blue light, with red/blue ratios of $1,4,8$, and 12. Whereas the rate of $\mathrm{CO}_{2}$ fixation was the highest for $\mathrm{red} / \mathrm{blue}$ light ratio of 1 , slightly higher effective and maximal quantum yields of PSII photochemistry were obtained for red light alone, than for the mixture of red and blue light, or blue light alone. A similar study was performed by Zheng and Van Labeke (2017) on three ornamental plants (Cordyline australis, Ficus benjamina, and Sinningia speciosa) grown for eight weeks at 100 $\mu \mathrm{mol}$ (photons) $\mathrm{m}^{-2} \mathrm{~s}^{-1}$ of red or blue, or $75 \%$ red with $25 \%$ blue, or white light. When grown under blue, or $75 \%$ red with $25 \%$ blue light, these plants had a greater $\mathrm{F}_{\mathrm{V}} / \mathrm{F}_{\mathrm{M}}$ ratio and effective quantum yield of PSII photochemistry in the light-adapted state, compared to plants grown under the red or the white light; also, lower quantum yields were correlated with lower biomass, obtained under red light. Interestingly, the thickness of palisade parenchyma tissue showed a good correlation with the effective quantum yield of PSII. (This needs to be further examined for the precise basis of this correlation.) On the other hand, Zhang et al. (2019) studied 3-week-old tomato plants grown for $18 \mathrm{~d}$ under $400 \mu \mathrm{mol}$ (photons) $\mathrm{m}^{-2} \mathrm{~s}^{-1}$ of red or blue, as well as red/blue light at a ratio of $9 / 1$ or of $7 / 3$. When the plants were exposed to $1,000 \mu \mathrm{mol}$ (photons) $\mathrm{m}^{-2} \mathrm{~s}^{-1}$ actinic light intensity, those grown under red light showed a lower effective quantum yield of PSII photochemistry at a steady state, which was correlated with a low steady-state rate of $\mathrm{CO}_{2}$ assimilation of these plants. However, plants grown in blue light showed the highest transient NPQ upon illumination with the same actinic light. Furthermore, Hamdani et al. (2019) have studied rice plants grown under red, blue, and white light of $300 \mu \mathrm{mol}$ (photons) $\mathrm{m}^{-2} \mathrm{~s}^{-1}$, using custom-designed LEDs. ChlFI data obtained on these samples with a PAM fluorometer showed that blue and red lights, as compared to white light, induced a higher NPQ and a lower effective quantum yield of PSII, while the $F_{V} / F_{M}$ ratio significantly decreased under blue light, but remained unchanged in the red light. On the other hand, further analysis revealed that plants grown with blue or red light had a decreased transcript abundance of both catalase and ascorbate peroxidase, as well as an increased $\mathrm{H}_{2} \mathrm{O}_{2}$ content, all of which suggest a compromised antioxidant system in these samples, even when exposed to a moderate light level.

It is well known that the highest quantum yield for $\mathrm{CO}_{2}$ fixation in many species is attained under red light compared to other wavelengths of light (Inada 1976, Evans 1987). However, other studies have shown that combining different wavelengths of light, and using it for the growth of plants, is advantageous to enhance the quantum yield of photosynthesis (Hogewoning et al. 2012); extended exposure to just red light results in low photosynthetic performance (see above). At another level of observation, we mention an effect in photosynthesis called 'The Emerson Enhancement Effect', which was first observed by Emerson et al. (1957), and led to the discovery of the existence of two light reactions and two pigment systems in photosynthesis (see Govindjee et al. 2017). In this study, Emerson and his workers showed that the rate of oxygen evolution measured with far-red light together with the light of a shorter wavelength is greater than the total sum of oxygen evolution measured when these two different light wavelengths are given separately. This effect is in photosynthesis, but there is another effect that deals with the role of phytochromes (see below).

The effects of red (R), far-red (FR), and R/FR ratio sensed by plant phytochromes (Fig. 5) have been reviewed by, e.g., Demotes-Mainard et al. (2016). As mentioned earlier, the Phys in plants can switch between two states, an R-absorbing inactive state (Pr), as well as an FR-absorbing active state (Pfr), and the $\mathrm{Pfr} /(\mathrm{Pfr}+\mathrm{Pr})$ ratio is known as the phytochrome photostationary state (PSS), which is low when the R/FR ratio is low. This ratio can vary among species, as it is determined not only by the growing conditions, but also by the forward and reverse rates of photoconversion, and the rates of thermal interconversion between the Pfr and Pr states (Fig. 5). A low R/FR is an important factor for signaling shade avoidance syndrome (Smith and Whitelam 1997, Ruberti et al. 2012), characterized by e.g., stem and leaf elongation, decreased branching, and changes in Chl content (Razzak et al. 2017, Kalaitzoglou et al. 2019, Yang et al. 2020). 
On the other hand, blue light and high $\mathrm{R} / \mathrm{FR}$ ratios are known to induce the development of sun-type chloroplasts (e.g., Lichtenthaler et al. 1980).

The UV-A and blue light, sensed by CRYs and/or PHOTs, are very important for the morphological development of plants, and, they have received considerable attention from plant physiologists (see a review by HuchéThélier et al. 2016). The photosynthetic activity has been shown to increase proportionally with the level of blue light during plant growth, compared to white light, but under blue light alone, it was lower (Matsuda et al. 2007, Hogewoning et al. 2010, Hernández and Kubota 2014). Further, the Chl content in plants was found to increase with the increasing proportion of blue light, when given in combination with white light (Matsuda et al. 2007), but it was shown to decrease in some species under blue light only. However, in all the species, the blue light, given in high proportion or alone, increased the Chl $a / b$ ratio (Matsuda et al. 2007, Hogewoning et al. 2010, Wang et al. 2015).

Since red and blue LED lights alone do not substitute for white light, other spectral components must be added, and on-going research includes the growth of plants under various light combinations of different colors of light, and light intensity, depending on the requirement of crops at different development stages (see reviews by Hasan et al. 2017, Bantis et al. 2018, Zheng et al. 2019, Paradiso and Proietti 2021). As an example, in a study on cucumber plants, Hogewoning et al. (2010) compared the effects of a LED-based artificial solar (AS) spectrum with the earlier methods using fluorescent tubes (FT), and a highpressure sodium lamp (HPS). The results support the use of LED-based AS spectrum for illumination since the data show 2.3 and 1.6 times greater total dry mass than from the FT and HPS-grown plants; further, the height of the AS plants was 4-5 times greater. We note that similar interesting results have been obtained by Guruprasad et al. (2007), in which the exclusion of solar UV-B and $\mathrm{UV}-\mathrm{B} / \mathrm{A}$ radiation, enhanced the fresh and dry mass, leaf area, as well as induced a dramatic increase in plant height, which were reflected in a net increase in the biomass of the plants. These and other results, reviewed above, give us much hope to solve the problem of increasing human population and dwindling resources.

\section{Overview and concluding remarks}

In this review, we have emphasized that distinct structure and configuration of photosynthetic pigments in the antenna of the two photosystems (I and II) in different oxygenic organisms (see 'Introduction') depend on environmental conditions, especially on the solar spectrum and changes in light intensity (see 'Spectral signatures of photosynthesis: Why chlorophyll $a$ ?'). The spectral advantage of Chl $a$ in terrestrial plants has been theoretically explained by Björn (1976) and Marosvölgyi and van Gorkom (2010), and this approach has recently been applied even in astrobiology (see Lehmer et al 2021). Details and specific predictions of this work still need to be examined.

Since ChlF is an important tool in the study of photosynthesis, and George C. Papageorgiou was a wellrecognized authority on this topic (see e.g., Papageorgiou and Govindjee 1967, 1968a,b; 2004, 2011, 2014; Papageorgiou 1975, 1996; Papageorgiou et al. 2007, Stirbet et al. 2019), we have presented, in this review, effects of light quality (different colors of light, i.e., different wavelengths of light) on photosynthesis measured using ChlF (see 'Light quality effects on photosynthesis, inferred from Chl fluorescence induction'). In particular, we have discussed (1) the importance of the 'quality' of excitation light, as well as of actinic light in measuring ChlF of photosynthetic organisms; and (2) interactions of blue, green, and red light with plant leaves, and their influence on the interpretation of ChlF data, related to differences in the 'depth' of penetration, into the leaf, of various spectral components of the light used.

Next, we have examined the influence of the spectral composition of environmental light for growth and other physiological functions of oxygenic organisms (see the section on 'Acclimation of oxygenic photosynthetic organisms under different colors of light'). Through the process of photomorphogenesis, the photosynthetic organisms fine-tune their growth, development, and metabolism to external light cues to optimize survival (Montgomery 2016, 2021). Related to this area of research, we have discussed chromatic acclimation in cyanobacteria, a complex survival mechanism triggered by changes in the ambient colors (wavelengths) of light. During this process, cyanobacteria change their pigments by 'remodeling' their PBS antenna complex, and sometimes even the entire organism, to dramatically increase their efficiency of light harvesting for photosynthesis (Sanfilippo et al. 2019). We then discussed the 'Regulation of photosynthesis in plants through stomatal and chloroplast movements', and presented examples of ChlF studies related to this topic. The stomatal movement is an important process in plants, which needs to be further investigated, since, as we know, the increased global $\left[\mathrm{CO}_{2}\right]$ has led to reduced transpiration and freshwater availability in temperate and northern hemisphere forests (Keenan et al. 2013). The possibility of tuning the stomatal response to blue light potentially represents a target to develop ideotypes with the 'ideal' balance between carbon gain, evaporative cooling, and maintenance of hydraulic status that is expected to maximize crop performance and productivity (Lawson and Vialet-Chabrand 2019, Matthews et al. 2020). Then, we discussed 'Light quality effects on the growth of different plant species of interest in horticulture', where LEDs have been used for illumination, as an example of the importance of the spectral composition of light for growth and other physiological functions of plants. Since this type of light source is much more energy-efficient and long-lasting than the others, it has led to an explosive development of computer-controlled systems for artificial illumination in horticulture (Zheng et al. 2019, Paradiso and Proietti 2021). Here we note that the inventors (Isamu Akasaki, Hiroshi Amano, and Shuji Nakamura) of blue LEDs (1990s) received the Nobel Prize in Physics (in 2014), especially since it allowed the realization of white-light LEDs, which today are replacing the traditional 
incandescent light bulbs, as well as the fluorescent bulbs. We end this perspective with a quote: 'Adopt the pace of Nature: her secret is patience.'- Ralph Waldo Emerson, 1803-1882, American philosopher, essayist, and poet.

\section{References}

Aasamaa K., Aphalo P.J.: The acclimation of Tilia cordata stomatal opening in response to light, and stomatal anatomy to vegetational shade and its components. - Tree Physiol. 37: 209-219, 2016.

Acuña A.M., Lemaire C., van Grondelle R. et al.: Energy transfer and trapping in Synechococcus WH 7803. - Photosynth. Res. 135: 115-124, 2018b.

Acuña A.M., van Alphen P., van Grondelle R., van Stokkum I.H.M.: The phycobilisome terminal emitter transfers its energy with a rate of $(20 \mathrm{ps})^{-1}$ to photosystem II. Photosynthetica 56: 265-274, 2018a.

Agati G., Fusi F., Mazzinghi P., di Paola M.L.: A simple approach to the evaluation of the reabsorption of chlorophyll fluorescence spectra in intact leaves. - J. Photoch. Photobio. B 17: 163-171, 1993.

Alami M., Lazar D., Green B.R.: The harmful alga Aureococcus anophagefferens utilizes 19'-butanoyloxyfucoxanthin as well as xanthophyll cycle carotenoids in acclimating to higher light intensities. - BBA-Bioenergetics 1817: 1557-1564, 2012.

Alboresi A., Gerotto C., Cazzaniga S. et al.: A red-shifted antenna protein associated with photosystem II in Physcomitrella patens. - J. Biol. Chem. 286: 28978-28987, 2011

Allakhverdiev S.I., Tomo T., Stamatakis K., Govindjee G.: International conference on 'Photosysnthesis Research for sustainibility-2015 in honor of George C. Papageorgiou', September 21-26, 2015, Crete, Greece. - Photosynth. Res. 130: $1-10,2016$

Anderson J.M., Andersson B.: The dynamic photosynthetic membrane and regulation of solar-energy conversion. Trends Biochem. Sci. 13: 351-355, 1988.

Anderson J.M., Aro E.-M.: Grana stacking and protection of Photosystem II in thylakoid membranes of higher plant leaves under sustained high irradiance: A hypothesis. - Photosynth. Res. 41: 315-326, 1994.

Andrés Z., Pérez-Hormaeche J., Leidi E.O. et al.: Control of vacuolar dynamics and regulation of stomatal aperture by tonoplast potassium uptake. - P. Natl. Acad. Sci. USA 111: E1806-E1814, 2014.

Arp T.B., Barlas Y., Aji V., Gabor N.M.: Natural regulation of energy flow in a green quantum photocell. - Nano Lett. 16: 7461-7466, 2016.

Arp T.B., Kistner-Morris J., Aji V. et al.: Quieting a noisy antenna reproduces photosynthetic light-harvesting spectra. - Science 368: 1490-1495, 2020.

Assmann S.M., Simoncini L., Schroeder J.I.: Blue light activates electrogenic ion pumping in guard cell protoplasts of Vicia faba L. - Nature 318: 285-287, 1985.

Bąba W., Kompała-Bąba A., Zabochnicka-Świątek M. et al.: Discovering trends in photosynthesis using modern analytical tools: More than 100 reasons to use chlorophyll fluorescence. Photosynthetica 57: 668-679, 2019.

Bae G., Choi G.: Decoding of light signals by plant phytochromes and their interacting proteins. - Annu. Rev. Plant Biol. 59: 281-311, 2008

Baker N.R.: Chlorophyll fluorescence: a probe of photosynthesis in vivo. - Annu. Rev. Plant Biol. 59: 89-113, 2008.

Ballottari M., Dall'Osto L., Morosinotto T., Bassi R.: Contrasting behavior of higher plant photosystem I and II antenna systems during acclimation. - J. Biol. Chem. 282: 8947-8958, 2007.

Bantis F., Smirnakou S., Ouzounis T. et al.: Current status and recent achievements in the field of horticulture with the use of light-emitting diodes (LEDs). - Sci. Hortic.-Amsterdam 235: 437-451, 2018.

Baránková B., Lazár D., Nauš J.: Analysis of the effect of chloroplast arrangement on optical properties of green tobacco leaves. - Remote Sens. Environ. 174: 181-196, 2016.

Belyaeva N.E., Schmitt F.-J., Paschenko V.Z. et al.: Model based analysis of transient fluorescence yield induced by actinic laser flashes in spinach leaves and cells of green alga Chlorella pyrenoidosa Chick. - Plant Physiol. Bioch. 77: 49-59, 2014.

Belyaeva O.B.: Studies of chlorophyll biosynthesis in Russia. Photosynth. Res. 76: 405-411, 2003.

Ben-Shem A., Frolow F., Nelson N.: Crystal structure of plant photosystem I. - Nature 426: 630-635, 2003.

Bernacchi C.J., Kimball B.A., Quarles D.R. et al.: Decreases in stomatal conductance of soybean under open-air elevation of $\left[\mathrm{CO}_{2}\right]$ are closely coupled with decreases in ecosystem evapotranspiration. - Plant Physiol. 143: 134-144, 2007.

Bertolino L.T., Caine R.S., Gray J.E.: Impact of stomatal density and morphology on water use efficiency in a changing world. Front. Plant Sci. 10: 225, 2019.

Bhaya D.: In the limelight: Photoreceptors in cyanobacteria. mBio 7: e00741-16, 2016.

Bielczynski L.W., Schansker G., Croce R.: Consequences of the reduction of the Photosystem II antenna size on the light acclimation capacity of Arabidopsis thaliana. - Plant Cell Environ. 43: 866-879, 2020.

Bína D., Gardian Z., Herbstová M. et al:: Novel type of redshifted chlorophyll $a$ antenna complex from Chromera velia. II. Biochemistry and spectroscopy. - BBA-Bioenergetics 1837: 802-810, 2014.

Björkman O., Demmig B.: Photon yield of $\mathrm{O}_{2}$ evolution of chlorophyll fluorescence characteristics at $77 \mathrm{~K}$ among vascular plants of diverse origins. - Planta 170: 489-504, 1987.

Björn L.O.: Why are plants green? Relationships between pigment absorption and photosynthetic efficiency. - Photosynthetica 10: 121-129, 1976.

Björn L.O., Ghiradella H.: Spectral tuning in biology I: Pigments. - In: Björn L.O. (ed.): Photobiology. Pp. 97-117. Springer, New York 2015.

Björn L.O., Govindjee G.: The evolution of photosynthesis and chloroplasts. - Curr. Sci. India 96: 1466-1474, 2009

Björn L.O., Papageorgiou G.C., Blankenship R.E., Govindjee G.: A viewpoint: Why chlorophyll $a$ ? - Photosynth. Res. 99: 85-98, 2009

Blain-Hartung M., Rockwell N.C., Moreno M.V. et al.: Cyanobacteriochrome-based photoswitchable adenylyl cyclases (cPACs) for broad spectrum light regulation of cAMP levels in cells. - J. Biol. Chem. 293: 8473-8483, 2018.

Blankenship R.E.: Molecular Mechanisms of Photosynthesis. $3^{\text {rd }}$ Edition. Pp. 320. Wiley-Blackwell, Oxford 2021.

Boichenko V.A., Klimov V.V., Miyashita H., Miyachi S.: Functional characteristics of chlorophyll d-predominating photosynthetic apparatus in intact cells of Acaryochloris marina. - Photosynth. Res. 65: 269-277, 2000.

Brecht M., Hussels M., Schlodder E., Karapetyan N.V.: Red antenna states of photosystem I trimers from Arthrospira platensis revealed by single-molecule spectroscopy. BBA-Bioenergetics 1817: 445-452, 2012.

Briantais J.-M., Vernotte C., Picaud M., Krause G.H.: A quantitative study of the slow decline of chlorophyll $a$ fluorescence in isolated chloroplasts. - BBA-Bioenergetics 548: 128-138, 1979. 
Briggs W.R.: Phototropism: some history, some puzzles, and a look ahead. - Plant Physiol. 164: 13-23, 2014.

Briggs W.R., Christie J.M.: Phototropins 1 and 2: versatile plant blue-light receptors. - Trends Plant Sci. 7: 204-210, 2002.

Brodersen C.R., Vogelmann T.C.: Do changes in light direction affect absorption profiles in leaves? - Funct. Plant Biol. 37: 403-412, 2010.

Brody S.S.: New excited state of chlorophyll. - Science 128: 838-839, 1958.

Brugnoli E., Björkman O.: Chloroplast movements in leaves: Influence on chlorophyll fluorescence and measurements of light-induced absorbance changes related to $\Delta \mathrm{pH}$ and zeaxanthin formation. - Photosynth. Res. 32: 23-35, 1992.

Büchel C.: Light harvesting complexes in chlorophyll ccontaining algae. - BBA-Bioenergetics 1861: 148027, 2020.

Campbell D., Hurry V., Clarke A.K. et al.: Chlorophyll fluorescence analysis of cyanobacterial photosynthesis and acclimation. - Microbiol. Mol. Biol. Rev. 62: 667-683, 1998.

Castillon A., Shen H., Huq E.: Phytochrome Interacting Factors: central players in phytochrome-mediated light signaling networks. - Trends Plant Sci. 12: 514-521, 2007.

Chater C.C.C., Caine R.S., Fleming A.J., Gray J.E.: Origins and evolution of stomatal development. - Plant Physiol. 174: 624638, 2017.

Chaves I., Pokorny R., Byrdin M. et al.: The cryptochromes: blue light photoreceptors in plants and animals. - Annu. Rev. Plant Biol. 62: 335-364, 2011.

Chen M., Blankenship R.E.: Expanding the solar spectrum used by photosynthesis. - Trends Plant Sci. 16: 427-431, 2011.

Chen M., Floetenmeyer M., Bibby T.S.: Supramolecular organization of phycobiliproteins in the chlorophyll $d$-containing cyanobacterium Acaryochloris marina. - FEBS Lett. 583: 2535-2539, 2009.

Chen M., Schliep M., Willows R.D. et al:: A red-shifted chlorophyll. - Science 329: 1318-1319, 2010.

Chow W.S.: Photoprotection and photoinhibition damage. In: Barber J. (ed.): Advances in Molecular and Cell Biology. Vol. 10. Pp. 151-196. JAI Press Inc., Stamford 1994.

Christie J.M.: Phototropin blue-light receptors. - Annu. Rev. Plant Biol. 58: 21-45, 2007.

Christie J.M., Blackwood L., Petersen J., Sullivan S.: Plant flavoprotein photoreceptors. - Plant Cell Physiol. 56: 401413, 2015.

Christie J.M., Briggs W.R.: Blue light sensing in higher plants. J. Biol. Chem. 276: 11457-11460, 2001.

Chukhutsina V.U., Liu X., Xu P., Croce R.: Light-harvesting complex II is an antenna of photosystem I in dark-adapted plants. - Nat. Plants 6: 860-868, 2020.

Croce R.: Beyond 'seeing is believing': the antenna size of the photosystems in vivo. - New Phytol. 228: 1214-1218, 2020.

Croce R., Chojnicka A., Morosinotto T. et al.: The lowenergy forms of photosystem I light-harvesting complexes: Spectroscopic properties and pigment-pigment interaction characteristics. - Biophys J. 93: 2418-2428, 2007.

Croce R., van Amerongen H.: Light-harvesting in photosystem I.Photosynth. Res. 116: 153-166, 2013a.

Croce R., van Amerongen H.: Light harvesting in photosystem II.Photosynth. Res. 116: 251-263, 2013b.

Croce R., van Amerongen H.: Natural strategies for photosynthetic light harvesting. - Nat. Chem. Biol. 10: 492-501, 2014.

Croce R., van Amerongen H.: Light harvesting in oxygenic photosynthesis: Structural biology meets spectroscopy. Science 369: eaay2058, 2020.

Croce R., van Grondelle R., van Amerongen H., van Stokkum I.H.M. (ed.): Light Harvesting in Photosynthesis. Foundations of Biochemistry and Biophysics. Pp. 625. CRC Press, Taylor \&
Francis Group, London 2018.

Cui M., Vogelmann T.C., Smith W.K.: Chlorophyll and light gradients in sun and shade leaves of Spinacia oleracea. Plant Cell Environ. 14: 493-500, 1991.

D'Amico-Damião V., Carvalho R.F.: Cryptochrome-related abiotic stress responses in plants. - Front. Plant Sci. 9: 1897, 2018.

Darko E., Heydarizadeh P., Schoefs B., Sabzalian M.R.: Photosynthesis under artificial light: the shift in primary and secondary metabolism. - Philos. T. Roy. Soc. B 369: 20130243, 2014.

Das M., Rabinowitch E., Szalay L., Papageorgiou G.: The "sieve effect" in Chlorella suspensions. - J. Phys. Chem. 71: 35433549, 1967.

Daszkowska-Golec A., Szarejko I.: Open or close the gate stomata action under the control of phytohormones in drought stress conditions. - Front Plant Sci. 4: 138, 2013.

Dau H.: Molecular mechanisms and quantitative models of variable photosystem II fluorescence. - Photochem. Photobiol. 60: 1-23, 1994.

Davis P.A., Caylor S., Whippo C.W., Hangarter R.P.: Changes in leaf optical properties associated with light-dependent chloroplast movements. - Plant Cell Environ. 34: 2047-2059, 2011.

Demmig-Adams B., Garab G., Adams III W.W., Govindjee G. (ed.): Nonphotochemical Quenching and Energy Dissipation in Plants, Algae and Cyanobacteria. Advances in Photosynthesis and Respiration. Vol. 40. Pp. 649. Springer, Dordrecht 2014.

Demotes-Mainard S., Péron T., Corot A. et al.: Plant responses to red and far-red lights, applications in horticulture. - Environ. Exp. Bot. 121: 4-21, 2016.

Dismukes G.C., Klimov V.V., Baranov S.V. et al.: The origin of atmospheric oxygen on Earth: the innovation of oxygenic photosynthesis. - P. Natl. Acad. Sci. USA 98: 2170-2175, 2001.

Drake P.L., de Boer H.J., Schymanski S.J., Veneklaas E.J.: Two sides to every leaf: water and $\mathrm{CO}_{2}$ transport in hypostomatous and amphistomatous leaves. - New Phytol. 222: 1179-1187, 2019.

Driesen E., Van den Ende W., De Proft M., Saeys W.: Influence of environmental factors light, $\mathrm{CO}_{2}$, temperature, and relative humidity on stomatal opening and development: A review. Agronomy 10: 1975, 2020.

Dueck T., Ieperen W., Taulavuori K.: Light perception, signalling and plant responses to spectral quality and photoperiod in natural and horticultural environments. - Environ. Exp. Bot. 121: 1-3, 2016.

Dutta S., Cruz J.A., Imran S.M. et al.: Variations in chloroplast movement and chlorophyll fluorescence among chloroplast division mutants under light stress. - J. Exp. Bot. 68: 35413555, 2017.

Duxbury Z., Schliep M., Ritchie R.J. et al.: Chromatic photoacclimation extends utilisable photosynthetically active radiation in the chlorophyll $d$-containing cyanobacterium, Acaryochloris marina. - Photosynth. Res. 101: 69-75, 2009.

Duysens L.N.M.: The flattening of the absorption spectrum of suspension as compared to that of solutions. - Biochim. Biophys. Acta 19: 1-12, 1956.

Duysens L.N.M.: Transfer and trapping of excitation energy in photosystem II. - In: Wolstenholme G.E.W., Fitzsimons D.W. (ed.): Chlorophyll Organization and Energy Transfer in Photosynthesis. Ciba Foundation Symposium 61 (New Series). Pp. 323-340. Excerpta Medica, Amsterdam-OxfordNew York 1979.

Duysens L.N.M., Sweers H.E.: Mechanisms of two photo- 
chemical reactions in algae as studied by means of fluorescence. - In: Japanese Society of Plant Physiologists (ed.): Studies on microalgae and photosynthetic bacteria. Pp. 353-372. University of Tokyo Press, Tokyo 1963.

Emerson R., Chalmers R., Cederstrand C.: Some factors influencing the long-wave limit of photosynthesis. - P. Natl. Acad. Sci. USA 43: 133-143, 1957.

Emerson R., Lewis C.M.: The dependence of the quantum yield of Chlorella photosynthesis on wavelength of light. - Am. J. Bot. 30: 165-178, 1943.

Emerson R., Rabinowitch E.: Red drop and the role of auxiliary pigments in photosynthesis. - Plant Physiol. 35: 477-485, 1960.

Engelmann E., Zucchelli G.., Casazza A.P. et al.: Influence of the photosystem I-light harvesting complex I antenna domains on fluorescence decay. - Biochemistry 45: 6947-6955, 2006.

Evans J.R.: The dependence of quantum yield on wavelength and growth irradiance. - Aust. J. Plant Physiol. 14: 69-79, 1987.

Evans J.R.: Leaf anatomy enables more equal access to light and $\mathrm{CO}_{2}$ between chloroplasts. - New Phytol. 143: 93-104, 1999.

Evans J.R.: Potential errors in electron transport rates calculated from chlorophyll fluorescence as revealed by a multilayer leaf model. - Plant Cell Physiol. 50: 698-706, 2009.

Evans J.R., Morgan P.B., von Caemmerer S.: Light quality affects chloroplast electron transport rates estimated from Chl fluorescence measurements. - Plant Cell Physiol. 58: 1652-1660, 2017.

Evans J.R., Vogelmann T.C.: Profiles of ${ }^{14} \mathrm{C}$ fixation through spinach leaves in relation to light absorption and photosynthetic capacity. - Plant Cell Environ. 26: 547-560, 2003.

Everroad C., Six C., Partensky F. et al.: Biochemical bases of type IV chromatic adaptation in marine Synechococcus spp.J. Bacteriol. 188: 3345-3356, 2006.

Flexas J., Escalona J.M., Evain S. et al.: Steady-state chlorophyll fluorescence (Fs) measurements as a tool to follow variations of net $\mathrm{CO}_{2}$ assimilation and stomatal conductance during water-stress in $\mathrm{C}_{3}$ plants. - Physiol. Plantarum 114: 231-240, 2002.

Franklin K.A., Quail P.H.: Phytochrome functions in Arabidopsis development. - J. Exp. Bot. 61: 11-24, 2010.

Frechilla S., Talbott L.D., Bogomolni R.A., Zeiger E.: Reversal of blue light-stimulated stomatal opening by green light. Plant Cell Physiol. 41: 171-176, 2000.

French C.S.: The distribution and action in photosynthesis of several forms of chlorophyll. - P. Natl. Acad. Sci. USA 68: 2893-2897, 1971.

French C.S., Brown J.S., Lawrence M.C.: Four universal forms of chlorophyll $a$. - Plant Physiol. 49: 421-429, 1972.

Fuente D., Keller J, Conejero J.A. et al.: Light distribution and spectral composition within cultures of micro-algae: Quantitative modelling of the light field in photobioreactors. Algal Res. 23: 166-177, 2017.

Fujita Y., Ohki K.: On the $710 \mathrm{~nm}$ fluorescence emitted by the diatom Phaeodactylum tricornutum at room temperature. Plant Cell Physiol. 45: 392-397, 2004.

Fushimi K., Hasegawa M., Ito T. et al.: Evolution-inspired design of multicolored photoswitches from a single cyanobacteriochrome scaffold. - P. Natl. Acad. Sci. USA 117: 15573-15580, 2020.

Fushimi K., Narikawa R.: Cyanobacteriochromes: photoreceptors covering the entire UV-to-visible spectrum. - Curr. Opin. Struct. Biol. 57: 39-46, 2019.

Fushimi K., Narikawa R.: Phytochromes and cyanobacteriochromes: Photoreceptor molecules incorporating a linear tetrapyrrole chromophore. - In: Yawo H., Kandori H., Koizumi A., Kageyama R. (ed.): Optogenetics. Advances in
Experimental Medicine and Biology. Vol. 1293. Pp. 167-187. Springer, Singapore 2021.

Gaidukov N.: Die Farbervänderung bei den Prozessen der Komplementären chromatischen Adaptation. [The color change in the processes of complementary chromatic adaptation.] - Ber. Deutsch. Bot. Ges 21: 517-522, 1903. [In German]

Gan F., Zhang S., Rockwell N.C. et al.: Extensive remodeling of a cyanobacterial photosynthetic apparatus in far-red light. Science 345: 1312-1317, 2014.

Genty B., Briantais J.-M., Baker N.R.: The relationship between the quantum yield of photosynthetic electron transport and quenching of chlorophyll fluorescence. - BBA-Gen. Subjects 990: 87-92, 1989.

Giera W., Szewczyk S., McConnel M.D. et al.: Uphill energy transfer in photosystem I from Chlamydomonas reinhardtii. Time-resolved fluorescence measurements at $77 \mathrm{~K}$. Photosynth. Res. 137: 321-335, 2018.

Gisriel C., Shen G., Kurashov V. et al:: The structure of Photosystem I acclimated to far-red light illuminates an ecologically important acclimation process in photosynthesis. Sci. Adv. 6: eaay6415, 2020a.

Gisriel C.J., Wang J., Brudvig G.W., Bryant D.A.: Opportunities and challenges for assigning cofactors in cryo-EM density maps of chlorophyll-containing proteins. - Commun. Biol. 3: 408, 2020b.

Gitelson A.A., Buschmann C., Lichtenthaler H.K.: Leaf chlorophyll fluorescence corrected for re-absorption by means of absorption and reflectance measurements. - J. Plant Physiol. 152: 283-296, 1998.

Gobets B., van Grondelle R.: Energy transfer and trapping in photosystem I. - BBA-Bioenergetics 1507: 80-99, 2001.

Goh C.-H.: Phototropins and chloroplast activity in plant blue light signaling. - Plant Signal. Behav. 4: 693-695, 2009.

Golbeck J.H.: Structure, function and organization of the photosystem I reaction center complex. - BBA-Rev. Bioenergetics 895: 167-204, 1987.

Gotoh E., Suetsugu N., Higa T. et al.: Palisade cell shape affects the light-induced chloroplast movements and leaf photosynthesis. - Sci. Rep.-UK 8: 1472, 2018b.

Gotoh E., Suetsugu N., Yamori W. et al.: Chloroplast accumulation response enhances leaf photosynthesis and plant biomass production. - Plant Physiol. 178: 1358-1369, 2018a.

Govindjee G.: Observations on P750A from Anacystis nidulans.Naturwissenschaften 50: 720-721, 1963.

Govindjee G.: Sixty-three years since Kautsky: Chlorophyll $a$ fluorescence. - Aust. J. Plant Physiol. 22: 131-160, 1995.

Govindjee G.: Chlorophyll $a$ fluorescence: a bit of basics and history. - In: Papageorgiou G.C., Govindjee G. (ed.): Chlorophyll $a$ Fluorescence: A Signature of Photosynthesis. Advances in Photosynthesis and Respiration. Vol. 19. Pp. 1-41. Springer, Dordrecht 2004.

Govindjee G., Braun B.Z.: Light absorption, emission and photosynthesis. - In: Stewart W.D.P. (ed.): Algal Physiology and Biochemistry, Pp. 346-390. Blackwell Scientific Publication Ltd., Oxford 1974.

Govindjee G., Papageorgiou G.C.: Chlorophyll fluorescence and photosynthesis: fluorescence transients. - In: Giese A.C. (ed.): Photophysiology: Current Topics in Photobiology and Photochemistry. Vol. 6. Pp. 1-46. Academic Press, New York 1971.

Govindjee G., Papageorgiou G.C., Govindjee R.: Eugene I. Rabinowitch: A prophet of photosynthesis and of peace in the world. - Photosynth. Res. 141: 143-150, 2019.

Govindjee G., Shevela D., Björn L.O.: Evolution of the Z-scheme of photosynthesis: a perspective. - Photosynth. Res. 133: 
$5-15,2017$

Greenbaum N.L., Mauzerall D.: Effect of irradiance level on distribution of chlorophylls between PS II and PS I as determined from optical cross-sections. - BBA-Bioenergetics 1057: 195-207, 1991.

Grossman A.R.: A molecular understanding of complementary chromatic adaptation. - Photosynth. Res. 76: 207-215, 2003.

Guruprasad K., Bhattacharjee S., Kataria S. et al.: Growth enhancement of soybean (Glycine max) upon exclusion of UV-B and UV-B/A components of solar radiation: characterization of photosynthetic parameters in leaves. Photosynth. Res. 94: 299-306, 2007.

Hák R., Lichtenthaler H.K., Rinderle U.: Decrease of the fluorescence ratio F690/F730 during greening and development of leaves. - Radiat. Environ. Bioph. 29: 329-336, 1990.

Hall J., Renger T., Müh F. et al.: The lowest-energy chlorophyll of photosystem II is adjacent to the peripheral antenna: Emitting states of CP47 assigned via circularly polarized luminescence. - BBA-Bioenergetics 1857: 1580-1593, 2016.

Hamaguchi T., Kawakami K., Shinzawa-Itoh K. et al.: Structure of the far-red light utilizing photosystem I of Acaryochloris marina. - Nat. Commun. 12: 2333, 2021.

Hamdani S., Khan N., Perveen S. et al:: Changes in the photosynthesis properties and photoprotection capacity in rice (Oryza sativa) grown under red, blue, or white light. Photosynth. Res. 139: 107-121, 2019.

Harper S.M., Neil L.C., Gardner K.H.: Structural basis of a phototropin light switch. - Science 301: 1541-1544, 2003.

Harris D., Bar-Zvi S., Lahav A. et al.: The structural basis for the extraordinary energy-transfer capabilities of the phycobilisome. - In: Harris J.R., Boekema E.J. (ed.): Membrane Protein Complexes: Structure and Function, Subcellular Biochemistry. Vol. 87. Pp. 57-82. Springer, Singapore 2018.

Harris D., Tal O., Jallet D. et al.: Orange carotenoid protein burrows into the phycobilisome to provide photoprotection. P. Natl. Acad. Sci. USA 113: E1655-E1662, 2016.

Hasan M.M., Bashir T., Ghosh R. et al.: An overview of LEDs' effects on the production of bioactive compounds and crop quality. - Molecules 22: 1420, 2017.

Haupt W., Scheuerlein R.: Chloroplast movement. - Plant Cell Environ. 13: 595-614, 1990.

Hayes S.: Location, location, location: phototropin 2 action at the chloroplast membrane. - Plant Physiol. 183: 27-28, 2020.

He D., Kozai T., Niu G., Zhang X.: Light-emitting diodes for horticulture. - In: Li J., Zhang G.Q. (ed.): Light-Emitting Diodes. Solid State Lighting Technology and Application Series. Vol. 4. Pp. 513-547. Springer, Cham 2019.

Herbstová M., Bína D., Kaňa R. et al.: Red-light phenotype in a marine diatom involves a specialized oligomeric red-shifted antenna and altered cell morphology. - Sci. Rep.-UK 7: 11976, 2017.

Hernández R., Kubota C.: Growth and morphological response of cucumber seedlings to supplemental red and blue photon flux ratios under varied solar daily light integrals. - Sci. Hortic.-Amsterdam 173: 92-99, 2014.

Hirose Y., Rockwell N.C., Nishiyama K. et al.: Green/red cyanobacteriochromes regulate complementary chromatic acclimation via a protochromic photocycle. - P. Natl. Acad. Sci. USA 110: 4974-4979, 2013.

Hirose Y., Song C., Watanabe M. et al.: Diverse chromatic acclimation processes regulating phycoerythrocyanin and rod-shaped phycobilisome in cyanobacteria. - Mol. Plant 12: 715-725, 2019

Ho M.Y., Niedzwiedzki D.M., MacGregor-Chatwin C. et al.: Extensive remodeling of the photosynthetic apparatus alters energy transfer among photosynthetic complexes when cyanobacteria acclimate to far-red light. - BBA-Bioenergetics 1861: 148064, 2020.

Ho M.Y., Shen G., Canniffe D.P. et al.: Light-dependent chlorophyll $\mathrm{f}$ synthase is a highly divergent paralog of PsbA of photosystem II. - Science 353: 213-227, 2016.

Hoang Q.T.N., Han Y.J., Kim J.I.: Plant phytochromes and their phosphorylation. - Int. J. Mol. Sci. 20: 3450, 2019.

Hogewoning S.W., Douwstra P., Trouwborst G. et al:: An artificial solar spectrum substantially alters plant development compared with usual climate room irradiance spectra. J. Exp. Bot. 61: 1267-1276, 2010.

Hogewoning S.W., Trouwborst G., Engbers G.J. et al.: Plant physiological acclimation to irradiation by light-emitting diodes (LEDs). - Acta Hortic. 761: 183-191, 2007.

Hogewoning S.W., Wientjes E., Douwstra P. et al.: Photosynthetic quantum yield dynamics: from photosystems to leaves. Plant Cell 24: 1921-1935, 2012.

Hohmann-Marriott M.F., Blankenship R.E.: Evolution of photosynthesis. - Annu. Rev. Plant Biol. 62: 515-548, 2011.

Howard M.M., Bae A., Königer M.: The importance of chloroplast movement, nonphotochemical quenching, and electron transport rates in light acclimation and tolerance to high light in Arabidopsis thaliana. - Am. J. Bot. 106: 1444$1453,2019$.

Hu K., Govindjee G., Tan J. et al.: Co-author and co-cited reference network analysis for chlorophyll fluorescence research from 1991 to 2018. - Photosynthetica 58: 110-124, 2020.

Hu Q., Miyashita H., Iwasaki I. et al.: A Photosystem I reaction center driven by chlorophyll $d$ in oxygenic photosynthesis. P. Natl. Acad. Sci. USA 95: 13319-13323, 1998.

Huché-Thélier L., Crespel L., Le Gourrierec J. et al.: Light signaling and plant responses to blue and UV radiations Perspectives for applications in horticulture. - Environ. Exp. Bot. 121: 22-38, 2016.

Iino M., Ogawa T., Zeiger E.: Kinetic properties of the blue-light response of stomata. - P. Natl. Acad. Sci. USA 82: 8019-8023, 1985.

Ikeuchi M., Ishizuka T.: Cyanobacteriochromes: a new superfamily of tetrapyrrole-binding photoreceptors in cyanobacteria. - Photoch. Photobio. Sci. 7: 1159-1167, 2008.

Inada K.: Action spectra for photosynthesis in higher plants. Plant Cell Physiol. 17: 355-365, 1976.

Inoue S.I., Kinoshita T: Blue light regulation of stomatal opening and the plasma membrane $\mathrm{H}^{+}$-ATPase. - Plant Physiol. 174: 531-538, 2017.

Ishishita K., Higa T., Tanaka H. et al.: Phototropin2 contributes to the chloroplast avoidance response at the chloroplast-plasma membrane interface. - Plant Physiol. 183: 304-316, 2020.

Jarillo J.A., Gabrys H., Capel J. et al.: Phototropin-related NPL1 controls chloroplast relocation induced by blue light. - Nature 410: 952-954, 2001.

Jávorfi T., Erostyák J., Gál J. et al.: Quantitative spectrophotometry using integrating cavities. - J. Photoch. Photobio. B 82: 127$131,2006$.

Jennings R.C., Zuccerelli G., Croce R., Garlaschi F.M.: The photochemical trapping rate from red spectral states in PSILHCI is determined by thermal activation of energy transfer to bulk chlorophylls. - BBA-Bioenergetics 1557: 91-98, 2003.

Johnson D.M., Smith W.K., Vogelmann T.C., Brodersen C.R.: Leaf architecture and direction of incident light influence mesophyll fluorescence profiles. - Am. J. Bot. 92: 1425-1431, 2005.

Joliot P., Joliot A.: Compartaive study of the fluorescence yield and of the C550 absorption change at room temperature. - 
BBA-Bioenergetics 546: 93-105, 1979.

Jordan P., Fromme P., Witt H.T. et al.: Three-dimensional structure of cyanobacterial photosystem I at $2.5 \AA$ resolution. Nature 411: 909-917, 2001.

Kadota A., Yamada N., Suetsugu N. et al.: Short actin-based mechanism for light-directed chloroplast movement in Arabidopsis. - P. Natl. Acad. Sci. USA 106: 13106-13111, 2009.

Kalaitzoglou P., van Ieperen W., Harbinson J. et al.: Effects of continuous or end-of-day far-red light on tomato plant growth, morphology, light absorption, and fruit production. - Front. Plant Sci. 10: 322, 2019.

Kalaji H.M., Schansker G., Brestic M. et al.: Frequently asked questions about chlorophyll fluorescence, the sequel. Photosynth. Res. 132: 13-66, 2017.

Kalaji H.M., Schansker G., Ladle R.J. et al.: Frequently asked questions about chlorophyll fluorescence: practical issues. Photosynth. Res. 122: 121-158, 2014.

Kale R., Hebert A.E., Frankel L.K. et al.: Amino acid oxidation of the D1 and D2 proteins by oxygen radicals during photoinhibition of photosystem II. - P. Natl. Acad. Sci. USA 114: 2988-2993, 2017.

Kami C., Lorrain S., Hornitschek P., Fankhauser C.: Lightregulated plant growth and development. - Curr. Top. Dev. Biol. 91: 29-66, 2010.

Kaňa R., Kotabová E., Komárek O. et al.: The slow S to M fluorescence rise in cyanobacteria is due to a state 2 to state 1 transition. - BBA-Bioenergetics 1817: 1237-1247, 2012.

Kaňa R., Prášil O., Komárek O. et al.: Spectral characteristic of fluorescence induction in a model cyanobacterium, Synechococcus sp. (PCC 7942). - BBA-Bioenergetics 1787: 1170-1178, 2009.

Karapetyan N.V., Bolychevtseva Yu.V., Yurina N.P. et al.: Longwavelength chlorophylls in PSI of cyanobacteria: Origin, localization, and functions. - Biochemistry-Moscow 79: 213 220, 2014

Karapetyan N.V., Schlodder E., van Grondelle R., Dekker J.P.: The long wavelength chlorophylls of photosystem I. - In: Golbeck J.H., Govindjee G., Sharkey T. (ed.): The LightDriven Plastocyanin: Ferredoxin Oxidoreductase. Advances in Photosynthesis and Respiration. Vol. 24. Pp. 177-192. Springer, Dordrecht 2006.

Karlsson P.E.: Blue light regulation of stomata in wheat seedlings. I. Influence of red background illumination and initial conductance level. - Physiol. Plantarum 66: 202-206, 1986.

Kasajima I., Suetsugu N., Wada M., Takahara K: Collective calculation of actual values of non-photochemical quenching from their apparent values after chloroplast movement and photoinhibition. - Am. J. Plant Sci. 6: 1792-1805, 2015.

Kato K., Shinoda T., Nagao R. et al.: Structural basis for the adaptation and function of chlorophyll $f$ in photosystem I. Nat. Commun. 11: 238, 2020.

Katz J.J., Norris J.R.: Chlorophyll and light energy transduction in photosynthesis. - In: Sanadi D.R., Packer L. (ed.): Current Topics in Bioenergetics. Vol. 5. Pp. 41-75. Academic Press, New York 1973

Kautsky H., Hirsch A.: Neue Versuche zur Kohlensäureassimilation. [New attempts on carbon dioxide assimilation.] Naturwissenschaften 19: 964, 1931. [In German]

Keenan T.F., Hollinger D.Y., Bohrer G. et al.: Increase in forest water-use efficiency as atmospheric carbon dioxide concentrations rise. - Nature 499: 324-327, 2013.

Kehoe D.M., Gutu A.: Responding to color: The regulation of complementary chromatic adaptation. - Annu. Rev. Plant Biol. 57: 127-150, 2006.
Khanna R., Li J., Tseng T.-S. et al.: COP1 jointly modulates cytoskeletal processes and electrophysiological responses required for stomatal closure. - Mol. Plant 7: 1441-1454, 2014.

Kiang N.Y., Segura A., Tinetti G. et al.: Spectral signatures of photosynthesis II: coevolution with other stars and the atmosphere on extrasolar worlds. - Astrobiology 7: 252-274, 2007b.

Kiang N.Y., Siefert J., Govindjee G., Blankenship R.E.: Spectral signatures of photosynthesis. I. Review of Earth organisms. Astrobiology 7: 222-251, 2007a.

Kinoshita T., Shimazaki K.: Biochemical evidence for the requirement of 14-3-3 protein binding in activation of the guard-cell plasma membrane $\mathrm{H}^{+}$-ATPase by blue light. - Plant Cell Physiol. 43: 1359-1365, 2002.

Kirilovsky D., Kerfeld C.A.: Cyanobacterial photoprotection by the orange carotenoid protein. -Nat. Plants 2: 16180, 2016.

Kitajima M., Butler W.L.: Quenching of chlorophyll fluorescence and primary photochemistry in chloroplasts by dibromothymoquinone. - BBA-Bioenergetics 376: 105-115, 1975.

Knox R.S.: Thermodynamics and the primary processes of photosynthesis. - Biophys. J. 9: 1351-1362, 1969.

Kodru S., Malavath T., Devadasu E. et al.: The slow S to M rise of chlorophyll $a$ fluorescence induction reflects transition from state 2 to state 1 in the green alga Chlamydomonas reinhardtii. - Photosynth. Res. 125: 219-231, 2015.

Koizumi M., Takahashi K., Mineuchi K. et al.: Light gradients and the transverse distribution of chlorophyll fluorescence in mangrove and Camellia leaves. - Ann. Bot.-London 81: 527 533, 1998.

Kok B.: A critical consideration of the quantum yield of Chlorella photosynthesis. - Enzymologia 13: 1-56, 1948.

Kolber Z.S., Prášil O., Falkowski P.G.: Measurements of variable chlorophyll fluorescence using fast repetition rate techniques: Defining methodology and experimental protocols. BBA-Bioenergetics 1367: 88-106, 1998.

Kollist H., Nuhkat M., Roelfsema M.R.G.: Closing gaps: linking elements that control stomatal movement. - New Phytol. 203: 44-62, 2014.

Kong S.G., Okajima K.: Diverse photoreceptors and light responses in plants. - J. Plant Res. 129: 111-114, 2016.

Kong S.G., Wada M.: Recent advances in understanding the molecular mechanism of chloroplast photorelocation movement. - BBA-Bioenergetics 1837: 522-530, 2014.

Kosugi M., Ozawa S.I., Takahashi Y. et al.: Red-shifted chlorophyll $a$ bands allow uphill energy transfer to photosystem II reaction centers in an aerial green alga, Prasiola crispa, harvested in Antarctica. - BBA-Bioenergetics 1861: 148139, 2020.

Kotabová E., Jarešová J., Kaňa R. et al.: Novel type of redshifted chlorophyll $a$ antenna complex from Chromera velia. I. Physiological relevance and functional connection to photosystems. - BBA-Bioenergetics 1837: 734-743, 2014.

Kouřil R., Nosek L., Opatíková M. et al.: Unique organization of photosystem II supercomplexes and megacomplexes in Norway spruce. - Plant J. 104: 215-225, 2020.

Krause G.H., Weis E.: Chlorophyll fluorescence and photosynthesis: The basics. - Annu. Rev. Plant Phys. 42: 313349, 1991.

Kubota-Kawai H., Burton-Smith R.N., Tokutsu R. et al.: Ten antenna proteins are associated with the core in the supramolecular organization of the photosystem I supercomplex in Chlamydomonas reinhardtii. - J. Biol. Chem. 294: 4304-4314, 2019.

Kumazaki S., Abiko K., Ikegami I. et al.: Energy equilibration 
and primary charge separation in chlorophyll $d$-based photosystem I reaction center isolated from Acaryochloris marina. - FEBS Lett. 530: 153-157, 2002.

Laisk A., Oja V.: Variable fluorescence of closed photochemical reaction centers. - Photosynth. Res. 143: 335-346, 2020.

Langsdorf G., Buschmann C., Sowinska M. et al.: Multicolour fluorescence imaging of sugar beet leaves with different $\mathrm{N}$-status by flash lamp UV-excitation. - Photosynthetica 38: 539-551, 2000

Larkum A.W.D.: The evolution of chlorophylls and photosynthesis. - In: Grimm B., Porra R.J., Rüdiger W., Scheer H. (ed.): Chlorophylls and Bacteriochlorophylls: Biochemistry, Biophysics, Functions and Applications. Pp. 261-282. Springer, Dordrecht 2006.

Larkum A.W.D., Kühl M.: Chlorophyll $d$ : the puzzle resolved. Trends Plant Sci. 10: 355-357, 2005.

Latouche G., Cerovic Z.G., Montagnini F., Moya I.: Lightinduced changes of NADPH fluorescence in isolated chloroplasts: a spectral and fluorescence lifetime study. BBA-Bioenergetics 1460: 311-329, 2000.

Lawson T., Blatt M.R.: Stomatal size, speed, and responsiveness impact on photosynthesis and water use efficiency. - Plant Physiol. 164: 1556-1570, 2014.

Lawson T., Terashima I., Fujita T., Wang Y.: Coordination between photosynthesis and stomatal behavior. - In: Adams III W.W., Terashima I. (ed.): The Leaf: A Platform for Performing Photosynthesis. Pp. 141-161. Springer, Cham 2018.

Lawson T., Vialet-Chabrand S.: Speedy stomata, photosynthesis and plant water use efficiency. - New Phytol. 221: 93-98, 2019.

Lazár D.: Chlorophyll a fluorescence induction. - BBABioenergetics 1412: 1-28, 1999.

Lazár D.: The polyphasic chlorophyll a fluorescence rise measured under high intensity of exciting light. - Funct. Plant Biol. 33: 9-30, 2006.

Lazár D.: Simulations show that a small part of variable chlorophyll $a$ fluorescence originates in photosystem I and contributes to overall fluorescence rise. - J. Theor. Biol. 335: 249-264, 2013

Lazár D.: Parameters of photosynthetic energy partitioning. J. Plant Physiol. 175: 131-147, 2015.

Lazár D., Nauš J.: Statistical properties of chlorophyll fluorescence parameters. - Photosynthetica 35: 121-127, 1998.

Lee Y., Kim Y.W., Jeon B.W. et al.: Phosphatidylinositol 4,5-bisphosphate is important for stomatal opening. - Plant J. 52: 803-816, 2007.

Lehmer O.R., Catling D.C., Parenteau M.N. et al.: The peak absorbance wavelength of photosynthetic pigments around other stars from spectral optimization. - Front. Astron. Space Sci. 8: 689441, 2021.

Levitan O., Chen M., Kuang X. et al.: Structural and functional analyses of photosystem II in the marine diatom Phaeodactylum tricornutum. - P. Natl. Acad. Sci. USA 116: 17316-17322, 2019.

Li J., Li G., Wang H., Deng X.W.: Phytochrome signaling mechanisms. - The Arabidopsis Book 2011: e0148, 2011.

Li T., Podola B., Melkonian M.: Investigating dynamic processes in a porous substrate biofilm photobioreactor - A modeling approach. - Algal Res. 13: 30-40, 2016.

Li X.-P., Björkman O., Shih C. et al.: A pigment-binding protein essential for regulation of photosynthetic light harvesting. Nature 403: 391-395, 2000.

Lichtenberg M., Kühl M.: Pronounced gradients of light, photosynthesis and $\mathrm{O}_{2}$ consumption in the tissue of the brown alga Fucus serratus. - New Phytol. 207: 559-569, 2015.

Lichtenberg M., Trampe E.C.L., Vogelmann T.C., Kühl M.: Light sheet microscopy imaging of light absorption and photosynthesis distribution in plant tissue. - Plant Physiol. 175: 721-733, 2017.

Lichtenthaler H.K.: Multi-colour fluorescence imaging of photosynthetic activity and plant stress. - Photosynthetica 59: 364-380, 2021.

Lichtenthaler H.K., Babani F.: Detection of photosynthetic activity and water stress by imaging the red chlorophyll fluorescence. - Plant Physiol. Bioch. 38: 889-895, 2000.

Lichtenthaler H.K., Buschmann C., Rahmsdorf U.: The importance of blue light for the development of sun-type chloroplasts. - In: Senger H. (ed.): The Blue Light Syndrome. Proceedings in Life Sciences. Pp. 485-494. Springer, BerlinHeidelberg 1980.

Lichtenthaler H.K., Lang M., Sowinska M. et al.: Detection of vegetation stress via a new high resolution fluorescence imaging system. - J. Plant Physiol. 148: 599-612, 1996.

Lin C.: Blue light receptors and signal transduction. - Plant Cell 14: S207-S225, 2002.

Liscum E., Nittler P., Koskie K.: The continuing arc toward phototropic enlightenment. - J. Exp. Bot. 71: 1652-1658, 2020.

Litvin F.F., Krasnovsky A.A.: Investigation of intermediate stages of chlorophyll formation. - Doklady Akademii Nauk SSSR 117: 106-109, 1957.

Liu H., Blankenship R.E.: On the interface of light-harvesting antenna complexes and reaction centers in oxygenic photosynthesis. - BBA-Bioenergetics 1860: 148079, 2019.

Liu H., Liu B., Zhao C. et al.: The action mechanisms of plant cryptochromes. - Trends Plant Sci. 16: 684-691, 2011.

Lüttge U.: $\mathrm{CO}_{2}$-concentrating: consequences in crassulacean acid metabolism. - J. Exp. Bot. 53: 2131-2142, 2002.

Lysenko V., Lazár D., Verduny T.: A method of a bicolor fastFourier pulse-amplitude modulation chlorophyll fluorometry.Photosynthetica 56: 1447-1452, 2018.

Magdaong N.C.M., Blankenship R.E.: Photoprotective, excitedstate quenching mechanisms in diverse photosynthetic organisms. - J. Biol. Chem. 293: 5018-5025, 2018.

Magyar M., Sipka G., Kovács L. et al.: Rate-limiting steps in the dark-to-light transition of Photosystem II - revealed by chlorophyll- $a$ fluorescence induction. - Sci. Rep.-UK 8: 2755, 2018.

Mamedov M., Govindjee G., Nadtochenko V., Semenov A.: Primary electron transfer processes in photosynthetic reaction centers from oxygenic organisms. - Photosynth. Res. 125: 5163, 2015.

Mao J., Zhang Y.C., Sang Y. et al.: A role for Arabidopsis cryptochromes and COP1 in the regulation of stomatal opening. - P. Natl. Acad. Sci. USA 102: 12270-12275, 2005.

Marosvölgyi M.A., van Gorkom H.J.: Cost of color of photosynthesis. - Photosynth. Res. 103: 105-109, 2010.

Marrs J.K., Reblin J.S., Logan B.A. et al.: Solar-induced fluorescence does not track photosynthetic carbon assimilation following induced stomatal closure. - Geophys. Res. Lett. 47: e2020GL087956, 2020.

Mascoli V., Bersanini L., Croce R.: Far-red absorption and lightuse efficiency trade-offs in chlorophyll $f$ photosynthesis. Nat. Plants 6: 1044-1053, 2020.

Matsubara S., Morosinotto T., Osmond C.B., Bassi R.: Shortand long-term operation of the lutein-epoxide cycle in lightharvesting antenna complexes. - Plant Physiol. 144: 926-941, 2007.

Matsuda R., Ohashi-Kaneko K., Fujiwara K., Kurata K.: Analysis of the relationship between blue-light photon flux density and 
the photosynthetic properties of spinach (Spinacia oleracea L.) leaves with regard to the acclimation of photosynthesis to growth irradiance. - Soil Sci. Plant Nutr. 53: 459-465, 2007.

Matthews J.S.A., Lawson T.: Climate change and stomatal physiology. - Annu. Plant Rev. Online 2: apr0667, 2019.

Matthews J.S.A., Vialet-Chabrand S., Lawson T.: Acclimation to fluctuating light impacts the rapidity of response and diurnal rhythm of stomatal conductance. - Plant Physiol. 176: 19391951, 2018.

Matthews J.S.A., Vialet-Chabrand S., Lawson T.: Role of blue and red light in stomatal dynamic behaviour. - J. Exp. Bot. 71: 2253-2269, 2020.

Mauzerall D.: Light-induced fluorescence changes in Chlorella, and the primary photoreactions for the production of oxygen. P. Natl. Acad. Sci. USA 69: 1358-1362, 1972.

Mauzerall D.: Why chlorophyll? - Ann. N. Y. Acad. Sci. 206: 483-494, 1973.

Mauzerall D.: Chlorophyll and photosynthesis. - Philos. T. Roy, Soc. B 273: 287-294, 1976.

Mawson B.T., Franklin A., Filion W.G., Cummins W.R.: Comparative studies of fluorescence from mesophyll and guard cell chloroplasts in Saxifraga cernua 1: Analysis of fluorescence kinetics as a function of excitation intensity. Plant Physiol. 74: 481-486, 1984.

McKown A.D., Guy R.D., Quamme L.et al.: Association genetics, geography and ecophysiology link stomatal patterning in Populus trichocarpa with carbon gain and disease resistance trade-offs. - Mol. Ecol. 23: 5771-5790, 2014.

Merzlyak M.N., Chivkunova O.B., Zhigalova T.V., Naqvi K.R.: Light absorption by isolated chloroplasts and leaves: effects of scattering and 'packing'. - Photosynth. Res. 102: 31-41, 2009.

Mi H., Klughammer C., Schreiber U.: Light-induced dynamic changes of NADPH fluorescence in Synechocystis PCC 6803 and its $n d h B$-defective mutant M55. - Plant Cell Physiol. 41: 1129-1135, 2000.

Mimuro M.: Photon capture, exciton migration and trapping and fluorescence emission in cyanobacteria and red algae. In: Papageorgiou G.C., Govindjee G. (ed.): Chlorophyll $a$ Fluorescence: A Signature of Photosynthesis. Advances in Photosynthesis and Respiration. Vol. 19. Pp. 173-195. Springer, Dordrecht 2004.

Mirkovic T., Ostroumov E.E., Anna J.M. et al.: Light absorption and energy transfer in the antenna complexes of photosynthetic organisms. - Chem. Rev. 117: 249-293, 2017.

Miyashita H., Ikemoto H., Kurano N. et al.: Chlorophyll $d$ as a major pigment. - Nature 383: 402, 1996.

Möglich A., Yang X., Ayers R.A., Moffat K.: Structure and function of plant photoreceptors. - Annu. Rev. Plant Biol. 61: 21-47, 2010.

Montgomery B.L.: Mechanisms and fitness implications of photomorphogenesis during chromatic acclimation in cyanobacteria. - J. Exp. Bot. 67: 4079-4090, 2016.

Montgomery B.L.: Lessons from Plants. Pp. 240. Harvard University Press, Cambridge 2021.

Moreno M.V., Rockwell N.C., Mora M. et al.: A far-red cyanobacteriochrome lineage specific for verdins. - P. Natl. Acad. Sci. USA 117: 27962-27970, 2020.

Muir C.D.: Making pore choices: repeated regime shifts in stomatal ratio. - P. Roy. Soc. Lond. B Bio. 282: 20151498, 2015.

Myers J., Graham J.R.: Enhancement in Chlorella. - Plant Physiol. 38: 105-116, 1963.

Natali A., Croce R.: Characterization of the major light-harvesting complexes (LHCBM) of the green alga Chlamydomonas reinhardtii. - PLoS ONE 10: e0119211, 2015.
Nauš J., Klinkovský T., Ilík P., Cikánek D.: Model studies of chlorophyll fluorescence reabsorption at chloroplast level under different exciting conditions. - Photosynth. Res. 40: 67-74, 1994.

Nauš J., Lazár D., Baránková B., Arnoštová B.: On the source of non-linear light absorbance in photosynthetic samples. Photosynth. Res. 136: 345-355, 2018.

Nauš J., Prokopová J., Řebíček J., Špundová M.: SPAD chlorophyll meter reading can be pronouncedly affected by chloroplast movement. - Photosynth. Res. 105: 265-271, 2010.

Nedbal L., Trtílek M., Kaftan D.: Flash fluorescence induction: A novel method to study regulation of photosystem II. J. Photoch. Photobio. B 48: 154-157, 1999.

Negi S., Perrine Z., Friedland N. et al.: Light regulation of light harvesting antenna size substantially enhances photosynthetic efficiency and biomass yield in green algae. - Plant J. 103: 584-603, 2020.

Nelson N., Junge W.: Structure and energy transfer in photosystems of oxygenic photosynthesis. - Annu. Rev. Biochem. 84: 659-683, 2015.

Nishio J.N.: Why are higher plants green? Evolution of the higher plant photosynthetic pigment complement. - Plant Cell Environ. 23: 539-548, 2000.

Nishio J.N., Sun J., Vogelmann T.C.: Carbon fixation gradients across spinach leaves do not follow internal light gradients. Plant Cell 5: 953-961, 1993.

Nobel P.S.: Photochemistry of photosynthesis. - In: Nobel P.S.: Photochemical and Environmental Plant Physiology. $4^{\text {th }}$ Edition. Pp. 228-275. Academic Press, Amsterdam 2009.

Nürnberg D.J., Morton J., Santabarbara S. et al.: Photochemistry beyond the red limit in chlorophyll $f$-containing photosystems. - Science 360: 1210-1213, 2018.

Ogawa T., Grantz D., Boyer J., Govindjee G.: Effects of cations and abscisic acid on chlorophyll $a$ fluorescence in guard cells of Vicia faba. - Plant Physiol. 69: 1140-1144, 1982.

Ogawa T., Misumi M., Sonoike K.: Estimation of photosynthesis in cyanobacteria by pulse-amplitude modulation chlorophyll fluorescence: problems and solutions. - Photosynth. Res. 133: 63-73, 2017.

Oguchi R., Douwstra P., Fujita T. et al.: Intra-leaf gradients of photoinhibition induced by different color lights: implications for the dual mechanisms of photoinhibition and for the application of conventional chlorophyll fluorometers. - New Phytol. 191: 146-159, 2011.

Oguchi R., Terashima I., Chow W.S.: The involvement of dual mechanisms of photoinactivation of photosystem II in Capsicum annuum L. plants. - Plant Cell Physiol. 50: 1815$1825,2009$.

Oh S., Montgomery B.L.: Phytochromes: Where to start? - Cell 171: 1254-1256, 2017.

Ohkubo S., Miyashita H.: A niche for cyanobacteria producing chlorophyll $f$ within a microbial mat. - ISME J. 11: 23682378, 2017.

Oka K., Ueno Y., Yokono M. et al.: Adaptation of light-harvesting and energy-transfer processes of a diatom Phaeodactylum tricornutum to different light qualities. - Photosynth. Res. 146: 227-234, 2020.

Olson J.M., Blankenship R.E.: Thinking about the evolution of photosynthesis. - Photosynth. Res. 80: 373-386, 2004.

Ort D.R., Merchant S.S., Alric J. et al.: Redesigning photosynthesis to sustainably meet global food and bioenergy demand. - P. Natl. Acad. Sci. USA 112: 8529-8536, 2015.

Osmond B., Chow W.S., Wyber R. et al.: Relative functional and optical absorption cross-sections of PSII and other photosynthetic parameters monitored in situ, at a distance 
with a time resolution of a few seconds, using a prototype light induced fluorescence transient (LIFT) device. - Funct. Plant Biol. 44: 985-1006, 2017.

Ostroumov E.E., Khan Y.R., Scholes G.D., Govindjee G.: Photophysics of photosynthetic pigment-protein complexes. In: Demmig-Adams B., Garab G., Adams III W.W., Govindjee G. (ed.): Non-photochemical quenching and energy dissipation in plants, algae and cyanobacteria. Advances in Photosynthesis and Respiration. Vol. 40. Pp. 97-128. Springer, Dordrecht 2014.

Ouzounis T., Rosenqvist E., Ottosen C.-O.: Spectral effects of artificial light on plant physiology and secondary metabolism: A review. - HortScience 50: 1128-1135, 2015.

Padhi B., Chauhan G., Kandoi D. et al.: A comparison of chlorophyll fluorescence transient measurements, using Handy PEA and FluorPen fluorometers. - Photosynthetica 59: 399-408, 2021.

Paik I., Huq E.: Plant photoreceptors: Multi-functional sensory proteins and their signaling networks. - Semin. Cell Dev. Biol. 92: 114-121, 2019.

Palenik B.: Chromatic adaptation in marine Synechococcus strains. - Appl. Environ. Microb. 67: 991-994, 2001.

Palmitessa O.D., Pantaleo M.A., Santamaria P.: Applications and development of LEDs as supplementary lighting for tomato at different latitudes. - Agronomy 11: 835, 2021.

Pan X., Cao P., Su X. et al.: Structural analysis and comparison of light-harvesting complexes I and II. - BBA-Bioenergetics 1861: 148038, 2020.

Pan X., Ma J., Su X. et al.: Structure of the maize photosystem I supercomplex with light-harvesting complexes I and II. Science 360: 1109-1113, 2018.

Papageorgiou G.C.: Chlorophyll fluorescence: an intrinsic probe of photosynthesis. - In: Govindjee G. (ed.): Bioenergetics of Photosynthesis. Pp. 319-371. Academic Press, New York 1975.

Papageorgiou G.C.: The photosynthesis of cyanobacteria (blue bacteria) from the perspective of signal analysis of chlorophyll $a$ fluorescence. - J. Sci. Ind. Res. India 155: 596-617, 1996.

Papageorgiou G.C., Govindjee G.: Changes in intensity and spectral distribution of fluorescence. Effect of light treatment on normal and DCMU-poisoned Anacystis nidulans. Biophys. J. 7: 375-389, 1967.

Papageorgiou G.C., Govindjee G.: Light-induced changes in the fluorescence yield of chlorophyll $a$ in vivo. I. Anacystis nidulans. - Biophys. J. 8: 1299-1315, 1968a.

Papageorgiou G.C., Govindjee G.: Light induced changes in the fluorescence yield of chlorophyll $a$ in vivo. II. Chlorella pyrenoidosa. - Biophys. J. 8: 1316-1328, 1968b.

Papageorgiou G.C., Govindjee G. (ed.): Chlorophyll a Fluorescence: A Signature of Photosynthesis. Advances in Photosynthesis and Respiration. Vol. 19. Pp. 818. Springer, Dordrecht 2004.

Papageorgiou G.C., Govindjee G.: Photosystem II fluorescence: slow changes - scaling from the past. - J. Photoch. Photobio. B 104: 258-270, 2011

Papageorgiou G.C., Govindjee G.: The non-photochemical quenching of the electronically excited state of chlorophyll $a$ in plants: definitions, timelines, viewpoints, open questions. In: Demmig-Adams B., Garab G., Adams III W.W., Govindjee G. (ed.): Nonphotochemical Quenching and Energy Dissipation in Plants, Algae and Cyanobacteria. Pp. 1-44. Advances in Photosynthesis and Respiration. Vol. 40. Springer, Dordrecht 2014

Papageorgiou G.C., Tsimilli-Michael M., Stamatakis K.: The fast and slow kinetics of chlorophyll $a$ fluorescence induction in plants, algae and cyanobacteria: a viewpoint. - Photosynth. Res. 94: 275-290, 2007.

Paradiso R., Proietti S.: Light-quality manipulation to control plant growth and photomorphogenesis in greenhouse horticulture: The state of the art and the opportunities of modern LED systems. - J. Plant Growth Regul., 2021. (In press)

Pattison P.M., Tsao J.Y., Brainard G.C., Bugbee B.: LEDs for photons, physiology and food. - Nature 563: 493-500, 2018.

Peers G., Truong T.B., Ostendorf E. et al.: An ancient lightharvesting protein is critical for the regulation of algal photosynthesis. - Nature 462: 518-521, 2009.

Pérez-Bueno M.K., Pineda M., Díaz-Casado E., Barón M.: Spatial and temporal dynamics of primary and secondary metabolism in Phaseolus vulgaris challenged by Pseudomonas syringae. Physiol. Plantarum 153: 161-174, 2015.

Pettai H., Oja V., Freiberg A., Laisk A.: Photosynthetic activity of far-red light in green plants. - BBA-Bioenergetics 1708: 311-321, 2005a.

Pettai H., Oja V., Freiberg A., Laisk A.: The long-wavelength limit of plant photosynthesis. - FEBS Lett. 579: 4017-4019, 2005b.

Pfündel E.E.: Deriving room temperature excitation spectra for photosystem I and photosystem II fluorescence in intact leaves from the dependence of $\mathrm{F}_{\mathrm{V}} / \mathrm{F}_{\mathrm{M}}$ on excitation wavelength. Photosynth. Res. 100: 163-177, 2009.

Pfündel E.E.: Simultaneously measuring pulse-amplitudemodulated (PAM) chlorophyll fluorescence of leaves at wavelengths shorter and longer than $700 \mathrm{~nm}$. - Photosynth. Res. 147: 345-358, 2021.

Pfündel E.E., Latouche G., Meister A., Cerovic Z.G.: Linking chloroplast relocation to different responses of photosynthesis to blue and red radiation in low and high light-acclimated leaves of Arabidopsis thaliana (L.). - Photosynth. Res. 137: 105-128, 2018.

Pi X., Zhao S., Wang W. et al.: The pigment-protein network of a diatom photosystem II-light-harvesting antenna supercomplex. - Science 365: eaaax4406, 2019.

Prášil O., Kolber Z.S., Falkowski P.G.: Control of the maximal chlorophyll fluorescence yield by the $\mathrm{Q}_{\mathrm{B}}$ binding site. Photosynthetica 56: 150-162, 2018.

Ptushenko O.S., Ptushenko V.V., Solovchenko A.E.: Spectrum of light as a determinant of plant functioning: A historical perspective. - Life 10: 25, 2020.

Qin X., Suga M., Kuang T., Shen J.R.: Structural basis for energy transfer pathways in the plant PSI-LHCI supercomplex. Science 348: 989-995, 2015.

Rappaport F., Béal D., Joliot A., Joliot P.: On the advantages of using green light to study fluorescence yield changes in leaves. - BBA-Bioenergetics 1767: 56-65, 2007.

Raven J.A.: Functional evolution of photochemical energy transformations in oxygen-producing organisms. - Funct. Plant Biol. 36: 505-515, 2009.

Razzak M.A., Ranade S.S., Strand Å., García-Gil M.: Environment: Differential response of Scots pine seedlings to variable intensity and ratio of R and FR light. - Plant Cell Environ. 40: 1332-1340, 2017

Remelli W., Santabarbara S.: Excitation and emission wavelength dependence of fluorescence spectra in whole cells of the cyanobacterium Synechocystis sp. PPC6803: Influence on the estimation of photosystem II maximal quantum efficiency. BBA-Bioenergetics 1859: 1207-1222, 2018.

Ritchie R.J., Larkum A.W.D., Ribas I.: Could photosynthesis function on Proxima Centauri b? - Int. J. Astrobiol. 17: 147176,2018

Rivadossi A., Zucchelli G., Garlaschi F.M., Jennings R.C.: The 
importance of PS I chlorophyll red forms in light-harvesting by leaves. - Photosynth. Res. 60: 209-215, 1999.

Rockwell N.C., Duanmu D., Martin S.S. et al.: Eukaryotic algal phytochromes span the visible spectrum. - P. Natl. Acad. Sci. USA 111: 3871-3876, 2014.

Rockwell N.C., Lagarias J.C.: A brief history of phytochromes. ChemPhysChem 11: 1172-1180, 2010.

Rockwell N.C., Lagarias J.C.: Phytochrome diversification in cyanobacteria and eukaryotic algae. - Curr. Opin. Plant Biol. 37: 87-93, 2017.

Rockwell N.C., Su Y.S., Lagarias J.C.: Phytochrome structure and signaling mechanisms. - Annu. Rev. Plant Biol. 57: 837858,2006

Roelfsema M.R.G., Hedrich R.: In the light of stomatal opening: new insights into 'the Watergate'. New Phytol. 167: 665-691, 2005.

Romero J.M., Cordon G.B., Lagorio M.G.: Modeling reabsorption of fluorescence from the leaf to the canopy level. Remote Sens. Environ. 204: 138-146, 2018.

Ronald J., Davis S.J.: Focusing on the nuclear and subnuclear dynamics of light and circadian signalling. - Plant Cell Environ. 42: 2871-2884, 2019.

Ross R.T., Calvin M.: Thermodynamics of light emission and free-energy storage in photosynthesis. - Biophys. J. 7: 595$614,1967$.

Ruberti I., Sessa G., Ciolfi A. et al:: Plant adaptation to dynamically changing environment: the shade avoidance response. - Biotechnol. Adv. 30: 1047-1058, 2012.

Rudall P.J., Hilton J., Bateman R.M.: Several developmental and morphogenetic factors govern the evolution of stomatal patterning in land plants. - New Phytol. 200: 598-614, 2013.

Russo M., Casazza A.P., Cerullo G. et al.: Direct evidence for excitation energy transfer limitations imposed by low-energy chlorophylls in photosystem I - Light harvesting complex I of land plants. - J. Phys. Chem. B 125: 3566-3573, 2021.

Sanfilippo J.E, Garczarek L., Partensky F., Kehoe D.M.: Chromatic acclimation in cyanobacteria: A diverse and widespread process for optimizing photosynthesis. - Annu. Rev. Microbiol. 73: 407-433, 2019.

Sanfilippo J.E., Nguyen A.A.., Karty J.A. et al.: Self-regulating genomic island encoding tandem regulators confers chromatic acclimation to marine Synechococcus. - P. Natl. Acad. Sci. USA 113: 6077-6082, 2016.

Santabarbara S., Casazza A.P., Belgio E. et al.: Light harvesting by long-wavelength chlorophyll forms (red forms) in algae: Focus on their presence, distribution and function. In: Larkum A.W.D., Grossman A.R., Raven J.R. (ed.): Photosynthesis in Algae: Biochemical and Physiological Mechanisms. Advances in Photosynthesis and Respiration. Vol. 45. Pp. 261-297. Springer, Cham 2020.

Santabarbara S., Monteleone F.V., Remellia W. et al.: Comparative excitation-emission dependence of the $\mathrm{F}_{\mathrm{V}} / \mathrm{F}_{\mathrm{M}}$ ratio in model green algae and cyanobacterial strains. - Physiol. Plantarum 166: 351-364, 2019

Schansker G., Tóth Z.S., Kovács L. et al.: Evidence for a fluorescence yield change driven by a light induced conformational change within photosystem II during the fast chlorophyll $a$ fluorescence rise. - BBA-Bioenergetics 1807: 1032-1043, 2011.

Schreiber U.: Pulse-amplitude-modulation (PAM) fluorometry and saturation pulse method: an overview. - In: Papageorgiou G.C., Govindjee G. (ed.): Chlorophyll a Fluorescence: A Signature of Photosynthesis. Advances in Photosynthesis and Respiration. Vol. 19. Pp. 279-319. Springer, Dordrecht 2004.

Schreiber U., Klughammer C.: New NADPH/9-AA module for the DUAL-PAM-100: Description, operation and examples of application. - PAM Appl. Notes 2: 1-13, 2009.

Schreiber U., Klughammer C.: Evidence for variable chlorophyll fluorescence of photosystem I in vivo. - Photosynth. Res. 149: 213-231, 2021.

Schreiber U., Klughammer C., Koblowski J.: High-end chlorophyll fluorescence analysis with the MULTI-COLORPAM. I. Various light qualities and their applications. - PAM Appl. Notes 1: 1-21, 2011.

Schreiber U., Klughammer C., Kolbowski J.: Assessment of wavelength-dependent parameters of photosynthetic electron transport with a new type of multi-color PAM chlorophyll fluorometer. - Photosynth. Res. 113: 127-144, 2012.

Schreiber U., Kühl M., Klimant I., Reising H.: Measurement of chlorophyll fluorescence within leaves using a modified PAM fluorometer with a fiber-optic microprobe. - Photosynth. Res. 47: 103-109, 1996.

Schreiber U., Schliwa U., Bilger W.: Continuous recording of photochemical and non-photochemical chlorophyll fluorescence quenching with a new type of modulation fluorometer. - Photosynth. Res. 10: 51-62, 1986.

Segečová A., Pérez-Bueno M.L., Barón M. et al.: Non-invasive determination of toxic stress biomarkers by high-throughput screening of photoautotrophic cell suspension cultures with multi-colour fluorescence imaging. - Plant Methods 15: 100, 2019.

Semchonok D.A., Li M., Bruce B.D. et al.: Cryo-EM structure of a tetrameric cyanobacterial photosystem I complex reveals novel subunit interactions. - BBA-Bioenergetics 1857: 1619$1626,2016$.

Semer J., Navrátil M., Špunda V., Štroch M.: Chlorophyll fluorescence parameters to assess utilization of excitation energy in photosystem II independently of changes in leaf absorption. - J. Photoch. Photobio. B 197: 111535, 2019.

Sheng X., Watanabe A., Li A. et al:: Structural insight into light harvesting for photosystem II in green algae. - Nat. Plants 5: 1320-1330, 2019.

Shevela D., Kern J.F., Govindjee G. et al.: Photosystem II. eLS 2: 1-20, 2021.

Shibata Y., Nishi S., Kawakami K. et al.: Photosystem II does not possess a simple excitation energy funnel: Time-resolved fluorescence spectroscopy meets theory. - J. Am. Chem. Soc. 135: 6903-6914, 2013.

Shimazaki K., Doi M., Assmann S.M., Kinoshita T.: Light regulation of stomatal movement. - Annu. Rev. Plant Biol. 58: 219-247, 2007.

Shtein I., Popper Z.A., Harpaz-Saad S.: Permanently open stomata of aquatic angiosperms display modified cellulose crystallinity patterns. - Plant Signal. Behav. 12: e1339858, 2017.

Shukla A., Biswas A., Blot N. et al.: Phycoerythrin-specific bilin lyase-isomerase controls blue-green chromatic acclimation in marine Synechococcus. - P. Natl. Acad. Sci. USA 109: 20136-20141, 2012.

Sipka G., Magyar M., Mezzetti A. et al.: Light-adapted chargeseparated state of photosystem II: structural and functional dynamics of the closed reaction center. - Plant Cell 33: 1286$1302,2021$.

Sipka H., Müller P., Brettel K. et al.: Redox transients of P680 associated with the incremental chlorophyll- $a$ fluorescence yield rises elicited by a series of saturating flashes in diurontreated photosystem II core complex of Thermosynechococcus vulcanus. - Physiol. Plantarum 166: 22-32, 2019.

Slattery R.A., Grennan A.K., Sivaguru M. et al.: Light sheet microscopy reveals more gradual light attenuation in lightgreen versus dark-green soybean leaves. - J. Exp. Bot. 67: 
4697-4709, 2016.

Slattery R.A., Ort D.R.: Perspectives on improving light distribution and light use efficiency in crop canopies. - Plant Physiol. 185: 34-48, 2021.

Smith H., Whitelam G.C.: The shade avoidance syndrome: multiple responses mediated by multiple phytochromes. Plant Cell Environ. 20: 840-844, 1997.

Somers D.E., Devlin P.F., Kay S.A.: Phytochromes and cryptochromes in the entrainment of the Arabidopsis circadian clock. - Science 282: 1488-1490, 1998.

Sonoike K., Hihara Y., Ikeuchi M.: Physiological significance of the regulation of photosystem stoichiometry upon high light acclimation of Synechocystis sp. PCC 6803. - Plant Cell Physiol. 42: 379-384, 2001.

Srivastava A., Zeiger E.: Fast fluorescence quenching from isolated guard cell chloroplasts of Vicia faba is induced by blue light and not by red light. - Plant Physiol. 100: 15621566, 1992.

Stamatakis K., Papageorgiou G.C., Govindjee G.: Effects of exogenous $\beta$-carotene, a chemical scavenger of singlet oxygen, on the millisecond rise of chlorophyll $a$ fluorescence of cyanobacterium Synechococcus sp. PCC 7942. - Photosynth. Res. 130: 317-324, 2016.

Stamatakis K., Tsimilli-Michael M., Papageorgiou G.C.: Fluorescence induction in the phycobilisome-containing cyanobacterium Synechococcus sp PCC 7942: Analysis of the slow fluorescence transient. - BBA-Bioenergetics 1767: 766$772,2007$.

Stirbet A., Govindjee G.: On the relation between the Kautsky effect (chlorophyll $a$ fluorescence induction) and photosystem II: basics and applications of the OJIP fluorescence transient. J. Photoch. Photobio. B 104: 236-257, 2011.

Stirbet A., Govindjee G.: Chlorophyll $a$ fluorescence induction: a personal perspective of the thermal phase, the J-I-P rise. Photosynth. Res. 113: 15-61, 2012.

Stirbet A., Lazár D., Guo Y., Govindjee G.: Photosynthesis: basics, history and modelling. - Ann. Bot.-London 126: 511537,2020

Stirbet A., Lazár D., Kromdijk J., Govindjee G.: Chlorophyll $a$ fluorescence induction: Can just a one-second measurement be used to quantify abiotic stress responses? - Photosynthetica 56: 86-104, 2018.

Stirbet A., Lazár D., Papageorgiou G.C., Govindjee G.: Chlorophyll $a$ fluorescence in cyanobacteria: relation to photosynthesis. - In: Mishra A.K., Tiwari D.N., Rai A.N. (ed.): Cyanobacteria - From Basic Science to Applications. Pp. 79-130. Academic Press, London 2019.

Stomp M., Huisman J., de Jongh F. et al.: Adaptive divergence in pigment composition promotes phytoplankton biodiversity. Nature 432: 104-107, 2004.

Stomp M., Huisman J., Stal L.J., Matthijs H.C.P.: Colorful niches of phototrophic microorganisms shaped by vibrations of the water molecule. - ISME J. 1: 271-282, 2007a.

Stomp M., Huisman J., Vörös L. et al.: Colourful coexistence of red and green picocyanobacteria in lakes and seas. - Ecol. Lett. 10: 290-298, $2007 \mathrm{~b}$.

Stomp M., van Dijk M.A., van Overzee H.M.J. et al.: The timescale of phenotypic plasticity and its impact on competition in fluctuating environments. - Am. Nat. 172: $169-185,2008$.

Strasser B.J., Strasser R.J.: Measuring fast fluorescence transients to address environmental questions: the JIP test. - In: Mathis P. (ed.): Photosynthesis: From Light to Biosphere. Vol. 5. Pp. 977-980. Kluwer Academic, Dordrecht 1995.

Strasser R.J., Tsimilli-Michael M., Srivastava A.: Analysis of the chlorophyll fluorescence transient. - In: Papageorgiou
G.C., Govindjee G. (ed.): Chlorophyll a Fluorescence: A Signature of Photosynthesis. Advances in Photosynthesis and Respiration. Vol. 19. Pp. 321-362. Springer, Dordrecht 2004.

Suetsugu N., Dolja V.V., Wada M.: Why have chloroplasts developed a unique motility system? - Plant Signal. Behav. 5: 1190-1196, 2010.

Suetsugu N., Higa T., Gotoh E., Wada M.: Light-induced movements of chloroplasts and nuclei are regulated in both cp-actin-filament-dependent and -independent manners in Arabidopsis thaliana. - PLoS ONE 11: e0157429, 2016.

Suetsugu N., Takami T., Ebisu Y. et al.: Guard cell chloroplasts are essential for blue light-dependent stomatal opening in Arabidopsis. - PLoS ONE 9: e108374, 2014.

Suetsugu N., Wada M.: Chloroplast photorelocation movement mediated by phototropin family proteins in green plants. Biol. Chem. 388: 927-935, 2007.

Suetsugu N., Wada M.: Chloroplast photorelocation movement. In: Sandelius A.S., Aronsson H. (ed.): The Chloroplasts. Plant Cell Monographs Series. Pp. 335-366. Springer, BerlinHeidelberg 2009.

Suga M., Ozawa S.I., Yoshida-Motomura K. et al.: Structure of the green algal photosystem I supercomplex with a decameric light-harvesting complex I. - Nat. Plants 5: 626-636, 2019.

Sun J., Nishio J.N., Vogelmann T.C.: Green light drives $\mathrm{CO}_{2}$ fixation deep within leaves. - Plant Cell Physiol. 39: 10201026, 1998.

Sušila P., Lazár D., Ilík P. et al.: The gradient of exciting radiation within a sample affects the relative height of steps in the fast chlorophyll $a$ fluorescence rise. - Photosynthetica 42: 161$172,2004$.

Takahashi K., Mineuchi K., Nakamura T. et al.: A system for imaging transverse distribution of scattered light and chlorophyll fluorescence in intact rice leaves. - Plant Cell Environ. 17: 105-110, 1994.

Takemiya A., Sugiyama N., Fujimoto H. et al.: Phosphorylation of BLUS1 kinase by phototropins is a primary step in stomatal opening. - Nat. Commun. 4: 2094, 2013.

Talbott L.D., Hammad J.W., Harn L.C. et al.: Reversal by green light of blue light-stimulated stomatal opening in intact, attached leaves of Arabidopsis operates only in the potassiumdependent, morning phase of movement. - Plant Cell Physiol. 47: 332-339, 2006.

Talbott L.D., Nikolova G., Ortiz A. et al.: Green light reversal of blue-light-stimulated stomatal opening is found in a diversity of plant species. - Am. J. Bot. 89: 366-368, 2002.

Tandeau de Marsac N.: Occurrence and nature of chromatic adaptation in cyanobacteria. - J. Bacteriol. 130: 82-91, 1977.

Terashima I., Fujita T., Inoue T. et al.: Green light drives leaf photosynthesis more efficiently than red light in strong white light: Revisiting the enigmatic question of why leaves are green. - Plant Cell Physiol. 50: 684-697, 2009.

Terashima I., Inoue Y.: Palisade tissue chloroplasts and spongy tissue chloroplasts in spinach: biochemical and ultrastructural differences. - Plant Cell Physiol. 26: 63-75, 1985a.

Terashima I., Inoue Y.: Vertical gradient in photosynthetic properties of spinach chloroplasts dependent on intra-leaf light environment. - Plant Cell Physiol. 26: 781-785, 1985b.

Terashima I., Saeki T.: Light environment within a leaf. I. Optical properties of paradermal sections of Camellia leaves with special reference to differences in the optical properties of palisade and spongy tissues. - Plant Cell Physiol. 24: 1493$1501,1983$.

Thapper A., Mamedov F., Mokvist F. et al.: Defining the far-red limit of photosystem II in spinach. - Plant Cell 21: 23912401, 2009. 
Trissl H.-W., Gao Y., Wulf K.: Theoretical fluorescence induction curves derived from coupled differential equations describing the primary photochemistry of photosystem II by an excitonradical pair equilibrium. - Biophys. J. 64: 974-988, 1993.

Tros M., Mascoli V., Shen G. et al.: Breaking the red limit: Efficient trapping of long-wavelength excitations in chlorophyll-f-containing photosystem I. - Chem. 7: 155-173, 2021.

Tsimilli-Michael M.: Revisiting JIP-test: An educative review on concepts, assumptions, approximations, definitions and terminology. - Photosynthetica 58: 275-292, 2020.

Tsimilli-Michael M., Stamatakis K., Papageorgiou G.C.: Dark-tolight transition in Synechococcus sp. PCC 7942 cells studied by fluorescence kinetics assesses plastoquinone redox poise in the dark and photosystem II fluorescence component and dynamics during state 2 to state 1 transition. - Photosynth. Res. 99: 243-255, 2009.

van Amerongen H., Valkunas L., van Grondelle R.: Photosynthetic excitons. Pp. 604. World Scientific Publishing, Singapore 2000.

Vavilin D.V., Tyystjärvi E., Aro E.-M.: Model for the fluorescence induction curve of photoinhibited thylakoids. - Biophys. J. 75: 503-512, 1998.

Vialet-Chabrand S., Matthews J.S.A., Simkin A.J. et al.: Importance of fluctuations in light on plant photosynthetic acclimation of Arabidopsis thaliana. - Plant Physiol. 173: 2163-2179, 2017.

Villafani Y., Yang H.W., Park Y.I.: Color sensing and signal transmission diversity of cyanobacterial phytochromes and cyanobacteriochromes. - Mol. Cells 43: 509-516, 2020.

Vogelmann T.C., Björn L.O.: Measurement of light gradients and spectral regime in plant tissue with a fiber-optic probe. Physiol. Plantarum 60: 361-368, 1984.

Vogelmann T.C., Bornman J.F., Josserand S.: Photosynthetic light gradients and spectral regime within leaves of Medicago sativa. - Philos. T. Roy. Soc. B 323: 411-421, 1989.

Vogelmann T.C., Evans J.R.: Profiles of light absorption and chlorophyll within spinach leaves from chlorophyll fluorescence. - Plant Cell Environ. 25: 1313-1323, 2002.

Vogelmann T.C., Han T.: Measurement of gradients of absorbed light in spinach leaves from chlorophyll fluorescence profiles. - Plant Cell Environ. 23: 1303-1311, 2000.

Wada M.: Chloroplast and nuclear photorelocation movements. P. Jpn. Acad. B-Phys. 92: 387-411, 2016.

Wallner T., Pedroza L., Voigt K. et al.: The cyanobacterial phytochrome 2 regulates the expression of motility-related genes through the second messenger cyclic di-GMP. Photoch. Photobio. Sci. 19: 631-643, 2020.

Wang F., Robson T.M., Casal J.J. et al.: Contributions of cryptochromes and phototropins to stomatal opening through the day. - Funct. Plant Biol. 47: 226-238, 2020.

Wang J., Lu W., Tong Y., Yang Q.: Leaf morphology, photosynthetic performance, chlorophyll fluorescence, stomatal development of lettuce (Lactuca sativa L.) exposed to different ratios of red light to blue light. - Front. Plant Sci. 7: 250, 2016.

Wang Q., Lin C.: Mechanisms of cryptochrome-mediated photoresponses in plants. - Annu. Rev. Plant Biol. 71: 103$129,2020$.

Wang W., Yu L.J., Xu C. et al.: Structural basis for blue-green light harvesting and energy dissipation in diatoms. - Science 363: eaav0365, 2019.

Wang X.Q., Wu W.H., Assmann S.M.: Differential responses of abaxial and adaxial guard cells of broad bean to abscisic acid and calcium. - Plant Physiol. 118: 1421-1429, 1998.

Wang X.Y., Xu X.M., Cui J.: The importance of blue light for leaf area expansion, development of photosynthetic apparatus, and chloroplast ultrastructure of Cucumis sativus grown under weak light. - Photosynthetica 53: 213-222, 2015.

White S., Anandraj A., Trois C.: NADPH fluorescence as an indicator of hydrogen production in the green algae Chlamydomonas reinhardtii. - Int. J. Hydrogen Energ. 39: 1640-1647, 2014.

Wientjes E., Croce R.: PMS: photosystem I electron donor or fluorescence quencher. - Photosynth. Res. 111: 185-191, 2012.

Wientjes E., Philippi J., Borst J.W., van Amerongen H.: Imaging the Photosystem I/Photosystem II chlorophyll ratio inside the leaf. - BBA-Bioenergetics 1858: 259-265, 2017.

Wientjes E., van Amerongen H., Croce R.: LHCII is an antenna of both photosystems after long-term acclimation. BBA-Bioenergetics 1827: 420-426, 2013b.

Wientjes E., van Amerongen H., Croce R.: Quantum yield of charge separation in photosystem II: Functional effect of changes in the antenna size upon light acclimation. - J. Phys. Chem. B 117: 11200-11208, 2013a.

Wientjes E., van Stokkum I.H.M., van Amerongen H., Croce R.: The role of the individual Lhcas in photosystem I excitation energy trapping. - Biophys J. 101: 745-754, 2011.

Wilson A., Ajlani G., Verbavatz J.-M. et al.: A soluble carotenoid protein involved in phycobilisome-related energy dissipation in cyanobacteria. - Plant Cell 18: 992-1007, 2006.

Wiltbank L.B., Kehoe D.M.: Two cyanobacterial photoreceptors regulate photosynthetic light harvesting by sensing teal, green, yellow, and red light. - mBio 7: e02130-15, 2016.

Wiltbank L.B., Kehoe D.M.: Diverse light responses of cyanobacteria mediated by phytochrome superfamily photoreceptors. - Nat. Rev. Microbiol. 17: 37-50, 2019.

Wong S.C., Cowan I.R., Farquhar G.D.: Stomatal conductance correlates with photosynthetic capacity. - Nature 282: 424426, 1979.

Wraight C.A., Crofts A.R.: Energy-dependent quenching of chlorophyll $a$ fluorescence in isolated chloroplasts. - Eur. J. Biochem. 17: 319-327, 1970.

Wu T., Lin Y., Zheng L. et al.: Analyses of multi-color plantgrowth light sources in achieving maximum photosynthesis efficiencies with enhanced color qualities. - Opt. Express 26: 4135-4147, 2018.

Xiong J.: Photosynthesis: what color was its origin? - Genome Biol. 7: 245, 2006.

Xiong D., Flexas J.: From one side to two sides: the effects of stomatal distribution on photosynthesis. - New Phytol. 228: 1754-1766, 2020.

Xiong J., Fischer W.M., Inoue K. et al.: Molecular evidence for the early evolution of photosynthesis. - Science 289: 1724$1730,2000$.

$\mathrm{Xu}$ B., Long Y., Feng X. et al.: GABA signalling modulates stomatal opening to enhance plant water use efficiency and drought resilience. - Nat. Commun. 12: 1952, 2021.

Xu C., Pi X., Huang Y. et al.: Structural basis for energy transfer in a huge diatom PSI-FCPI supercomplex. - Nat. Commun. 11: $5081,2020 \mathrm{~b}$.

Xu P., Chukhutsina V.U., Nawrocki W.J. et al.: Photosynthesis without $\beta$-carotene. - eLife 9: e58984, 2020a.

Yamamoto H.Y., Higashi R.M.: Violaxanthin deepoxidase: Lipid composition and substrate specificity. - Arch. Biochem. Biophys. 190: 514-522, 1978.

Yamamoto H.Y., Nakayama T., Chichester C.: Studies on the light and dark interconversions of leaf xanthophylls. - Arch. Biochem. Biophys. 97: 168-173, 1962.

Yamauchi S., Takemiya A., Sakamoto T. et al.: The plasma membrane $\mathrm{H}^{+}$-ATPase AHA1 plays a major role in stomatal opening in response to blue light. - Plant Physiol. 171: 2731 - 
$2743,2016$.

Yang F., Liu Q., Cheng Y. et al.: Low red/far-red ratio as a signal promotes carbon assimilation of soybean seedlings by increasing the photosynthetic capacity. - BMC Plant Biol. 20: $148,2020$.

Yeh K.C., Wu S.H., Murphy J.T., Lagarias J.C.: A cyanobacterial phytochrome two-component light sensory system. - Science 277: 1505-1508, 1997.

Yu X., Liu H., Klejnot J., Lin C.: The cryptochrome blue light receptors. - The Arabidopsis Book 8: e0135, 2010.

Zamzam N., Rakowski R., Kaucikas M. et al.: Femtosecond visible transient absorption spectroscopy of chlorophyll- $f$ containing photosystem II. - P. Natl. Acad. Sci. USA 117: 23158-23164, 2020.

Zeiger E., Armond P., Melis A.: Fluorescence properties of guard cell chloroplasts. Evidence for linear electron transport and light-harvesting pigments of photosystem I and II. - Plant Physiol. 67: 17-20, 1980.
Zhang Y., Kaiser E., Zhang Y. et al.: Red/blue light ratio strongly affects steady-state photosynthesis, but hardly affects photosynthetic induction in tomato (Solanum lycopersicum). Physiol. Plantarum 167: 144-158, 2019.

Zhao C., Gan F., Shen G., Bryant D.A.: RfpA, RfpB, and RfpC are the master control elements of far-red light photoacclimation (FaRLiP). - Front. Microbiol. 6: 1303, 2015.

Zheng L., He H., Song W.: Application of light-emitting diodes and the effect of light quality on horticultural crops: a review. HortScience 54: 1656-1661, 2019.

Zheng L., Van Labeke M.-C.: Long-term effects of red- and bluelight emitting diodes on leaf anatomy and photosynthetic efficiency of three ornamental pot plants. - Front. Plant Sci. 8: 917, 2017.

Zouni A., Witt H.T., Kern J. et al.: Crystal structure of photosystem II from Synechococcus elongatus at 3.8 Å resolution. Nature 409: 739-743, 2001.

(C) The authors. This is an open access article distributed under the terms of the Creative Commons BY-NC-ND Licence. 